\title{
Electroactive biomaterials: Vehicles for controlled delivery of therapeutic agents for drug delivery and tissue regeneration
}

DOI:

10.1016/j.addr.2017.12.012

\section{Document Version}

Accepted author manuscript

Link to publication record in Manchester Research Explorer

Citation for published version (APA):

Tandon, B., Magaz , A., Balint, R., Blaker, J., \& Cartmell, S. (2017). Electroactive biomaterials: Vehicles for controlled delivery of therapeutic agents for drug delivery and tissue regeneration. Advanced Drug Delivery Reviews. https://doi.org/10.1016/j.addr.2017.12.012

Published in:

Advanced Drug Delivery Reviews

\section{Citing this paper}

Please note that where the full-text provided on Manchester Research Explorer is the Author Accepted Manuscript or Proof version this may differ from the final Published version. If citing, it is advised that you check and use the publisher's definitive version.

\section{General rights}

Copyright and moral rights for the publications made accessible in the Research Explorer are retained by the authors and/or other copyright owners and it is a condition of accessing publications that users recognise and abide by the legal requirements associated with these rights.

\section{Takedown policy}

If you believe that this document breaches copyright please refer to the University of Manchester's Takedown Procedures [http://man.ac.uk/04Y6Bo] or contact uml.scholarlycommunications@manchester.ac.uk providing relevant details, so we can investigate your claim.

\section{OPEN ACCESS}


Drug Delivery Reviews

Elsevier Editorial System(tm) for Advanced

Manuscript Draft

Manuscript Number: ADDR-D-17-00149R1

Title: Electroactive biomaterials: Vehicles for controlled delivery of therapeutic agents for drug delivery and tissue regeneration

Article Type: SI: Wound healing \& Scar war

Keywords: Piezoelectrics; Conductive polymers; Photovoltaics; Electrets; Electric signals; Drugs; Wounds

Corresponding Author: Professor Sarah H Cartmell, PhD Bioengineering

Corresponding Author's Institution: School of Materials, University of Manchester

First Author: Biranche Tandon

Order of Authors: Biranche Tandon; Adrian Magaz; Richard Balint; Jonny J Blaker; Sarah H Cartmell, PhD Bioengineering

Abstract: Electrical stimulation for delivery of biochemical agents such as genes, proteins and RNA molecules amongst others, holds great

potential for controlled therapeutic delivery and in promoting tissue regeneration. Electroactive biomaterials have the capability of delivering these agents in a localized, controlled, responsive and efficient manner. These systems have also been combined for the delivery of both physical and biochemical cues and can be programmed to achieve enhanced effects on healing by establishing control over the microenvironment. This review focuses on current state-of-the-art research of electroactive-based materials towards the delivery of drugs and other therapeutic signalling agents for wound care treatment. Future directions and current challenges for developing effective electroactive approach based therapies for wound care are discussed. 

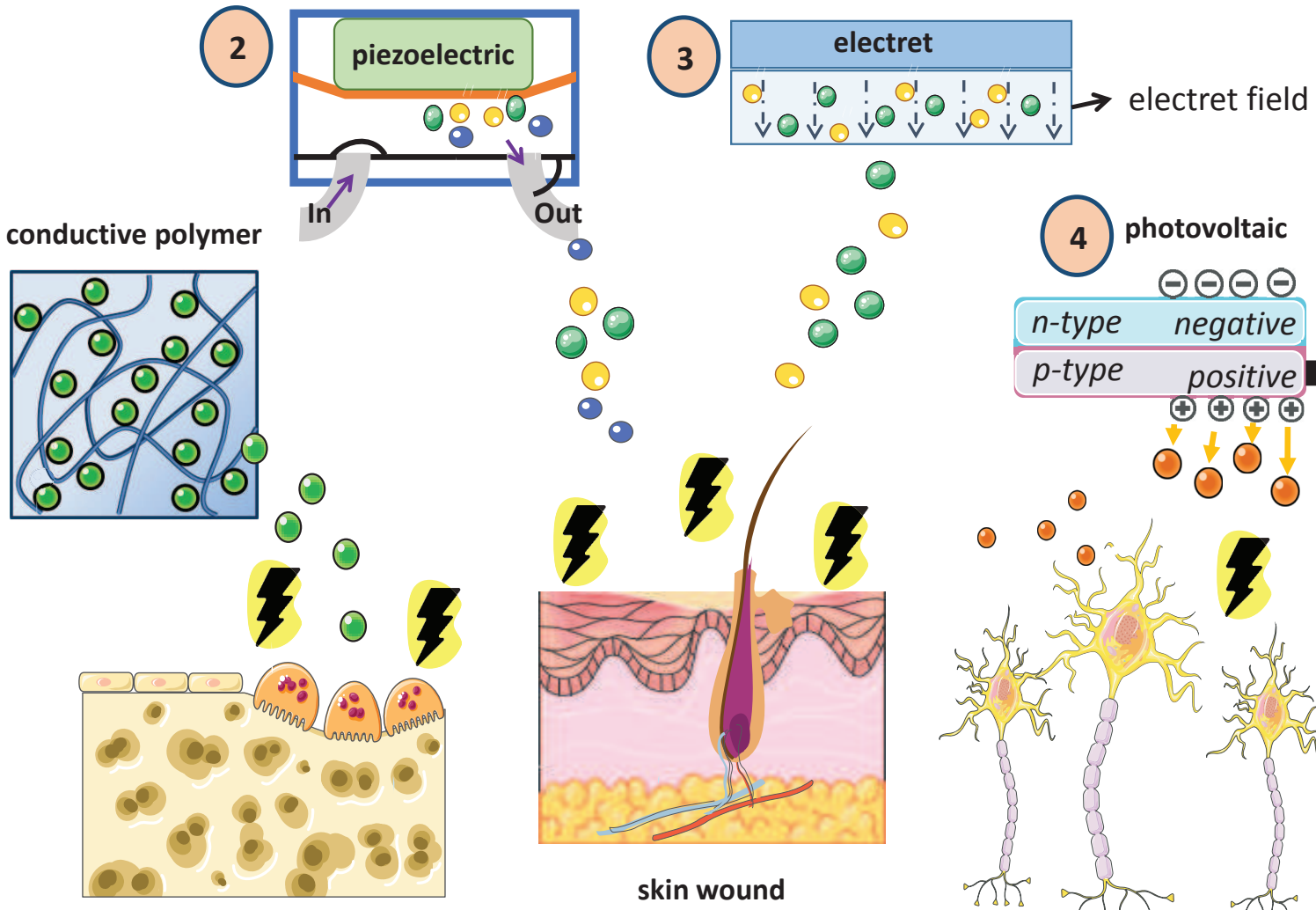

$0_{0}^{0}$

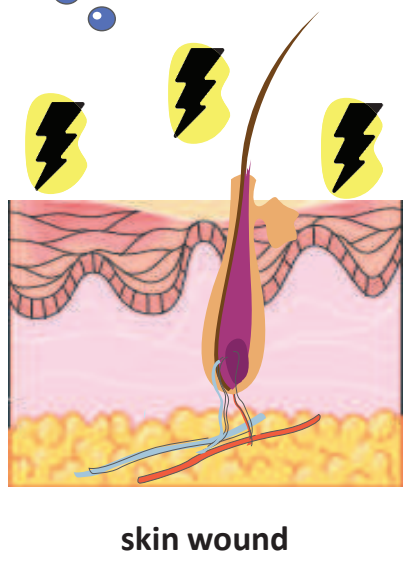

bone repair

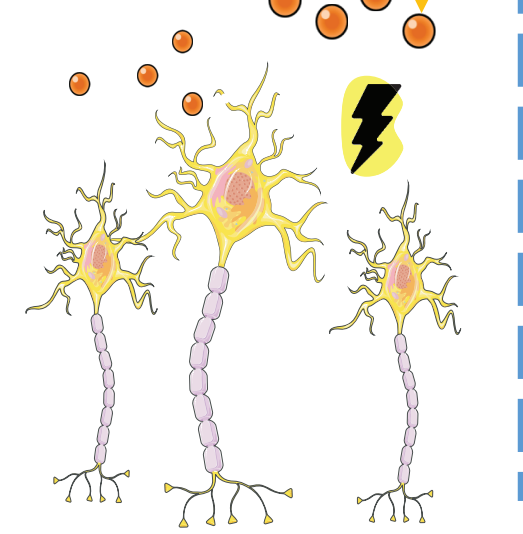

$3 \begin{gathered}\text { Electric cues } \\ \text { and electrical } \\ \text { stimulation }\end{gathered}$

00 Biochemical 08 therapeutic agents neuro stimulation 


\section{Electroactive biomaterials: Vehicles for controlled delivery of 2 therapeutic agents for drug delivery and tissue regeneration}

3 Biranche Tandon ${ }^{\mathrm{a}, \mathrm{b}}$, Adrián Magaz ${ }^{\mathrm{b}}$, Richard Balint ${ }^{\mathrm{a}}$, Jonny J. Blaker ${ }^{\mathrm{a}, \mathrm{b}}$, Sarah H. Cartmell ${ }^{\mathrm{a}, *}$

$4 \quad{ }^{a}$ School of Materials, The University of Manchester, Manchester, M13 9PL, UK

5 bio-Active Materials Group, School of Materials, MSS Tower, The University of Manchester,

6 Manchester, M13 9PL, UK

7 *Corresponding author at: School of Materials, The University of Manchester, Manchester, M13 9PL,

$8 \quad$ UK; e-mail: sarah.cartmell@manchester.ac.uk

\section{Abstract}

10 Electrical stimulation for delivery of biochemical agents such as genes, proteins and RNA molecules

11 amongst others, holds great potential for controlled therapeutic delivery and in promoting tissue

12 regeneration. Electroactive biomaterials have the capability of delivering these agents in a localized,

13 controlled, responsive and efficient manner. These systems have also been combined for the delivery

14 of both physical and biochemical cues and can be programmed to achieve enhanced effects on healing

15 by establishing control over the microenvironment. This review focuses on current state-of-the-art

16 research in electroactive-based materials towards the delivery of drugs and other therapeutic

17 signalling agents for wound care treatment. Future directions and current challenges for developing

18 effective electroactive approach based therapies for wound care are discussed.

19 Keywords

20 Piezoelectrics; Conductive polymers; Photovoltaics; Electrets; Electric signals; Drugs; Wounds

21 Abbreviations: CP, conductive polymers; PPy, polypyrrole; PEDOT, poly(3,422 ethylenedioxythiophene); PANI, polyaniline; PLLA, poly(L-lactide); PVDF, poly(vinylidene 23 fluoride); PVDF-TrFE, poly-(vinylidenefluoride-co-trifluro-ethylene); PHB, polyhydroxy-butyrate; 24 HA, hydroxyapatite; BT, barium titanate; LNKN, lithium sodium potassium niobate; LN, lithium 1 
25 niobate; PZT, lead zirconate titanate; ZO, zinc oxide; BNNT, boron nitride nanotubes; PV,

26 photovoltaic; NGF, neural growth factor; PSS, polystyrene sulfonate; PAA, poly(acrylic acid); BDNF,

27 brain-derived neurotrophic factor; ATP, adenosine triphosphate; PLGA, poly(lactide-co-glycolide);

28 GO, graphene oxide; PEG, poly(ethylene glycol); PCL, poly(e-caprolactone); PPV, poly(p-

29 phenylenevinylene); PAAM, polyacrylamide; NP, nanoparticle; PEI, poly(ethylene imine); TDD,

30 transdermal drug delivery; PTFE, polytetrafluoroethylene; PP, polypropylene; TMC, N- trimethyl

31 chitosan; PVT, photovoltaic therapy; NPVDs, photovoltaic based nanoparticle cells; MOFs, metal

32 organic frameworks; ES, electrical stimulation; SPAN, self-doped sulfonated polyaniline; PU,

33 polyurethane; KNN, potassium sodium niobate; ROS, reactive oxygen species; P3HT-PCBM, poly(3-

34 hexylthiophene)-phenyl-C61-butyric acid methyl ester; PPy-PTh, polypyrrole-thiophene; PXDOP,

35 poly(3,4-alkylenedioxypyrrole); PFM, piezoresponse force microscopy

36 Graphical abstract

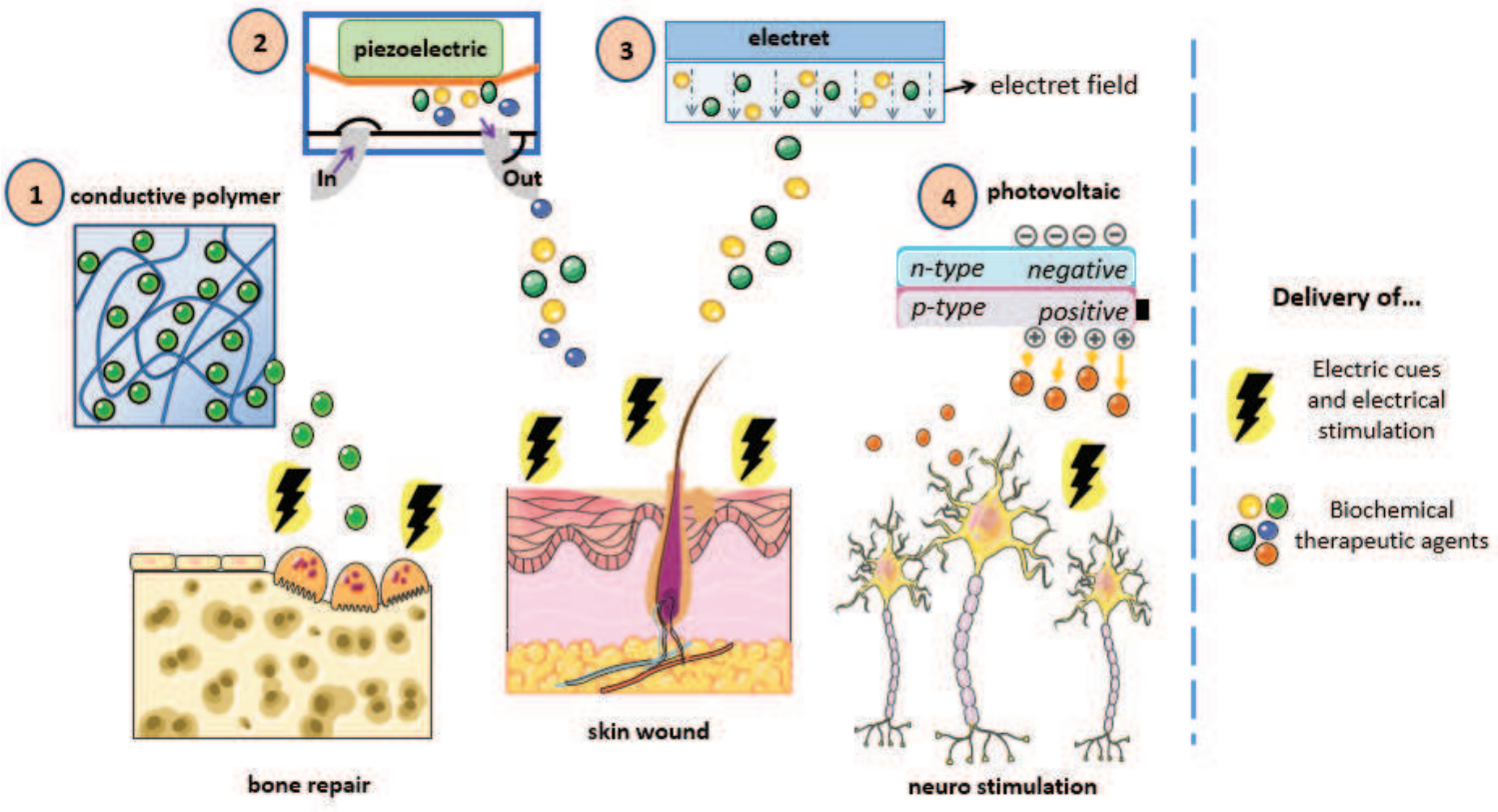




\section{$41 \quad$ 1. Introduction}

42 Wound healing is a coordinated process relying on precise spatiotemporal mechanisms of action.

43 Significant progress has been made to identify specific signals (e.g. small molecules, cytokines,

44 growth factors, RNA interface, genes, cell-based therapies) of therapeutic benefit $[1,2]$. To this end,

45 there is great interest in applying these mechanisms to enhance and accelerate wound healing and

46 enable tissue repair that otherwise could not occur naturally. However, despite the advances made in

47 the field, wound regeneration continues to be a constant challenge for health-care professionals.

48 Injuries to healthy tissues are known to give rise to localized electric fields that play a key role in the

49 process of healing of these wounded tissues [3]. Both delivery of therapeutic drugs and electrical

50 stimulation therapies have been identified as essential tools to enhance the process of wound healing

51 [4-6]. Advances in the delivery systems of these therapeutics have been reviewed $[7,8]$, however,

52 establishing control over their release and stimulus is challenging. To this regard, electroactive

53 biomaterials are gaining prominence and are the focus of the current review in the field of

54 therapeutics for drug delivery and tissue regeneration.

\section{2. Electroactive biomaterials and their modes of action}

56 The family of electroactive biomaterials (Figure 1) is considered a new generation of smart materials

57 that allow direct delivery of electrical signals by control over the electric potential. They have the

58 advantage that they can be combinatorially active (i.e. stimulatory to the tissues as well as triggering

59 controlled/responsive release of therapeutics). Such systems provide clinicians and scientists with an

60 alternative delivery mechanism in wound care, facilitating in turn the development of new therapeutic

61 approaches for patients.

62 Electroactive biomaterials have the potential to have their chemical, electrical and physical properties

63 tailored for the specific needs of their application. The family of electroactive biomaterials includes

64 conductive polymers, piezoelectrics, photovoltaic materials, and electrets. 


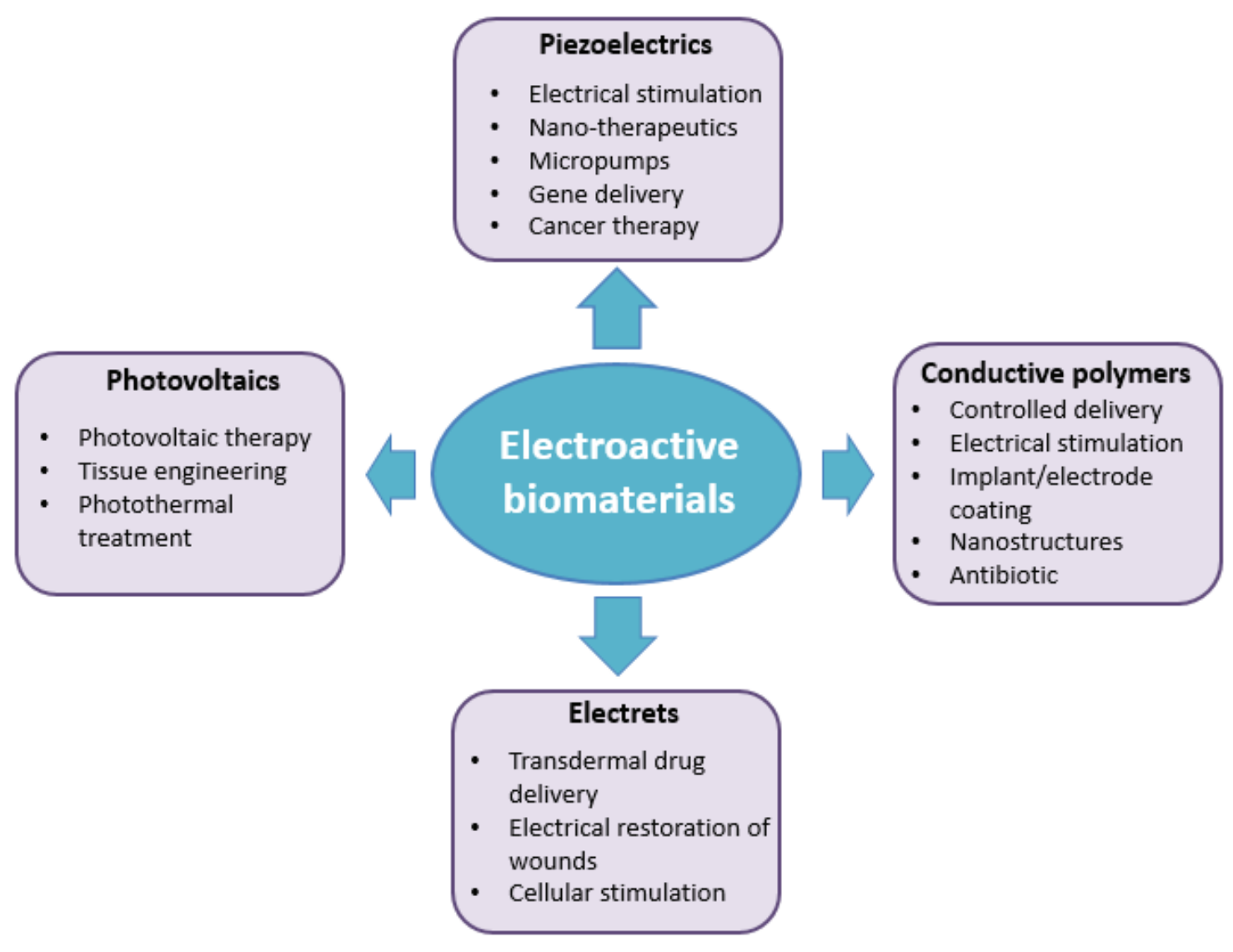

66 Figure 1 The family of electroactive materials and their applications

\section{$67 \quad 2.1$ Conductive polymers}

68 Conductive polymers $(\mathrm{CP})$ are organic polymers that offer a compromise between the good electrical,

69 magnetic and optical properties of metals and the ease of processing and mechanical properties

70 associated with polymers [9-12]. Currently there are over 25 conductive polymer systems $[9,10]$. The

71 most widely researched of these are polypyrrole (PPy), poly(3,4-ethylenedioxythiophene) (PEDOT)

72 and polyaniline (PANI) $[9,10]$.

73 CPs are electrically conductive due to the ease with which electrons jump within and between their

74 polymer chains [13]. A key factor in this conductivity is the "dopant" [13-15]. Conductive polymers

75 are synthesized in an oxidized state and require a negatively charged (anion) molecule - the dopant -

76 to enter the polymer so that the polymer backbone can be stabilized [16]. This dopant is what

77 introduces a charge carrier into this system by removing or adding electrons from/to the polymer 4 
chain, creating polarons or bipolarons. Polarons and bipolarons are loosely held, localized electrons that are surrounded by a distortion in the crystal lattice. When an electrical potential is applied, the backbone is disrupted by the movement of the dopant molecules in or out of the polymer. This allows electrical charge to be passed through a polymer in the form of the above-mentioned polarons and bipolarons [13-15,17]. Many of the CPs have been shown to be cell friendly, supporting the growth of a large number of cell types and displaying good biocompatibility in animal models [13,18-22]. For example, PPy has been demonstrated to support the growth, adhesion and differentiation of neural [23,24], glial [25], endothelial [26,27] and bone cells [18,28], fibroblasts [29], keratinocytes [29] and mesenchymal stem cells [30]. Similarly, PEDOT has been demonstrated biocompatible with neural [31] and neuroblastoma cells [32], epithelial cells [13], and the L929 [33] and NIH3T3 fibroblasts cell 88 lines [13].

\subsection{Piezoelectric materials}

90 Since their discovery in 1880 by the Curie brothers, piezoelectric materials have found applications in 91 different fields such as energy harvesting, biomedical instrumentation, tissue engineering and drug

92 delivery [34-39]. These materials are capable of generating charges (i.e. electrical output) in response to applied mechanical deformations (i.e. direct effect) and also deform in response to applied electric fields (i.e. converse effect) [38]. This effect is attributed to their non-centrosymmetric crystal/chemical structure, which is deformed on application of a force resulting in formation of a net dipole leading to electric polarization [40]. Though these materials are inherently piezoelectric, the

97 dipoles are randomly oriented in the bulk of the material and need to be rearranged to enhance their

98 piezoelectric feature. The procedure used to carry out such rearrangement is termed poling and involves the application of a high electric field at a specific temperature followed by cooling the

100 material under the same electric field [41]. A schematic of the poling procedures and representation of 101 direct and converse piezoelectric effects is shown in Figure 2. 
a)

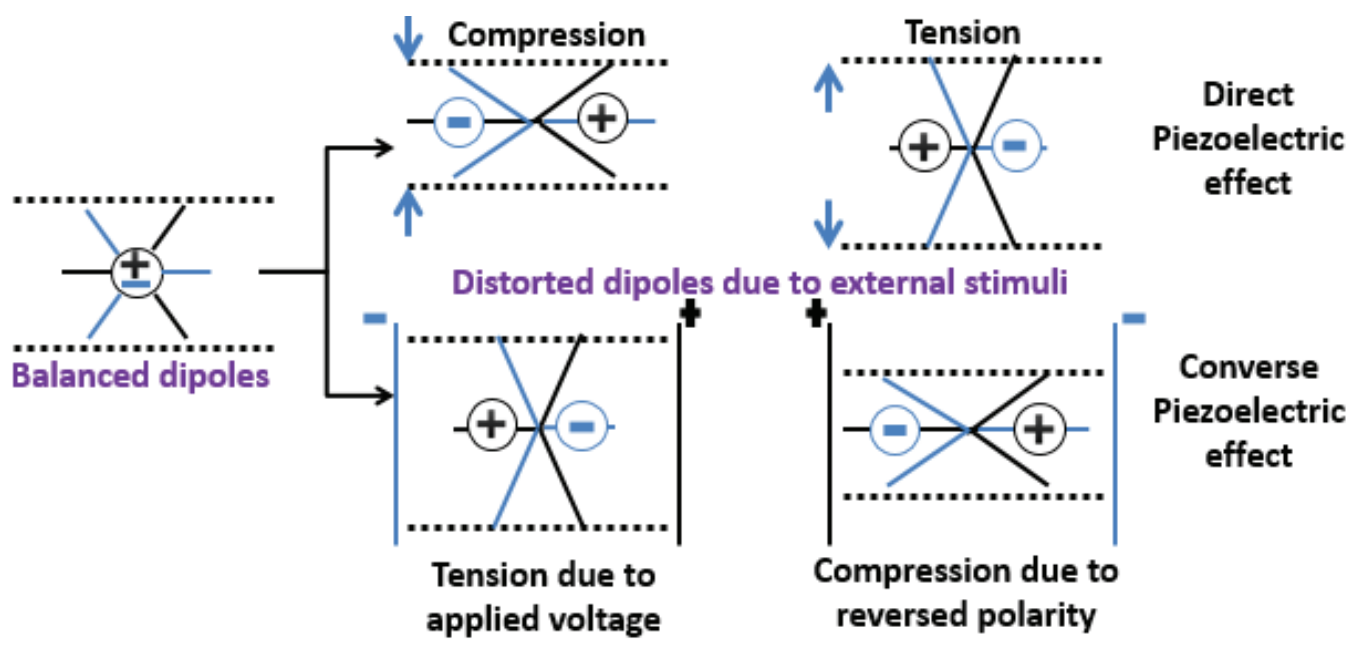

102
Corona voltage

b)

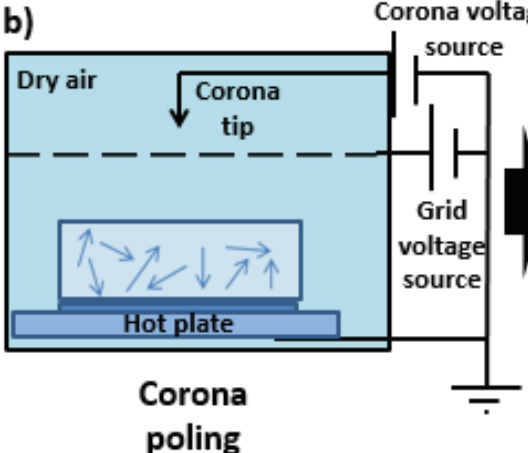

To electric supply

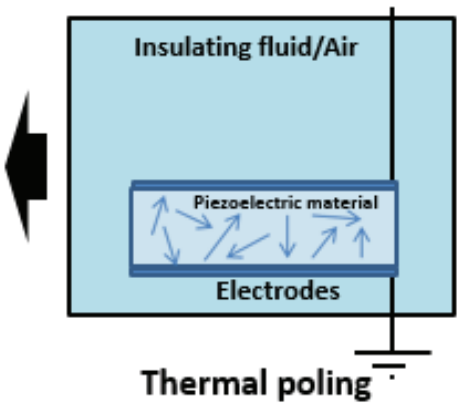

Figure 2 a) Direct and converse piezoelectric effect mechanisms and b) types of poling procedures to maximize piezoelectricity

Piezoelectric materials can be based on synthetic polymers or ceramics, naturally occurring materials or hydrogel systems (a list of piezoelectric materials is shown in Table 1). These materials can be fabricated into macro-, micro or nano- level structures and consequently be used for efficient and controlled release of drugs and therapeutic agents. The potential applications of these materials in the field of medicine require considerable attention of the scientific community.

Table 1 Piezoelectric materials and their classifications

\begin{tabular}{lll}
\hline Polymers & Ceramics & Others \\
\hline Poly(L-Lactide) (PLLA) & Hydroxyapatite (HA) & Diphenylalanine \\
Poly-(vinylidene fluoride) (PVDF) & Barium titanate (BT) & Collagen
\end{tabular}




\begin{tabular}{|c|c|c|}
\hline Poly-(vinylidene fluoride-co-trifluro & Lithium sodium potassium & Boron nitride nano tubes \\
\hline ethylene) (PVDF-TrFE) & niobate (LNKN) & (BNNTs) \\
\hline \multirow[t]{3}{*}{ Polyhydroxy-butyrate (PHB) } & Lithium niobate (LN) & Silk \\
\hline & Lead zirconate titanate $(\mathrm{PZT}$ & \\
\hline & Zinc Oxide (ZO) & \\
\hline
\end{tabular}

111

\section{$112 \quad 2.3$ Electrets}

113 Electrets are dielectric materials capable of retaining quasi permanent electrical charge or dipole

114 polarisation which is not destroyed over time $[42,43]$. The process of fabricating electrets is similar to

115 the poling process of piezoelectric materials by which the material is charged at a constant voltage. A

116 dielectric material is sandwiched between electrodes, heated to softening temperature and a direct

117 current electric field is applied and maintained while the material is cooled to room temperature [44].

118 Based on the type of charges developed on the surface of the electret, they can be classified into two

119 types (i) homocharged and (ii) heterocharged [45]. The different types of electrets and the charges

120 associated with their formation are shown in Figure 3. 
a) Heterocharged Electrets Surface charging opposite to that of electrodes occur due to dipolar, ionic and spatial charge rearrangement.

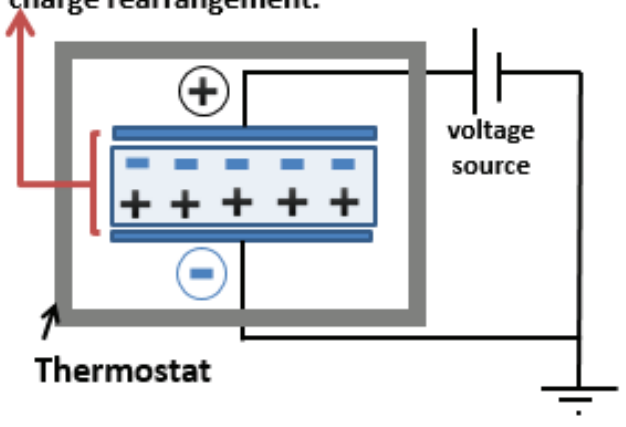

b) Homocharged Electrets Surface charging similar to that of electrodes occur mainly due to charge injection* at high voltages.

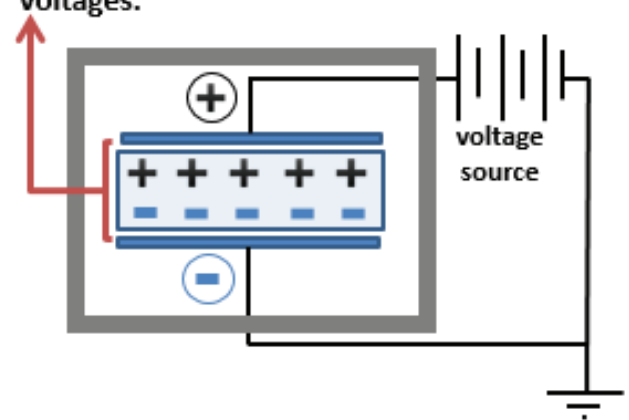

121

c) Types of Electret charges

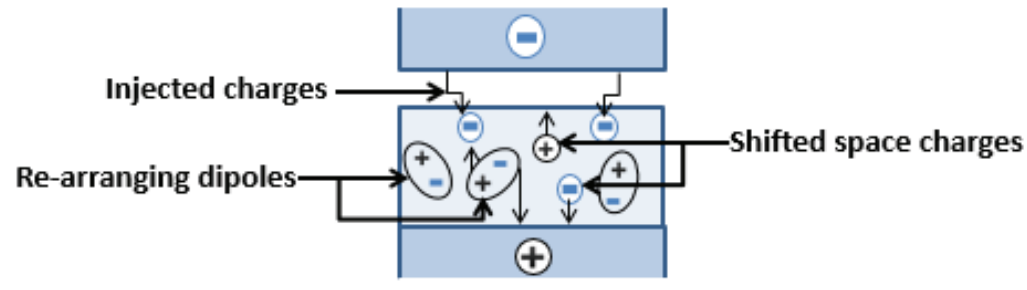

Figure 3 Types of electrets: (a) heterocharged and (b) homocharged (*injected charges are those which get deposited on the material surface from the surrounding electrode); and (c) charge carriers involved during the formation of electrets

\subsection{Photovoltaic materials}

Photovoltaics (PV) is the process of converting light into electrical power by using semiconductor materials that are able to absorb and trap light while exciting a charge carrier to a higher energy state, creating an electron flow: light absorption creates electron-hole pairs, and electrons and holes respectively migrate to opposite electrodes [46] (Figure 4a).

Essentially, a PV device (Figure 4a) consists of two regions, an n-type dope region and a $p$-type dope region, respectively featuring an excess of electrons and a deficit of electrons (i.e. holes), and the presence of contacts $[47,48]$. When both components come into contact, the excess of electrons flow from the $n$-type dope region into the $p$-type dope region, creating an electric field in between. 
134 While PV devices can be found in many forms, these can be classified into three main types. The

135 simplest PV device consists of an electron donor and an electron acceptor sandwiched together into a

136 thin film (single or double layer) for the charge carrier to be allowed to diffuse through the junction

137 (Figure 4b) [49]. However, the thinner the film the less amount of light it can entrap. The previous

138 shortcoming can be addressed by mixing the electron donor and electron acceptor components into a

139 blend (Figure 4b) [50], enhancing carrier diffusion. These PV devices generally consist of composite

140 blends mixing semiconductor nanoparticles with conjugated polymers [51-54], where one functions

141 as an electron donor and the other as an electron acceptor [52]. Blending semiconductor nanoparticles

142 with conjugated polymers combines the easy processability and low cost of the polymer with the high

143 charge mobility of the nanoparticle, which may include spherical, rod-like or branched organic and

144 inorganic particles such as $\mathrm{CdSe}, \mathrm{ZnO}, \mathrm{PbS}$, fullerene derivatives or single-walled nanotubes [55-57].

145 The performance of the composite can be enhanced in terms of light absorbance, charge separation or

146 charge transport, which depends on the choice of the conjugated polymer and the processing condition

147 [58,59]. However, the size and shape of the nanoparticle is also key: branched morphologies exhibit

148 higher efficiencies compared to the use of nanorods or quantum dots [50], and small dimensions (i.e.

149 large surface area to volume ratio) improve energy absorption and emission owning to high optical

150 density [52]. An alternative to the PV blend device format is for a conjugated polymer to be inserted

151 into a porous inorganic network as an ordered heterojunction-like structure (Figure 4b) [60]. Electron

152 transport is facilitated this way as the interface between the polymer and the inorganic component is

153 mainly governed by the dimension of the nanostructure particle, these interfaces can be chemically

154 controlled to assist charge separation or block charge recombination across the donor-acceptor

155 interface [60]. 
a)

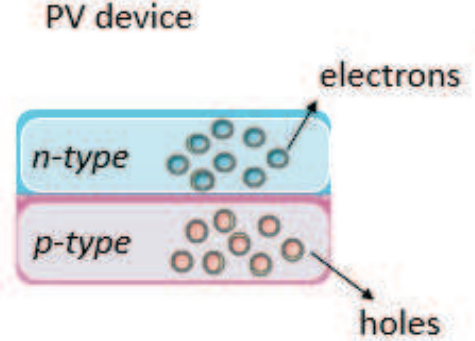

b) Photovoltaic heterojunctions

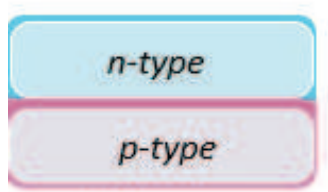

Planar

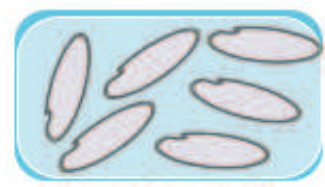

Blended bulk

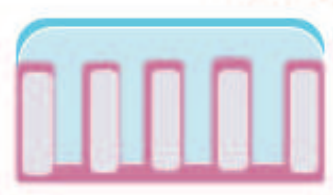

Ordered

\section{Photovoltaic mechanism}

light source

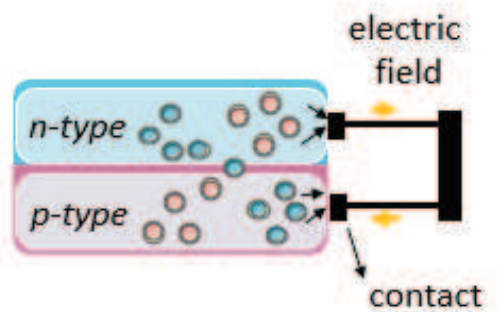

c) Nanoscopic PV device (NPVD)

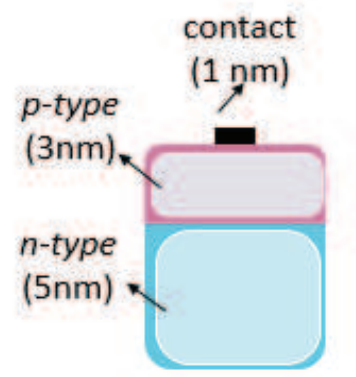

realistic design

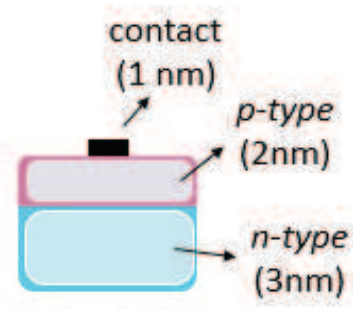

optimal design

157 Figure 4 Photovoltaic mechanism: a) conventional photovoltaic cell where electron-hole pairs

158 migrate to opposite electrodes upon photo stimulation and electric current is produced; b) photovoltaic

159 cells depicting the schematics of a planar heterojunction, a blended bulk heterojunction and an

160 ordered heterojunction; c) model of a conceptual nanoscopic photovoltaic device depicting realistic

161 and optimal design dimensions

\section{3. Electroactive biomaterials as drug delivery systems}

\section{$163 \quad 3.1$ Electrochemically controlled drug delivery based on CPs}

164 CPs have been investigated as potential candidates for drug delivery systems since as early as the

165 1980s, when Zinger and Miller demonstrated that glutamate and ferrocyanide can be released from

166 polypyrrole films through the application of an electric potential [61].

$167 \quad$ 3.1.1 Drug loading and release mechanisms for CPs 
168 Drug delivery systems based on CPs exploit the polymers' ability to be electrically switched between

169 an oxidized and a reduced state, resulting in the uptake or expulsion of charged molecules from the

170 bulk of the polymer [62-64]. A wide range of solutions have been developed based on this

171 phenomenon for the loading and controlled delivery of both positively and negatively charged and

172 neutral drug compounds [62,65-67]. Amongst others, dexamethasone [68], heparin [69], dopamine

173 [70], naproxen [71], neutrophin-3 [72], and neural growth factor (NGF) [22,31] have all been

174 successfully bound and released from conductive polymers.

175 Loading of the drug compound can be performed in a number of ways depending on the type of the

176 drug (Figure 5): small anionic compounds can be loaded through one-step immobilization (Figure

177 5a), as dopants during the polymer synthesis process $[65,73,74]$. This is the simplest method;

178 however, if the drug molecule interferes with the polymerization process, the created material will

179 suffer from low conductivity and drug loading capacity, and unfavourable mechanical properties [65].
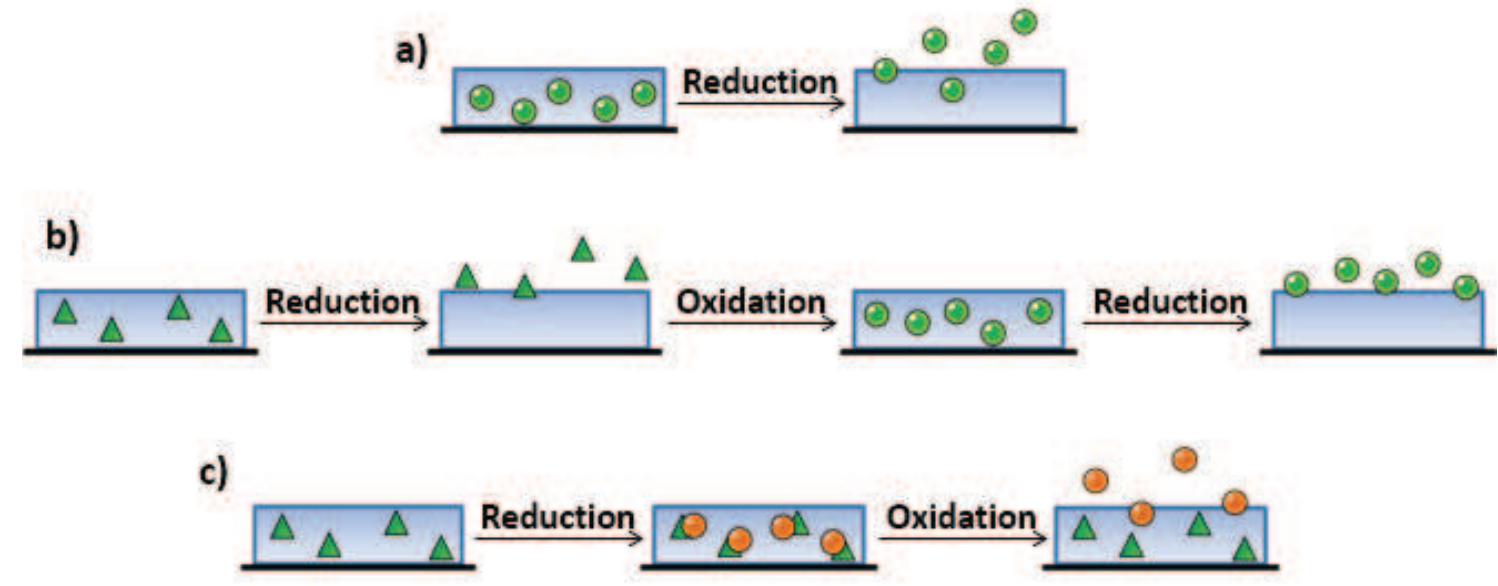

180

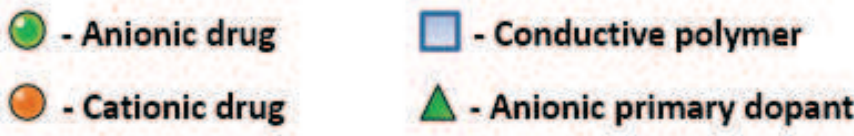

181 Figure 5 Mechanisms of drug loading and release in CPs: a) one-step loading of anionic drug; b)

182 three-step loading of anionic drug; and c) loading of cationic drug 
This limitation of the one-step methods can be overcome through the use of the more elaborate threestep method $[11,65,67,74]$. The three-step method (Figure 5b) separates the synthesis and drug loading processes, allowing both to be carried out with optimal parameters. First, the polymer is synthesized using an ideal anionic "primary" dopant. Following synthesis, a reducing potential is applied flushing out the primary dopant. Afterwards, the desired medicinal compound can be incorporated into the polymer by reversing the potential. A great benefit of this method is its application to the loading of large anionic compounds. However, if the process of removing the dopant and incorporating the drug are inefficient, drug loading capacity will be limited [65].

In a comparison of the one-step and three-step methods, post-synthesis loading has been shown to produce the highest loading for ciprofloxacin, while incorporation during synthesis provided the highest loading for quercetin [74]. This difference was due to quercetin crystallizing on the surface of the polymer when introduced post-synthesis and the subsequent matrix conditioning steps removing it [74]. Cationic drugs require a modified version (Figure 5c) of the three-step method $[63,67,73-75]$. Here, the polymer is synthesized with a large primary anionic dopant that, due to its size, is immobilized inside the polymer matrix during synthesis. Following this, the application of a reducing potential to the polymer results in the positively charged drug entering the material to maintain electroneutrality. This method was successfully applied to the loading and release of dopamine [70] and chlorpromazine [64], using poly(styrene-sulfonate) (PSS) and melanin as the dopant respectively. It has also been adapted to the loading of the neutral drug, $N$-methylphenothiazine, relying on the hydrophobic-hydrophilic interaction between the drug and an anionic "host" molecule, $\beta$ cyclodextrins [76]. can be unbound by either the removal of a negative potential or the application of an oxidizing positive - potential $[67,77,78]$. The required voltage, generally speaking, depends on the reduction 
$[62,63,73,80-82]$. A higher potential results in faster release [83-85]. For example, $-2 \mathrm{~V}$ releases

209 fluorescein from nanoporous PPy films 3-4 times faster than -1.5 V [81]. A similar trend was

210 observed during the co-release of fluorescein and dexamethasone from PPy sponges, where $-2 \mathrm{~V}$

211 produced a two-fold release rate compared to $-0.5 \mathrm{~V}$ [82]. On the other hand, too high potentials can

212 result in the destruction of the bound drug compound through oxidation or hydrolysis, as it was

213 observed in the case of dopamine above $-0.6 \mathrm{~V}$ [63], and neural growth factor above $3 \mathrm{~V}$ [86].

214 Switching to the opposite polarity can help maintain the drug inside the polymer matrix by

215 counteracting diffusion $[83,85,87,88]$. However, this does not apply to every case as during the

216 release of the cationic compound acetylcholine from PEDOT:PSS both $+1 \mathrm{~V}$ and $-1 \mathrm{~V}$ produced a the

217 same release profile [73].

218 The method of delivering the potential is also important: different drug release profiles have been

219 observed depending on whether pulsed potential, pulsed current or cyclic voltammetry was applied

220 [66]. In another study, potentiodynamic stimulation generated higher drug release efficiency than

221 potentiostatic stimulation [65]. Cyclic voltammetry has been stated as the most efficient method for

222 stimulation [11], also allowing greater control over release speed through the setting of different scan

223 rates [89]. Beyond the applied electrical potential, stimulation time [86,90]; polymer film roughness,

224 porosity, density and thickness $[11,62,66,67,84,91]$; the dopant $[84,87]$; and temperature $[83,92]$ are

225 known to affect and allow greater control over optimising the release profile.

226 The chemical environment can also have a profound effect. The release of insulin from PPy-gold

227 nanoparticle composites has been observed to be $\mathrm{pH}$-sensitive with the release slowing down at low

$228 \mathrm{pH}$ [85]. The co-application of an electric potential further increased this sensitivity [85]. A strange

229 relationship was noted between $\mathrm{pH}$ and the effect of the electric potential in the case of safranin

230 release from PPy-poly-(acrylic acid) (PPy-PAA) hydrogel composites. At $\mathrm{pH}$ 6.4, a potential of +0.4

$231 \mathrm{~V}$ enhanced release, while $-0.4 \mathrm{~V}$ helped block diffusion. On the other hand, at $\mathrm{pH} 3.8$ the exact

232 opposite was seen with $-0.4 \mathrm{~V}$ promoting release, and $+0.4 \mathrm{~V}$ preventing it [93]. In contrast to these 
$233 \mathrm{pH}$ dependent responses, the release of aspirin from PPy-montmorillonite composites was insensitive

234 to whether it was performed at $\mathrm{pH} 3.4,7.4$ or 11.4 [94]. Chemistry alone can be used to propagate the

235 release of the drug compounds. Hydrazine and alkaline medium was able trigger the release of

236 adenosine triphosphate (ATP) from PPy membranes, albeit to a lesser extent compared to an electrical

237 potential [95].

\section{3.1.2 Polypyrrole (PPy) and poly-(3,4-ethylenedioxythiophene) (PEDOT)}

239 PPy and PEDOT are members of the polyheterocycles family of conductive polymers, and have been

240 almost predominantly the CP of choice for drug delivery applications $[13,85,96,97]$. PPy and PEDOT

241 films have been used, for example, for the release of chlorpromazine [64], dexamethasone $[68,79,98]$,

242 neurotrophin-3 $[66,99,100]$, risperidone $[88,101,102]$, brain-derived neurotrophic factor (BDNF)

243 [103], adenosine triphosphate (ATP) [95], dopamine [63], acetylcholine [73], methotrexate [83],

244 betulin [104], quercetin and ciprofloxacin [74]. However, this section will focus on the more advanced

245 drug delivery solutions that have been developed in recent years based on these two polymers.

246 For many applications, simple CP films alone do not provide sufficient drug storage capacity [89].

247 The use of micro- and nanostructures can provide a solution to this by offering greater volume and

248 surface area for drug binding. One such structure was created from PPy nanowires, where the micro-

249 and nanogaps between the wires served as reservoirs for the binding of ATP and dexamethasone [89].

250 Micro- and nano-tubes consisting of a drug laden inner core of bacterial cellulose [80], PLLA or

251 poly(lactide-co-glycolide) (PLGA) [105] and an outer shell of PEDOT have also been fabricated.

252 Sponge-like structures can be created by polymerising PPy around sacrificial nano- or microbeads that

253 are then later removed. Such nanostructures have been used for the release of rhodamine B [106],

254 dexamethasone [82,107], fluoroscein [81,82], chlorpromazine [92], and risperidone [91]. The

255 nanoporous PPy structure provided a capacity nine times greater compared to conventional PPy films

256 in the case of fluorescein [81], and four times greater in case of risperidone [91]. Brush-like structures

257 were generated by depositing PPy on top of aligned carbon nanotube surfaces for the delivery of 14 
neurotrophin-3, possessing a surface area ten times higher than a film [108]. A similar approach was used for the enhanced binding and release of dexamethasone and penicillin [109]. A petal-like structure was achieved through polymerising PEDOT on top of single-wall carbon nanotubes immobilized on a gold surface [110]. Compared to neat PEDOT this material possessed improved conductivity, charge capacity and drug release rate [110]. Furthermore, it was able to resist three times longer the degradation effects (e.g. delimitation and cracking) of cycling the CP through its redox states during electrical stimulation [110]. Carbon nanotubes have been used in an alternative approach by Luo et al. as containers for drug molecules [111]: PPy was electropolymerized on the open ends of dexamethasone loaded carbon nanotubes, providing a seal on the ends of the nanotubes that could be opened with electrical stimulation [111].

Nanocomposites offer an additional solution to improving drug-loading capacity. Graphene oxide (GO) has been successfully combined with PPy to generate a composite material with twice greater dexamethasone binding capacity than PPy alone, a linear release profile up to 400 stimulations, and no passive drug diffusion [112]. GO has been used in combination with PEDOT to deliver dexamethasone in a smart coating for orthopaedic implants [113]. An interesting new approach in CP composites is the use of clay particles, such as palygorskite [114] and montmorillonite [94], that lend their large specific surface area to the composite material.

PPy and PEDOT have been combined with hydrogels, that are themselves important drug delivery tools, made from PAA [93,115], poly(lactic-co-glycolic acid)-co-poly(ethylene glycol) (PLGA-PEG) [78], alginate [116], and xanthan [117]. These blends combine the high electrical conductivity and electrically and chemically switchable properties of CPs, with the high swelling ability, excellent small molecules diffusivity, and good biocompatibility of hydrogels $[93,115]$.

Ge et al. used microfabrication to construct a PPy based microchip with 36 independent electrodes. This novel device is able to supply multiple drugs at the same time or sequentially over multiple days, while offering greater control over doses then simple PPy films [77]. The same authors have also 
created a very interesting self-activating system by turning the $\mathrm{CP}$ based drug release system into a

284 galvanic cell. Magnesium was coated onto one side of a PPy coated porous cellulose film.

285 Submerging the film into a $\mathrm{NaCl}$ solution resulted in the magnesium oxidizing, which in turn resulted

286 in the reduction of the PPy, releasing the bound ATP [118]. This created a flexible, lightweight and

287 partially-biodegradable device that does not require an external power source to operate [118]. Similar

288 solutions have been developed by coating magnesium onto PPy nanowires containing ATP [119], and

289 depositing PEDOT/GO onto biodegradable magnesium substrate [113].

290 In order to overcome limitations that might arise from limited drug loading capacity, the molecular

291 weight of the medicinal compound, or the drug-dopant interference, a drug binding method based on

292 biotin-streptavidin coupling has been proposed $[86,120]$. This technique was successfully used for the

293 binding and release of molecules both directly attached to the polymer [86] or coated on the surface of

294 intermediating gold nanoparticles [120].

a)

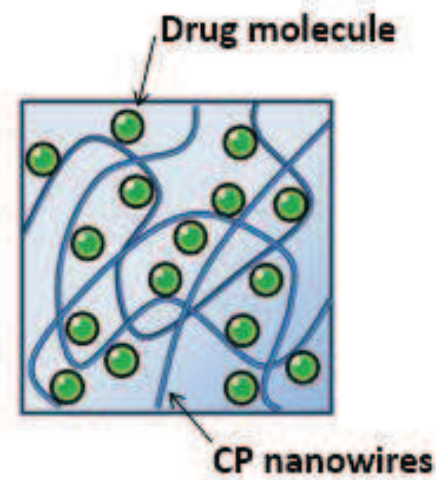

c)

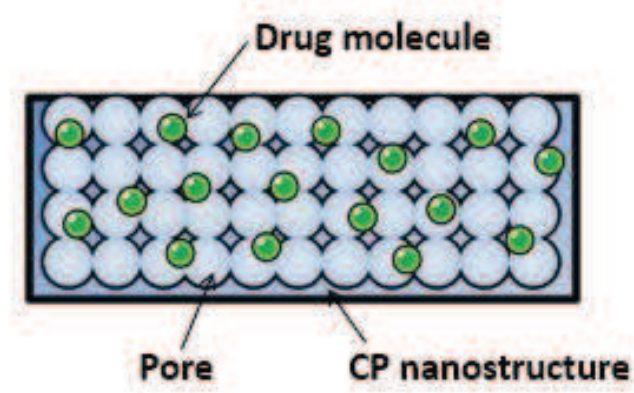

b)

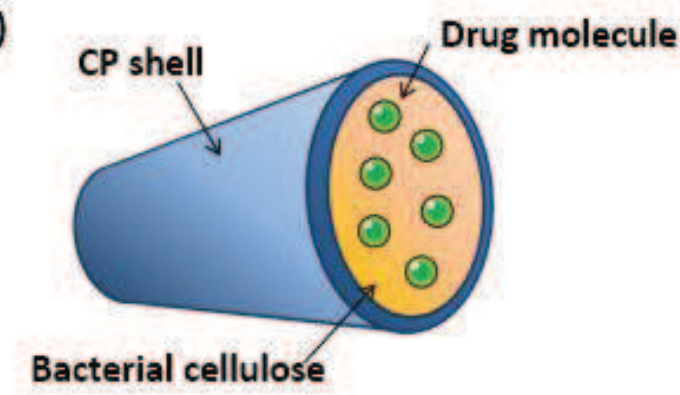

d)

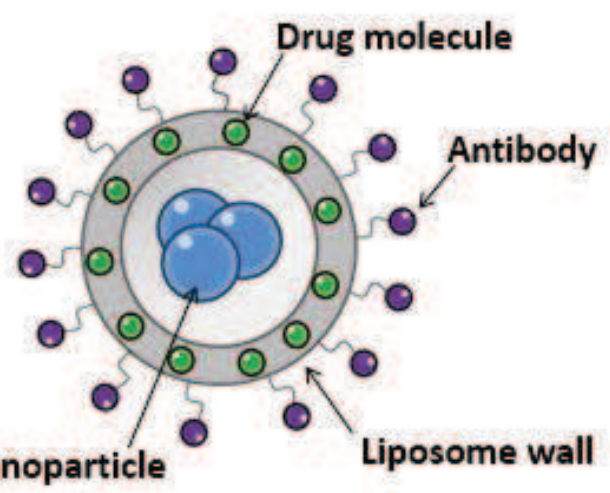


296 Figure 6 Examples of advanced CP based drug delivery solutions: a) nanowires [89]; b) microtubes

297 [80]; c) nanoporous structures [106]; and d) nanoparticles [121]

298 Nanoparticles have also been fabricated out of CPs (Figure 6). An encapsulation efficiency of 95\%

299 was achieved when loading ketoprofen inside PPy-iron oxide nanoparticles [122]. PPy nanoparticles

300 with the capability to release both at acidic and basic $\mathrm{pH}$ have been engineered, enabling their use in a

301 wide range of tissue environments, including the $\mathrm{pH}$ 1-3 of the stomach and the $\mathrm{pH} 7-8$ of the colon

302 [123]. These PPy nanoparticles have also been immobilized in a calcium alginate hydrogel for the

303 sustained $\mathrm{pH}$ dependent release of the anti-inflammatory drug piroxicam [123]. In a recent study, a

304 targeted nanocarrier system was developed for chemotherapy, where rapamycin was bound in a

305 liposome wall formed around PPy nanoparticles. The liposome was coated with Herceptin®

306 (trastuzumab) that binds specifically to the HER2/neu receptor expressed by breast cancer cells,

307 enabling target cell specific cellular uptake. Exposing the target area/cells to an $808 \mathrm{~nm}$ laser heated

308 up the particles, releasing rapamycin and triggering apoptosis [121].

309 A very different drug release mechanism was engineered by Jeon et al. [124], instead of the

310 electrostatic binding and release, a delivery system exploiting the mechanical swelling and contraction

311 of PPy was fabricated. PPy pores were polymerized on top of anodized aluminium oxide membranes

312 [124]. The PPy pores could be opened and closed through the application of an electrical potential,

313 releasing on demand the bovine serum albumin contained in a reservoir situated on one side of the

314 membrane [124]. The created device possessed a very fast response time in the range of $10 \mathrm{~s}$, and a

315 capacity only limited by the reservoir behind the aluminium oxide membrane [124].

\section{$316 \quad 3.1 .3$ Other conductive polymers}

317 The field of CP based drug delivery is dominated by PPy and PEDOT. However, there are examples

318 of other CPs being applied, including degradable electroactive copolymers synthesized from

319 oligoaniline and PEG or poly( $\varepsilon$-caprolactone) (PCL) blocks. The resultant materials were found to be 320 degradable in vitro, supported the adhesion of human dermal fibroblasts, and successfully delivered 
dexamethasone with potential cycling between $0.7 \mathrm{~V}$ and $-0.5 \mathrm{~V}$ [125]. Oligoaniline has also been

322 combined with oligoalanine to form electroactive supramolecular polymers for the delivery of

323 dexamethasone phosphate [126]. Poly( $N$-methylpyrrolylium) poly(styrenesulfonate) was successfully

324 used as a cation exchanger for the binding and the release of dopamine [70]. The conductive polymer

poly(p-phenylenevinylene) (PPV) has been applied in combination with polyacrylamide (PAAM) to

create a hydrogel with a tailorable release profile. The presence of PPV in the hydrogel delayed the

release of salicylic acid in the first three hours, and this blocking effect could be extended to above

fifteen hours with the application of a $0.1 \mathrm{~V}$ anodic potential. Release could be triggered with the application of a cathodic potential, the rate increasing with greater electric field strength. The release profile could be further optimised by varying the crosslinking density, and the size of the drug and the pores in the hydrogel [127].

\subsection{Piezoelectrically active materials for drug delivery}

333 The piezoelectric principle of some materials has been researched in the field of drug delivery; for instance, in the fabrication of micropumps to treat diseases such as diabetes, with direct effects on tissue healing [128-132], or in the development of hybrid composite scaffolds made out of piezoelectrically active materials [133-135].

\subsubsection{Drug release mechanism on piezoelectric based materials}

338 The use of the piezoelectric mechanism for driving micropumps for drug delivery is common due to

339 various advantages such as low power consumption, wide range of frequency operation, a rapid signal

340 response and the ability of piezo actuators to be integrated in microsystems with ease [136].

341 Micropumps are preferred drug delivery systems as they provide better control, precision, accuracy

342 and reliability than other drug delivery methods such as oral, injectable, nanoparticle based delivery

343 or others [137]. Primarily localized delivery of insulin in diabetic patients has been explored using

344 micropumps alongside some other lesser researched fields [138]. A schematic of the working

345 principle of different types of piezoelectric micropumps for drug delivery is shown in Figure 7. 


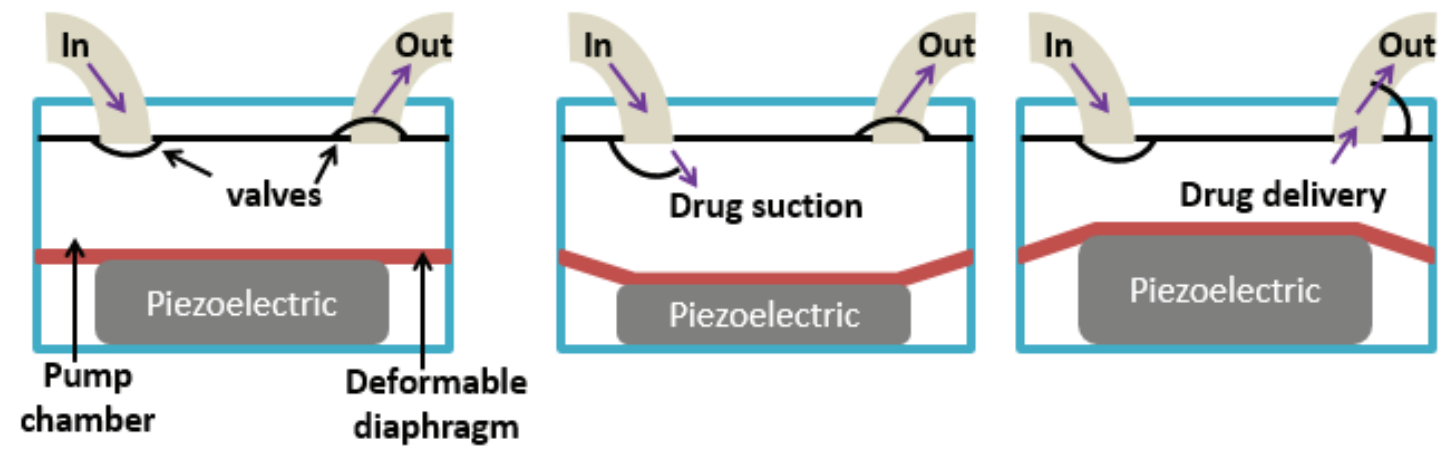

Piezoelectric pump with valves

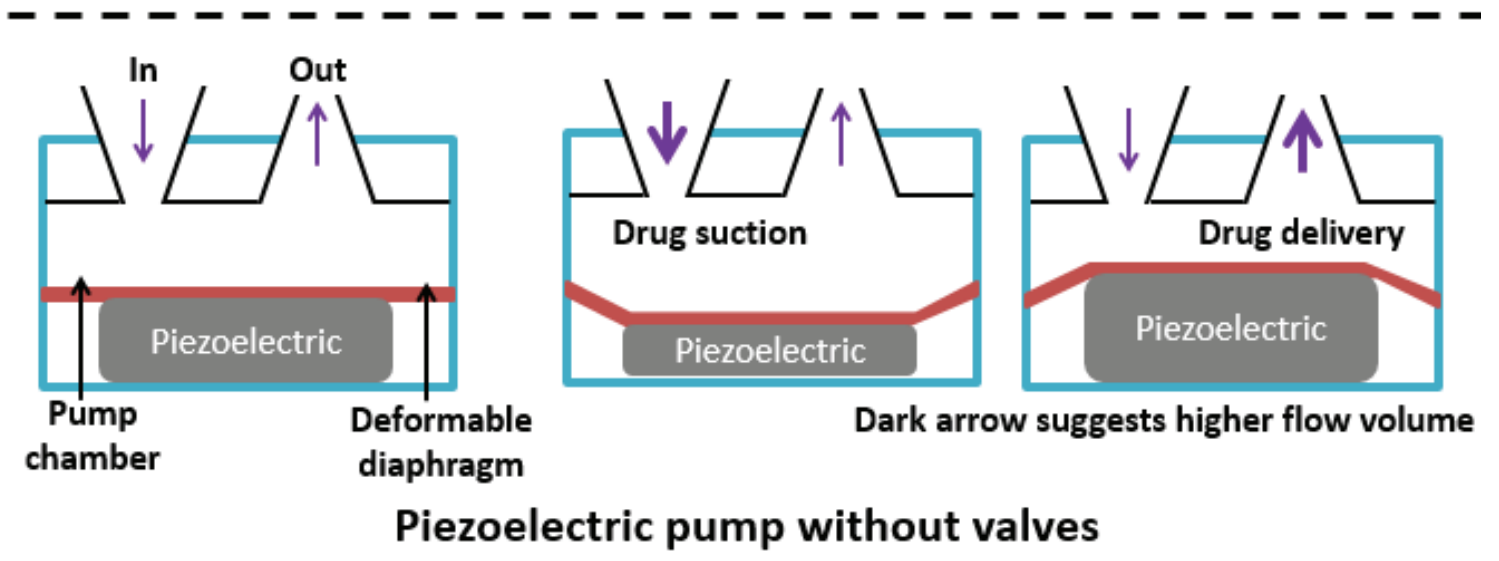

347 Figure 7 Schematic of working principle of piezoelectric micropumps with or without valves, based

348 on deformable piezoelectric based diaphragms that regulate drug suction and delivery

349 PZT based actuators are the most commonly utilized piezomaterials over the past three decades to

350 fabricate micropumps for controlled release of drugs $[34,137,139]$; piezoelectric micropumps with

351 and without valves have been studied extensively [137,140]. In 2014, Wei et al. reported the design

352 and fabrication of a valve-less piezoelectric micropump which was screen printed on a substrate using

353 multiple layers of different materials [141]. These pumps printed on flexible substrates have possible

354 applications in wearable smart fabric devices for drug/bactericide delivery. The absence of valves in

355 the micropumps makes their design and fabrication process simpler and also, they are less prone to

356 clogging and require lower voltages of operation [136,141]. A drive frequency of $3 \mathrm{kHz}$ was used to

357 achieve a maximum flow rate of $38 \mu \mathrm{L} / \mathrm{min}$. Different designs reported for valve-less pumps have

358 been well optimized for higher delivery rates (i.e. flow rates) and better reliability [136,142]. 
However, successful operation of valve-less micropumps depends on the efficiency of the flow rectification process of the proposed design [140]. The presence of valves in micropumps ensure

361 precise control over the flow rate, direction and stability, and makes them more reliable than valve-

362 less designs [143]. Modifications to different parts of the micropump such as vibrating mechanisms and valve design can be made to improve the performance [143-145]. Wang et al. proposed the use of

364 a folding vibrator system in combination with check valves and compressible spaces [143]. A

365 minimum stable flow rate of $160 \mu \mathrm{L} / \mathrm{min}$ was obtained using a low drive voltage. The study clearly

366 suggests that highly efficient micropumps can be fabricated if proper design considerations are made.

367 To ensure successful implantation of these micropumps, it is important to use biocompatible components to design them. However, the non-degradability of these pumps limits their use as invasive procedures may be required for implantation and removal of these pumps after the function has been served.

Advances in microfluidics and nanofabrication technologies have enabled the miniaturisation of 372 implantable drug delivery systems [146,147]. Piezoelectric based micropumps could be worn as 373 dermal patches, smart wearables or implanted within the body with a power source to achieve 374 delivery of desired drug profiles. This approach of administering drugs in a controlled manner is 375 encouraging, with some of these implantable pumps commercially available. However, the use of drug-loaded implants/scaffolds is a more promising solution. Through the use of drug-loaded scaffolds, an efficient delivery of drugs can be ensured and the repair process enhanced due to the 378 presence of localized electrical environments set up by the electroactive scaffolds $[148,149]$.

379 However, controlling the adsorption and release behaviour of drugs through external stimuli has been 380 explored [150].

Piezoelectric materials have been used to develop hybrid composite scaffolds for the release of drugs and genes [133-135]. In 2010, Ciofani et al. reported the use of BTNPs dispersions in glycol-chitosan to form complexes with a widely used chemotherapy drug, doxorubicin, to enhance its delivery to cells and improve treatment efficiency [134]. Similar to this study, Suh et al. reported on increased 
cellular uptake of BTNPs coated with polyethylenimine (PEI) [133]. Both studies highlight the use of

386 BTNPs as vectors without any mentions of the role of the piezoelectric properties and their possible

387 role in altering delivery of genes or drugs. On similar lines, a more recent study published in 2016

388 highlights the use of BNNTs for delivery of fluorescent probes and drugs such as curcumin, a potent anti-inflammatory, anti-microbial and anti-oxidant wound-healing agent [135]. Curcumin was shown

390 to be entrapped within the nanotubes through characterisation by transmission electron microscopy

391 imaging [135]. In another study, He et al. reported loading of electrospun fibrous PVDF membranes

392 with antibacterial drug enrofloxacin for treating dermal injuries [151]. The drug release profile

393 observed was similar to that desired for wound healing processes [151]. In this study, it was

394 mentioned that the enrofloxacin was present in large portions on the outer surface of the fibres and

395 diffusion was the main driving mechanism of drug release [151]. However, the contribution of the

396 piezoelectric effect towards drug loading and release was not studied in any of these works and

397 remains to be explored.

$398 \quad 3.3$ Electret mediated delivery of drugs

399 Electrets for drug delivery mainly come in the form of patches and are mainly limited to transdermal

400 delivery. They can carry different values of surface potentials depending on the amount of surface

401 charges retained. These can subsequently give rise to electrostatic fields and microcurrents which can

402 assist in the process of wound healing and transdermal drug delivery (i.e. TDD, a process of

403 administrating drugs/therapeutic agents through intact skin) $[152,153]$. 

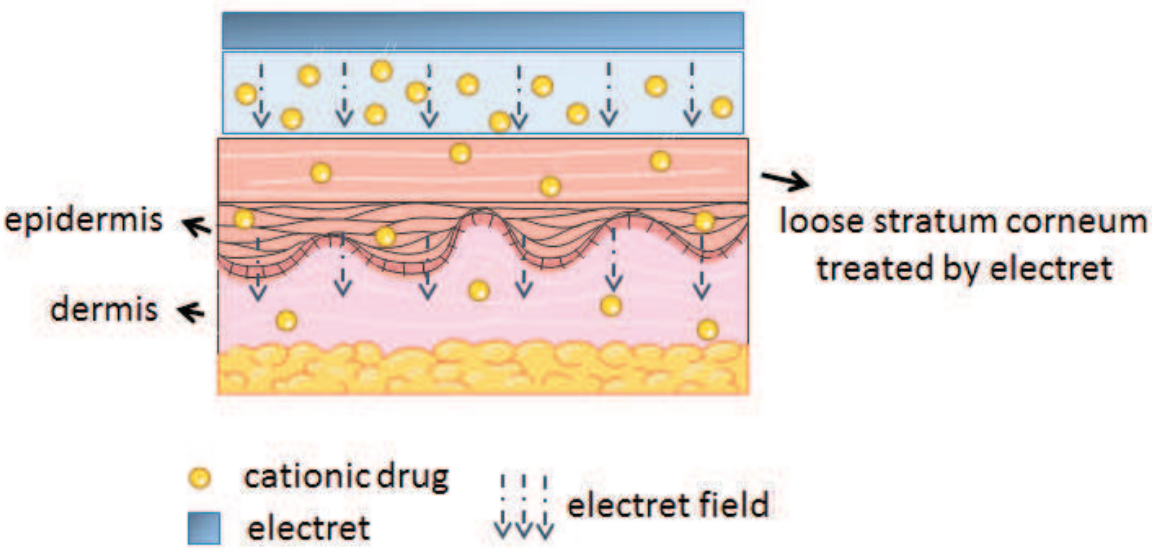

$405 \quad$ Figure 8 Transdermal drug delivery system based on electrets

406 Research reported over the last two decades have shown that the electrical fields generated by

407 electrets based on polytetrafluoroethylene (PTFE) and polypropylene (PP) are capable of altering the 408 permeability of skin and promote transdermal delivery of drugs [154-156] (Figure 8). Regulation of

409 the electret state of the skin, arrangement and fluidity of lamellar lipids and structure of proteins in the

410 stratum corneum (the outermost layer of skin considered to be the main barrier for TDD), leading to

411 formation of wide gaps have been shown to be the key mechanisms for improvement of TDD

412 [154,155,157-159]. Cui et al. performed several studies using PP electrets prepared by film casting

413 technique, combined with different chemical enhancers (that promote TDD by altering skin structure)

414 for different types of drug formulations [158,160,161]. In one of the studies, it was observed that

415 electrets of various surface potentials alone enhanced the permeation of meloxicam, a low molecular

416 weight drug $(<1 \mathrm{kDa})$, more than the chemical enhancer on its own [161]. However, in case of

417 cyclosporine A, a drug with higher molecular weight $(>1 \mathrm{kDa})$, electrets alone of different surface

418 potentials were not able to achieve similar levels of drug permeation as the chemical enhancer [160].

419 Similar results were obtained in a study by Murthy et al. which showed that Teflon electrets were

420 unable to enhance delivery of high molecular weight drugs [162]. To this regard, a novel approach has

421 been suggested by Tu et al. to address the issue of delivering high molecular weight drugs [158]. The

422 study shows that using drug loaded $N$ - trimethyl chitosan nanoparticles (TMC NPs) in combination 
with PP electret films enhances transdermal delivery of protein drugs, thanks in part to the

424 mucoadhesive ability of chitosan to be absorbed across mucosa epithelia. The results obtained in the studies are promising, showing that the skin permeation to protein drugs and nanoparticles is increased with the increase of surface voltage of positively charged electrets, and gradually decreases with an increase of surface voltage of negatively charged electrets. However, there are factors that require optimization for success of such systems. In particular, the nature, sign and magnitude of the surface potential of the electret, the type of drugs and the type of nanoparticles are all equally important to be analysed [158]. Also, it is important to assure that the surface charge of the electrets is

431 not shielded by moisture or other contaminants [162].

\section{$432 \quad 3.4$ Targeted drug delivery using photovoltaic materials}

433 One of the main goals of drug delivery systems is to minimize the exposure of the drug to healthy

434 tissues while achieving an appropriate therapeutic dosage concentration in the wound site.

435 Photovoltaic materials have recently started to gain attention in therapeutic applications as a way to

436 control the release of specific drugs when the charge intensity or polarity of the material changes upon

437 external light stimulation (i.e. near infrared or laser source, 650 - $900 \mathrm{~nm}$ wavelength). This is known

438 as photovoltaic therapy (PVT), where positively and negatively charged drugs can be loaded onto the

439 surface of a PV device (either on n-type or p-type doped regions) by means of electrical attraction (i.e.

440 negative or positive) and be released to target sites via electrical repulsion upon light initiation

\section{1 (Figure 9).}

442 To date, PV devices have not been extensively research for drug delivery applications and scarce

443 examples are found in the literature. The proof of concept dates back to 2013 when Bhuyan et al.

444 demonstrated that negatively charged bovine serum albumin and positively charged poly-L-lysine,

445 attached to the positive and negative sides of a PV cell respectively, were released upon external

446 photo stimulation [163]. 


\section{PV devices as drug delivery carriers}

a) light source

\begin{tabular}{|c|c|}
\hline n-type & neutral \\
\hline$p$-type & neutral \\
\hline
\end{tabular}

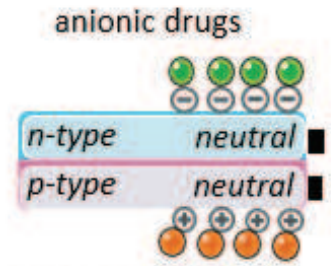

cationic drugs
447

448 Figure 9 Photovoltaic devices used as drug delivery carriers: a) PV device coated with positively

449 charged drugs, which are released upon stimulation and attracted back again in a retractable-wise

450 manner; b) PV device coated with positively and negatively charged drugs that are attracted to

451 opposite sites upon stimulation of the device instead of being repelled towards the environment

452 As long as the principle of photovoltaics is maintained, PV devices can be manufactured from a wide

453 range of micro/nano mesoporous materials such as silica $[164,165]$, with tuneable pore sizes, shapes

454 and morphologies, which also provide for high drug loading capacity and manipulative surface in

455 terms of cell-material interactions. For instance, micro-size PV cells from silica have already been

456 manufactured, being more effective at dissipating heat when they range below the millimetre size

457 [163]. However, the move is now focused towards developing nanoscale devices in formats other than

458 films that could further facilitate drug delivery. For instance, photovoltaic based nanoparticle cells

459 (NPVDs) have already been envisioned with designs theoretically functional [166], and have been

460 produced from silica, gold and silver materials [167]. However, it is important to target the 
sequestration of these NPVDs as drug carriers to the wound site (Table 2), and an optimal size of

462 around $6 \mathrm{~nm}$ (n-type thickness of $3 \mathrm{~nm}$, $p$-type thickness of $2 \mathrm{~nm}$ and contact thickness of $2 \mathrm{~nm}$ ) is

463 required for them to be successfully used as delivery carriers to ensure maximum renal filtration.

464 Based on the current technology, the realistic achievable NPVD size is $9 \mathrm{~nm}$ (n-type thickness of 5

$465 \mathrm{~nm}$, p-type thickness of $3 \mathrm{~nm}$ and contact thickness of $1 \mathrm{~nm}$ ), though, with an $8 \mathrm{~nm}$ glomerular pore

466 size [166] (Figure 4c). The activation of these NPVDs remains in the near infrared, and any drug can

467 theoretically be transported.

468 Table 2 Size dimensions of nanoparticles regarding their target site and route of excretion

\begin{tabular}{lll}
\hline Target tissue & Size particle & Excretion route \\
\hline Any & $3-10 \mathrm{~nm}$ & Renal filtration [168] \\
Liver and brain tissue & $10-30 \mathrm{~nm}$ & Phagocyte system [169] \\
Lung and inflamed tissues & $30-80 \mathrm{~nm}$ & Phagocyte system [170] \\
Liver and spleen & $>80 \mathrm{~nm}$ & Hepatobiliary excretion [169] \\
\hline
\end{tabular}

469

\subsubsection{Drug loading and release on photovoltaic based materials}

471 Two hypothetical mechanisms of action have been proposed regarding PVT, mainly drug

472 retractability and contact to $p$-type region. In the drug retractability mechanism [166] (Figure 9a), a

473 PV device in neutral state is coated with a positively charged drug on the $p$-type region. Upon

474 stimulation, positive and negative charges form in the $p$-type and $n$-type regions respectively, and the

475 presence of a contact in the p-type region allows positive charges to interact with the environment and repel the positively charged drug in the material. When stimulation ceases, both the $p$-type and $n$-type

477 regions return to their neutral state attracting the drug and any other charged molecules from the

478 environment, thus, controlling timing and duration of the drug-environment interactions in a back and

479 forth of neutral and charging cycles and reducing the impact of any side effects. In the contact to $p$ -

480 type region mechanism [166], contacts are only applied on the p-type region of the device. While

481 contacts can be applied to both the p-type and n-type regions for higher drug capacity (i.e. positively 
charge drugs adsorbed onto the p-type and negatively charged drugs adsorbed onto the $n$-type

regions), there is a chance that upon stimulation of the device the negatively and positively charged

drugs will be attracted to opposite regions upon initial repulsion (Figure 9b). This limits drug

interaction at the desired site of action, but can be easily solved by removing the contact from the $n$ -

type region so that negative charges do not interact with the environment. In this sense, higher drug delivery efficacy is achieved at the expense of a reduced drug capacity.

\subsubsection{Metal organic frameworks as photovoltaic devices in wound care}

Metal organic frameworks (MOFs) are highly porous network materials consisting of metal ions linked together by organic bridging ligands $[171,172]$. MOFs were first proposed as an alternative new controlled drug delivery system back in 2004 [173] due to their combined high pore volume, regular porosity, and tuneable organic groups within the framework that allow easy modulation of the pore size and makes them more competitive as therapeutic containers [174-178] than conventional pore materials (Figure 10). Since then, several studies on the use of MOFs as delivery vehicles of molecular therapeutics (i.e. antimicrobial metal ions [179] or homeostasis regulators such as copper [180]) and gaseous therapeutics (i.e. nitric oxide [181]) for skin wound treatment have emerged in the form of hydrogel systems [182-184].
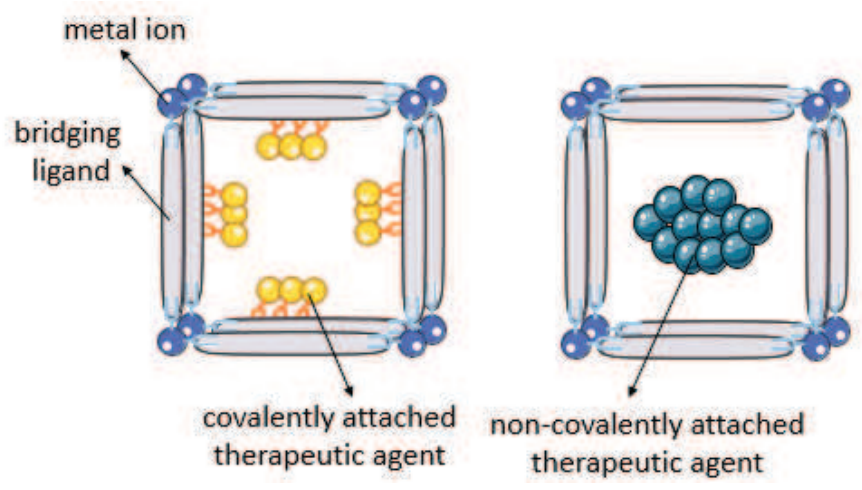

Figure 10 Schematic representation of a metal organic framework (MOF) structure used as a delivery 500 carrier 
501 Although MOFs are mainly non-conductive, the use of structural doping or short inorganic and

502 conjugated organic bridging ligands in their structures can extend their potential to be used as PV

503 devices [185-187]. PV-based MOF systems have been thoroughly reviewed by Kaur et al. [188]. In

504 this sense, there is growing interest in combining the capabilities of MOFs with the PV effect for

505 these devices to be used as therapeutic delivery carriers to promote and enhance skin regeneration.

506 4. The stimulatory response of electroactive materials in wound healing

507 Electrical stimulation (ES) alone has been shown beneficial for the treatment of wounds and injuries.

508 ES has been shown to aid the re-epithelisation of skin and corneal wounds; to enhance angiogenesis;

509 and to promote the migration of fibroblasts, keratynocytes and epithelial cells [189-195]. ES's ability

510 to induce re-innervation $[196,197]$ and increase skin blood flow [198] aids in the healing of wounds.

511 ES can show significant antibacterial effects, for example, it has been demonstrated to reduce the

512 number of methicillin-resistant Staphylococcus aureus colonies by over $87 \%$ both in vitro and in vivo

513 [199]. Furthermore, ES has been successfully used in the treatment of diabetic ulcers [200]; and nerve

514 damage in sciatic nerve [201] and spinal cord injury models [202]; and as an osteoinductive tool in

515 treating normal and non-union fractures, osteoporosis and osteoarthrosis [203-207]. ES's ability to

516 manage pain is also an important consideration $[208,209]$. Transcutaneous ES has been shown as to

517 be a non-invasive, drug-free alternative in managing acute and chronic pain [208], in one example

518 reducing pain scores by $38 \%$ and drug consumption by $25 \%$ [209].

\section{$519 \quad$ 4.1 Stimulatory response of CPs in tissue repair}

520 The use of CPs in the treatment of injuries ranges from conduits [210] and injectable particles [211]

521 for the repair of nerve damage, to tissue engineered solutions [212] and biosensing devices [213].

522 Most of the wound healing techniques developed from CPs utilize their antibacterial properties [214-

523 218]. Wound covering fabrics produced from PPy and PANI have been shown to decimate

524 populations of E. coli, E. agglomerans, B. subtilis and S. aureus $[214,217,218]$. The antibacterial

525 effect of CPs have been attributed to the excessive positive charge and oxidizing potential of the 
polycationic backbone of the polymer disrupting the cell wall and interfering with bacterial

527 respiration; and to the electron donor-acceptor character of CPs hindering bacterial adhesion and

528 blocking biofilm formation [214,216,217]. The effect has also been demonstrated to be a result of the

529 polymer itself, and not due to the oxidising agent or dopant used during the synthesis of the CP [216].

530 Their already strong bactericidal effect has been enhanced through the binding and release of silver

531 nanoparticles [215] and the antibacterial drug ciprofloxacin hydrochloride [87].

532 When used synergistically, ES and CPs have been shown to activate dermal fibroblasts and promote the expression of $\mathrm{TGF} \beta_{1}$ and other key factors that drive cell proliferation, differentiation, inflammation response, keratinocyte migration and extra-cellular matrix production [219]. Human dermal fibroblasts cultured on PPy-PDLLA composite membranes displayed enhanced proliferation when stimulated with a direct current [220]. Comparably, ES delivered through nanofibres of PANI blended with PLLA-co-PCL was observed to increase the growth and adhesion of NIH-3T3 fibroblasts [221]. Stimulating human skin fibroblasts on PPy/PLLA membranes resulted in greater viability and mitochondrial activity [222]. A tenfold increase in the secretion of interleukin-6 and

540 interleukin-8, two cytokines important for wound repair and the growth of new blood vessels, was reported when exposing skin fibroblasts on conductive PPy and degradable PLLA composite scaffolds to an electrical stimulus [223]. The delivery of ES through conductive polymers can be useful for the formation of new blood vessels: human umbilical vein endothelial cells stimulated with 200-400 $\mathrm{mV} / \mathrm{cm}$ on PANI-coated PCL fibres exhibited highly enhanced viability and adhesion [224]. of longer neurites $[225,226]$. Nerve stem cells displayed a similar behaviour, extending more neurites when stimulated on a PLLA/PANI scaffold [226], and enhanced proliferation and neurite outgrowth on PANI-PCL/gelatin substrates [227]. ES and conductive scaffolds have been combined with stem cell based therapies: the pre-stimulation of human neural progenitor cells on PPy scaffolds before transplantation improved functional outcomes in rat stroke models [228]. Bone formation was 
552 regulation of osteogenic markers, accelerated cell differentiation, and improved calcium deposition

553 and matrix mineralization [229]. The delivery of $200 \mu \mathrm{A}$ of direct current for 4 hours for 21 days

554 increased the calcium deposition by $100 \%$ in human adipose-derived mesenchymal stem cells

555 cultured on PPy-PCL substrates [230]. Similarly, marrow stromal cells and MC3T3-E1 pre-osteoblast

556 cells displayed significantly increased mineralisation when stimulated on self-doped sulfonated

557 polyaniline (SPAN)-based electrodes [231].

$558 \quad 4.2$ The piezoelectric mechanism in tissue regeneration

559 As previously stated, ES therapy has been well established as an important cue for enhancing the

560 process of wound healing in different tissues $[232,233]$ by governing cellular behaviour and tissue

561 response. Piezoelectric materials in the form of scaffolds and NPs (Figure 11) have been used to

562 administer this cue efficiently to cells with great therapeutic potential in treating cancer, bone injures

563 and neural disorders $[37,40,234-239]$.

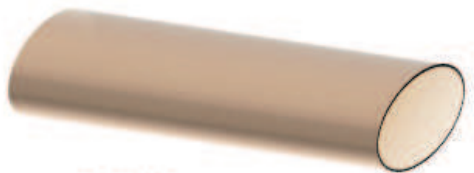

Tubular structure

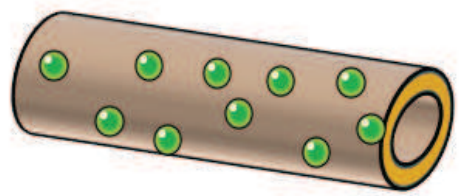

Hollow conduit with NPs/drugs

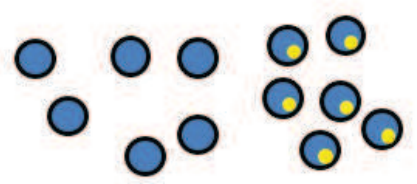

Nanoparticles with/without drug/bioactive agent loading

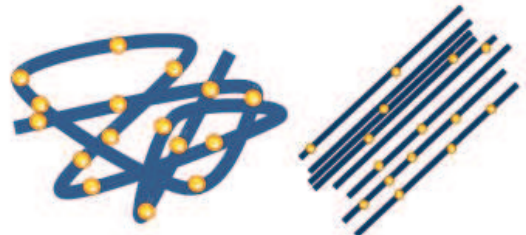

Random/align fibres with NPs/drugs

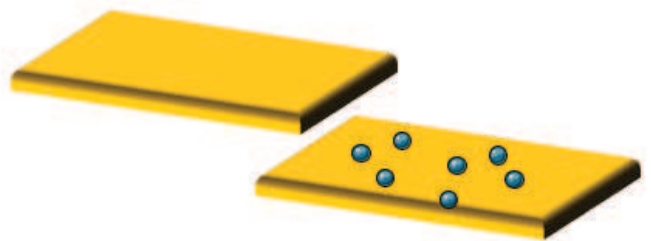

Membrane films with/without NPs/drugs

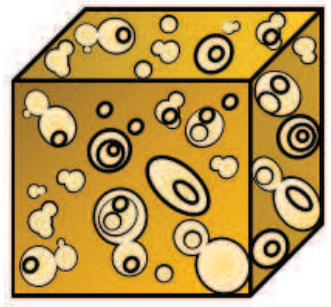

Porous scaffold 
566 Piezoelectric polymers as nerve guidance channels were reported by Aebischer $e t$ al. in the late $20^{\text {th }}$ 567 century [240-242]. Compelling in vivo results obtained by use of PVDF and its copolymers in these 568 studies affirmed the role of electrical charges in the process of nerve repair. However, research in the 569 following years was more focussed on deciphering the mechanisms through which electrical 570 stimulation influences nerve cell behaviour [243,244]. The field has gathered growing interest of the scientific community in the last few years. To this regard, BN, ZO and BT piezoelectric nanomaterials that have been fabricated in various forms including: nanotubes, nanowires and nanospheres, 573 providing greater surface area to volume ratio for better cell-material interactions [245,246]. BNNTs 574 and BTNPs have shown promising results for wireless neuronal stimulation. For instance, Ciofani et 575 al. used BNNTs and BTNPs in two different studies using different neuronal like cell lines [237,247]. 576 The piezoelectric nanomaterials stimulated by ultrasound generated potentials in the range of 0.07 to $5770.19 \mathrm{mV}$ [247] that contributed to greater neurite sprouts by a 30 -fold increase compared to the 578 controls after treatment [237]. Other than piezoelectric nanoparticle systems, scaffolds based on 579 piezoelectric materials have been explored for nerve regeneration [238,247-252]. In a series of studies 580 by Lee et al., electrospun piezoelectric membranes of PVDF-TrFE were fabricated and different cell 581 lines were tested for neuroregenration capability $[250,253,254]$. The effect of fibre alignment and 582 piezoelectricity on neurite extension of dorsal root ganglion neurons was assessed, and it was reported 583 that cell growth and neurite extension was well-supported by annealed and aligned fibres that also 584 exhibited the greatest piezoelectric effect [250]. These results were confirmed by another study which reported that PVDF electrospun scaffolds with controlled alignment and physical properties were best suited for survival and differentiation of monkey neural stem cells [252]. Both in vivo and in vitro results obtained were supportive of the use of piezoelectric conduits for repairing nerve injuries $588[250,253,254]$. Unlike these studies in which the initiation of the piezoelectric mechanism of the 589 scaffold relies on the cellular interactions and natural animal movements, several studies have 590 reported on externally simulating the effect using ultrasound or vibrating waves $[248,249,255]$. 
Piezoelectric electrospun PVDF and BTNPs nanocomposite membranes with and without external

mechanical stimulation have also been studied in recent years for nerve tissue engineering applications $[251,256]$.

Similar studies conducted by Ciofani et al. with BNNTs and BTNPs enhanced gene expression and cytokine production by stimulating osteoblasts, myoblasts and fibroblasts in comparison to controls $[235,236,239,257]$. However, such non-invasive techniques using piezoelectric nanoparticles to deliver the electrical therapy to wounds and injuries is relatively new and requires extensive research before clinical applications are approved [238].

Piezoelectric scaffolds have been used as wound patches for dermal injuries to electrically stimulate the injury site ensuring enhanced recovery through improved cellular response. The presence of piezo receptors on cells and their role in controlling cell behaviour to enhance wound healing corroborates the use of piezoelectrics to stimulate cell response [258,259]. The piezo receptors on cells are activated when cells undergo mechanical deformation in response to an injury or otherwise, this deformation activates ionic channels consequently leading to generation of electrical signals which assist in intracellular signalling and hold great physiological importance $[258,259]$. A study by Ying et al. focused on exploiting the piezoelectric property of PVDF electrospun scaffolds blended with polyurethane (PU) for treatment of skin wounds [260]. These were deformed in a controlled manner, and enhanced migration (to the scratched area of scaffolds in a wound healing assay) and adhesion of fibroblasts were observed when compared to non-deformed samples [260]. A more recent study published in 2017 by Bhang et al. reported ZO based piezoelectric dermal patches [261]. The study included in vitro and in vivo results supporting the promotion of wound healing through generation of 612 optimum levels of electric potentials ranging from 300-900 mV. These electric potentials enhanced 613 dermal fibroblast activity and lead to the upregulation of biochemical factors such as CD68 protein 614 and vascular endothelial growth factor contributing towards improved wound healing [261]. Tan et al. 615 observed that potassium sodium niobate $(\mathrm{KNN})$ based piezo ceramics show surface selective 616 antibacterial activity [262]. They observed that reactive oxygen species (ROS) were formed around 31 
617 the piezoelectric ceramic surfaces as a result of microelectrolytic activity. The formation of ROS

618 around the cathode surface was higher and led to significant antibacterial activity, while the ROS

619 levels generated remaining safe for mammalian cells. This study suggests that inherently antibacterial

620 scaffolds can also be manufactured using piezoelectric materials.

621 The most prominent use of piezoelectric materials as scaffolds has been found in the field of bone

622 tissue engineering [36,37]. Use of piezoelectric materials for bone repair application ensures that the

623 electrical stimulation therapy is delivered to the injury area effectively. Piezoelectric materials are

624 capable of restoring the electrical microenvironment around the injury site and can generate electrical

625 signals which can alter cellular behaviour [263,264]. Piezoelectric polymers such as PVDF, PVDF-

626 TrFE, PLLA, PHB alongside piezoelectric ceramics including BT, LN, LNKN, HA have been

627 assessed for their osteogenic capability $[36,37,148]$. In particular, the last two years have seen a rise in

628 the number of publications in this area and the promising results obtained point towards a clinical

629 solution to the problem of orthopaedic regeneration [148,234,264-269].

630 Control over the amount of electrical stimulation delivered by nanoparticles or scaffolds has been

631 established by controlling the uptake of NPs by cells (specific amount of NPs), or a material with

632 optimized piezoelectric characteristics to generate physiological levels of potentials in response to

633 deformation. To mechanically stimulate the piezoelectric materials in vitro and consequently study the

634 effect of piezo characteristics on drug release, different strategies such as deformable cell culture

635 plates or ultrasound should be utilized, while in the case of scaffolds implanted in vivo, the same can

636 achieved through the natural movement of the animal. It must be noted that different stimulation

637 mechanisms such as ultrasound, bending and others are capable of inducing different responses and

638 the choice of methodology should depend on the type of application desired.

\section{$639 \quad 4.3$ Electrets as exogenous stimulators for wound healing}

640 Other than the use of electrets as transdermal delivery of drugs, electrets have been found useful as

641 exogenous electrical stimulators in terms of wound healing in several tissues such as bone and skin 
642 [270]. The first studies on the use of electrets for healing of dermal wounds dates back to the 1990s

643 [152]. In an in vivo study conducted in pigs, it was found that the treatment of skin wounds using

644 PTFE electrets enhanced the growth of epithelial cells and accelerated the process of wound healing

645 [152]. Though the results obtained in this study were compelling, there has not been considerable

646 amount of research for fabricating electret based wound dressings. On the other hand, HA based

647 electrets have gathered significant attention in the past decade, not only for skin but also for bone

648 tissue engineering [270-273]. Nakamura et al. fabricated wound dressings based on silk fibroin and

649 HA electrets and tested their dermal healing capability in vitro and in vivo $[274,275]$. It was observed

650 that cellular migration and angiogenesis was promoted by the presence of charged HA in wound

651 dressings. Chitosan and HA based electret membranes have also been reported for bone healing

652 applications $[272,276]$. While chitosan electrets show stable surface charges $[277,278]$, HA electrets

653 have exhibited accelerated bone bonding rate and osteogenic gene expression in vivo [279-281]. In

654 this regard, Qu et al. showed that heat treated chitosan electrets showed superior charge storage

655 stability, with in vivo studies exhibiting their enhanced osteogenic potential as guided bone

656 regeneration membranes [276]. In a similar study by the same group, the relatively poor mechanical

657 properties of chitosan was enhanced with negatively charged HA into a composite electret membrane

658 [272]. Their results showed that electret composite membranes based on chitosan and HA could

659 promote osteoblast proliferation and differentiation in vitro, with potential clinical applications as a

660 new strategy for such electret based scaffolds. The nerve healing potential of electrically charged

661 electrets have also been reported on poled PVDF [241,282], PTFE [283] and PLGA [284] polymers in

662 the form of film conduit scaffolds, suggesting the potential of electret guides prepared by electrical

663 poling for peripheral nerve regeneration.

$664 \quad$ 4.4 Photovoltaic mediated tissue response

665 Strategies are emerging for the use of photovoltaic-based materials as carriers of electrical stimuli for

666 tissue regeneration. For instance, in 2015 Lorach et al. demonstrated that subretinal array implants

667 with $70 \mu \mathrm{m}$-wide photovoltaic pixels were able to provide highly localized stimulation to retinal 33 
neurons in rats, and that the electrical receptive fields recorded were similar in size to the natural visual receptive ones [285]. This opens up the possibility to using photovoltaic arrays as functional restoration wireless devices that can safely elicit and modulate cellular responses, not only on the retina [286-288] but on other tissues as well [289]. A similar strategy can be envisioned to facilitate wound healing rates $[290,291]$, which may serve as a promising modality for controlling and treating various skin diseases and disorders. To this regard, the usefulness of delivering specific electrical signals for enhanced wound healing is demonstrated by its ability to induce re-epithelization of skin wounds by enhancing angiogenesis, blocking edema formation or promoting migration and proliferation of various skin cells (i.e. fibroblasts, keratinocytes and epithelial cells) [189-191]. Photovoltaic based materials such as poly(3-hexylthiophene)-phenyl-C61-butyric acid methyl ester (P3HT-PCBM) have also been proposed as optical modulators of cellular activity based on their photothermal effect upon light stimulation [292]. Light absorption generates different photo-excited states in the material that release thermal energy into the living cells of the environment, and such photoexcitation could be useful into developing new platforms for cell control by light to promote wound healing [293-295]. To this regard, electrospun photovoltaic based P3HT/PCL fibres were shown to significantly increased proliferation, extracellular matrix secretion and favour cell morphology of fibroblasts into the characteristic spindle shape upon light stimulation in vitro using white light-emitting diodes within the range of visible light (390-750 nm) [296].

\section{Future perspectives on the use of electroactive biomaterials in drug delivery and tissue regeneration}

Future CP-based drug delivery systems will see the use of biodegradable variants of CPs $[125,126]$ that degrade at the end of their useful lifetime and clear from the patient's body without the need for removal surgery. Such polymers have already been developed by combining polypyrrole-thiophene (PPy-PTh) [297] or quaterthiophene [298] with degradable ester linkages. New CP materials will be created to become more resilient to the structural damage and conductivity loss caused by repeated redox switching. A good example of one such promising material is poly(3,4-alkylenedioxypyrrole) 
694 (PXDOP) [299]. Novel approaches based on the co-delivery of multiple medicinal compounds,

695 injectable CP microcapsules, or micro- and nano-porous structures are currently of great interest and

696 will see wider application $[14,300,301]$. Also of great interest are CP based drug delivery systems that

697 are self-regulating, i.e. release drug compounds in response to changes in mechanical, biological

698 chemical and/or electrical conditions in their vicinity, without the need for an external power source,

699 and will likely be developed in the future [14,67].

700 The area of piezoelectric polymers and ceramics for tissue engineering applications has been

701 researched extensively in the last decade [37], and they have shown great potential for use in the field

702 of controlled therapeutics. The capabilities of these materials for delivery of electric cues and essential

703 drugs to the damaged wound have been studied independently. However, the correlation between the

704 two processes and the mechanism through which the release of drugs can be affected due to the

705 piezoelectric characteristics (varying surface charge and potential of the material) remains to be

706 explored. While significant progress has been made towards improving wound healing, the current

707 research in the area is focused on the use of synthetic polymers or ceramics, and there is recent

708 interest in developing piezoelectric hydrogels and controlled (bio)degradable piezoelectrics [302-

709 304]. There is a need for developing strategies for loading piezoelectric materials with different

710 hydrophobic and hydrophilic drugs and studying their release kinetics in vitro and in vivo. The

711 challenge is to fabricate a smart bio-active scaffold with combined capability. A drug-loaded

712 piezoelectric scaffold with tuneable release of drug or composites based on piezomaterials might be

713 utilized for this purpose. Emerging strategies are focused on developing bioreactors to mimic in vivo

714 conditions and explore the mechanical stimulation of the material to provide suitable electric cues and

715 drug profile release before these therapies can be translated from the bench to the market. A new

716 generation of bioreactors is needed to achieve a deep knowledge of the transduction effects of these

717 materials on specific cells. Indeed, piezoelectric characteristics of different biological systems and

718 biomaterials have been studied using piezoresponse force microscopy (PFM) [305,306], a technique

719 to study the material characteristics at the nanoscale and obtain a better understanding of the 
mechanisms by which the physiological processes are affected [307]. Nevertheless, as discussed in

721 this review, piezoelectric materials have independently been used for delivery of drugs or electrical

722 stimulation of cells and tissues, and amalgamating these two approaches is promising.

723 There is limited literature on the use of electrets for dermal, bone and neural healing applications, and

724 considerable amount of research is still required to confirm their usage for TDD or wound dressings.

725 Though these materials have been found useful for TDD, there has been little mention of how the

726 release behaviour of specific drugs can be controlled. Some electrets also possess piezo properties

727 [308], however, their combined role on release behaviour of drugs is still to be explored. Combining their capability for TDD and altering cellular behaviour is a promising area of research. Electrets also

729 present unique capability of being used for fabrication of smart electronic skins [309], and while the

730 typical format is in the form of films, there is significant research scope for developing novel electret

731 hydrogel dressings. However, the ability to permanently store charges on these other formats might

732 pose challenging.

733 PV-based devices present significant challenge in preparing assemblies of particles that result in 734 continuous but separate conduction paths for electrons and holes [310], and further formulation 735 optimization is required to improve efficiency of light entrapment in these devices. For instance, 736 surface plasmon resonance, metal-particle scattering and surface structuring techniques have been 737 studied as new alternatives to enhance light trapping in PV devices [311-313]. On the other hand, 738 most PV systems to date come in the format of films [54], which is useful for wound dressings. PV 739 systems in the form of gels and hydrogels have been developed as well [314]. However, these systems 740 should also be developed towards other formats such as porous sponges, fibres, rods or spherical 741 structures $[50,315]$ for the purpose of facilitating drug delivery at the wound site. To this regard, 742 Labastide et al. have envisioned organizing n-type and p-type moieties into separate spherical 743 nanoparticles and arranging them into stable superlattices whose structure is defined by the 744 nanoparticle radii [310]. Further research on PV-based MOFs should be carried out; existing systems 
745 have proven poor performances and their capability as photovoltaic based delivery carriers for wound

746 healing has not been tested yet. Extensive research towards attaching and releasing drugs or other

747 therapeutics from PV cells in the most efficient way is needed both in vitro and in vivo clinical

748 applications before this technology can be translated from the bench to the market. Another issue to

749 bear in mind is degradability and cytotoxicity of the existing PV materials. In this sense, surface

750 modification is a factor to take into account for enhanced delivery efficiency, and pharmacokinetics of

751 the therapeutic loaded PV based device is an important step that demands full investigation to

752 estimate their actual performance. Although important improvements need to be taken care of before

753 clinical applications are a reality, there might be a bright future in their application as delivery

754 systems for wound treatment.

\section{6. Conclusions}

756 Controlled delivery of drugs and electrical stimulation are promising approaches for enhanced wound

757 healing of damaged tissues, which are well demonstrated by conductive polymers, electrets,

758 piezoelectric and photovoltaic based materials. The capability of conductive polymers and

759 piezoelectrics as multi-tasking scaffolds is well supported by the encouraging results presented, while

760 electrets and photovoltaics are still new to the field of research. Electroactive biomaterials have been

761 found useful for treating injuries to tissues such as skin, bone and nerve. However, clinical translation

762 for wound healing is achievable after thorough attempts are made to overcome the limitations

763 presented by individual systems. There is a need to amalgamate different electroactive systems, such

764 as piezoelectrics and CPs to eliminate the need of an external stimulation device to attain desired

765 outcomes.

766 The field of electroactive biomaterials for release of therapeutic agents is growing. There are

767 challenges and limitations in the translation of these new therapeutic approaches that remain to be

768 answered, such as safety, cost, and efficacy of treatment and degradability of the material. It is safe to

769 predict that as our understanding of electroactive materials improves along with technological 
770 advancements in scaffold fabrication, therapeutic encapsulation and drug release, the near future will

771 see electroactive based techniques become a standard practice for wound regeneration.

\section{Competing interests}

773 The authors declare no potential conflicts of interests with respect to the research, authorship and/or

774 publication of this article.

\section{Funding sources and acknowledgments}

776 BT is grateful to the Commonwealth Scholarship Commission (UK) for PhD funding; AM

777 acknowledges the EPSRC DTP and The University of Manchester for PhD funding (EP/N509565/1, 778 studentship 1786315); RB acknowledges the EPSRC for fellowship support (EP/P016898/1). The

779 views contained within are those of the authors and do not represent the views of funding 780 organizations. 


\section{References}

[1] B. Behm, P. Babilas, M. Landthaler, S. Schreml, Cytokines, chemokines and growth factors in wound healing, J. Eur. Acad. Dermatol. Venereol. JEADV. 26 (2012) 812-820. doi:10.1111/j.1468-3083.2011.04415.x.

[2] H. Brem, M. Tomic-Canic, Cellular and molecular basis of wound healing in diabetes, J. Clin. Invest. 117 (2007) 1219-1222. doi:10.1172/JCI32169.

[3] B. Reid, M. Zhao, The electrical response to injury: molecular mechanisms and wound healing, Adv. Wound Care. 3 (2014) 184-201. doi:10.1089/wound.2013.0442.

[4] G. Thakral, J. LaFontaine, B. Najafi, T.K. Talal, P. Kim, L.A. Lavery, Electrical stimulation to accelerate wound healing, Diabet. Foot Ankle. 4 (2013). doi:10.3402/dfa.v4i0.22081.

[5] R.R. Isseroff, S.E. Dahle, Electrical stimulation therapy and wound healing: Where are we now?, Adv. Wound Care. 1 (2012) 238-243. doi:10.1089/wound.2011.0351.

[6] L.C. Kloth, Electrical stimulation technologies for wound healing, Adv. Wound Care. 3 (2014) 81-90. doi:10.1089/wound.2013.0459.

[7] J.S. Boateng, K.H. Matthews, H.N.E. Stevens, G.M. Eccleston, Wound healing dressings and drug delivery systems: a review, J. Pharm. Sci. 97 (2008) 2892-2923. doi:10.1002/jps.21210.

[8] P. Koria, Delivery of growth factors for tissue regeneration and wound healing, BioDrugs Clin. Immunother. Biopharm. Gene Ther. 26 (2012) 163-175. doi:10.2165/11631850-00000000000000 .

[9] R. Balint, N.J. Cassidy, S.H. Cartmell, Conductive polymers: Towards a smart biomaterial for tissue engineering, Acta Biomater. 10 (2014) 2341-2353. doi:10.1016/j.actbio.2014.02.015.

[10] D.. Ateh, H.. Navsaria, P. Vadgama, Polypyrrole-based conducting polymers and interactions with biological tissues, J. R. Soc. Interface. 3 (2006) 741-752. doi:10.1098/rsif.2006.0141.

[11] D. Svirskis, J. Travas-Sejdic, A. Rodgers, S. Garg, Electrochemically controlled drug delivery based on intrinsically conducting polymers, J. Control. Release Off. J. Control. Release Soc. 146 (2010) 6-15. doi:10.1016/j.jconrel.2010.03.023.

[12] B. Guo, L. Glavas, A.-C. Albertsson, Biodegradable and electrically conducting polymers for biomedical applications, Prog. Polym. Sci. $38 \quad$ (2013) 1263-1286. doi:10.1016/j.progpolymsci.2013.06.003.

[13] L. Ghasemi-Mobarakeh, M.P. Prabhakaran, M. Morshed, M.H. Nasr-Esfahani, H. Baharvand, S. Kiani, S.S. Al-Deyab, S. Ramakrishna, Application of conductive polymers, scaffolds and electrical stimulation for nerve tissue engineering, J. Tissue Eng. Regen. Med. 5 (2011) e1735. doi:10.1002/term.383.

[14] R. Ravichandran, S. Sundarrajan, J.R. Venugopal, S. Mukherjee, S. Ramakrishna, Applications of conducting polymers and their issues in biomedical engineering, J. R. Soc. Interface. 7 Suppl 5 (2010) S559-579. doi:10.1098/rsif.2010.0120.focus.

[15] X. Liu, K.J. Gilmore, S.E. Moulton, G.G. Wallace, Electrical stimulation promotes nerve cell differentiation on polypyrrole/poly (2-methoxy-5 aniline sulfonic acid) composites, J. Neural Eng. 6 (2009) 065002. doi:10.1088/1741-2560/6/6/065002.

[16] G. Wallace, G. Spinks, Conducting polymers - bridging the bionic interface, Soft Matter. 3 (2007) 665-671. doi:10.1039/B618204F.

[17] J.L. Bredas, G.B. Street, Polarons, bipolarons, and solitons in conducting polymers, Acc. Chem. Res. 18 (1985) 309-315. doi:10.1021/ar00118a005.

[18] B. Lakard, L. Ploux, K. Anselme, F. Lallemand, S. Lakard, M. Nardin, J.Y. Hihn, Effect of ultrasounds on the electrochemical synthesis of polypyrrole, application to the adhesion and growth of biological cells, Bioelectrochemistry. $75 \quad$ (2009) 148-157. doi:10.1016/j.bioelechem.2009.03.010.

[19] J.-W. Lee, F. Serna, J. Nickels, C.E. Schmidt, Carboxylic acid-functionalized conductive polypyrrole as a bioactive platform for cell adhesion, Biomacromolecules. 7 (2006) 16921695. doi:10.1021/bm060220q. 
[20] P.R. Bidez, S. Li, A.G. MacDiarmid, E.C. Venancio, Y. Wei, P.I. Lelkes, Polyaniline, an electroactive polymer, supports adhesion and proliferation of cardiac myoblasts, J. Biomater. Sci. Polym. Ed. 17 (2006) 199-212. doi:10.1163/156856206774879180.

[21] X. Cui, V.A. Lee, Y. Raphael, J.A. Wiler, J.F. Hetke, D.J. Anderson, D.C. Martin, Surface modification of neural recording electrodes with conducting polymer/biomolecule blends, J. Biomed. Mater. Res. 56 (2001) 261-272.

[22] B. Garner, A.J. Hodgson, G.G. Wallace, P.A. Underwood, Human endothelial cell attachment to and growth on polypyrrole-heparin is vitronectin dependent, J. Mater. Sci. Mater. Med. 10 (1999) 19-27.

[23] Z. Zhang, M. Rouabhia, Z. Wang, C. Roberge, G. Shi, P. Roche, J. Li, L.H. Dao, Electrically conductive biodegradable polymer composite for nerve regeneration: electricity-stimulated neurite outgrowth and axon regeneration, Artif. Organs. 31 (2007) 13-22. doi:10.1111/j.15251594.2007.00335.x.

[24] P.M. George, A.W. Lyckman, D.A. LaVan, A. Hegde, Y. Leung, R. Avasare, C. Testa, P.M. Alexander, R. Langer, M. Sur, Fabrication and biocompatibility of polypyrrole implants suitable for neural prosthetics, Biomaterials. 26 (2005) 3511-3519. doi:10.1016/j.biomaterials.2004.09.037.

[25] X. Wang, X. Gu, C. Yuan, S. Chen, P. Zhang, T. Zhang, J. Yao, F. Chen, G. Chen, Evaluation of biocompatibility of polypyrrole in vitro and in vivo, J. Biomed. Mater. Res. A. 68 (2004) 411-422. doi:10.1002/jbm.a.20065.

[26] J.H. Collier, J.P. Camp, T.W. Hudson, C.E. Schmidt, Synthesis and characterization of polypyrrole-hyaluronic acid composite biomaterials for tissue engineering applications, J. Biomed. Mater. Res. 50 (2000) 574-584.

[27] Z. Zhang, R. Roy, F.J. Dugré, D. Tessier, L.H. Dao, In vitro biocompatibility study of electrically conductive polypyrrole-coated polyester fabrics, J. Biomed. Mater. Res. 57 (2001) 63-71.

[28] Z. Wang, C. Roberge, Y. Wan, L.H. Dao, R. Guidoin, Z. Zhang, A biodegradable electrical bioconductor made of polypyrrole nanoparticle/poly(D,L-lactide) composite: A preliminary in vitro biostability study, J. Biomed. Mater. Res. A. 66A (2003) 738-746. doi:10.1002/jbm.a.10037.

[29] D.D. Ateh, P. Vadgama, H.A. Navsaria, Culture of human keratinocytes on polypyrrole-based conducting polymers, Tissue Eng. 12 (2006) 645-655. doi:10.1089/ten.2006.12.645.

[30] H. Castano, E.A. O'Rear, P.S. McFetridge, V.I. Sikavitsas, Polypyrrole thin films formed by admicellar polymerization support the osteogenic differentiation of mesenchymal stem cells, Macromol. Biosci. 4 (2004) 785-794. doi:10.1002/mabi.200300123.

[31] D.-H. Kim, S.M. Richardson-Burns, J.L. Hendricks, C. Sequera, D.C. Martin, Effect of immobilized nerve growth factor on conductive polymers: electrical properties and cellular response, Adv. Funct. Mater. 17 (2007) 79-86. doi:10.1002/adfm.200500594.

[32] M.H. Bolin, K. Svennersten, X. Wang, I.S. Chronakis, A. Richter-Dahlfors, E.W.H. Jager, M. Berggren, Nano-fiber scaffold electrodes based on PEDOT for cell stimulation, Sens. Actuators B Chem. 142 (2009) 451-456. doi:10.1016/j.snb.2009.04.062.

[33] V. Karagkiozaki, P.G. Karagiannidis, M. Gioti, P. Kavatzikidou, D. Georgiou, E. Georgaraki, S. Logothetidis, Bioelectronics meets nanomedicine for cardiovascular implants: PEDOTbased nanocoatings for tissue regeneration, Biochim. Biophys. Acta BBA - Gen. Subj. 1830 (2013) 4294-4304. doi:10.1016/j.bbagen.2012.12.019.

[34] E.A. Tetteh, M.A. Boatemaa, E.O. Martinson, A review of various actuation methods in micropumps for drug delivery appliactions, Proc. 11th Int. Conf. Electron. Comput. Comput. ICECCO 2014. (2014). doi:10.1109/ICECCO.2014.6997540.

[35] K.S. Ramadan, D. Sameoto, S. Evoy, A review of piezoelectric polymers as functional materials for electromechanical transducers, Smart Mater. Struct. 23 (2014) 033001. doi:10.1088/0964-1726/23/3/033001. 
[36] C. Ribeiro, V. Sencadas, D.M. Correia, S. Lanceros-Mendez, Piezoelectric polymers as biomaterials for tissue engineering applications, Colloids Surf B Biointerfaces. 136 (2015) 4655. doi:10.1016/j.colsurfb.2015.08.043.

[37] A.H. Rajabi, M. Jaffe, T.L. Arinzeh, Piezoelectric materials for tissue regeneration: A review, Acta Biomater. 24 (2015) 12-23. doi:10.1016/j.actbio.2015.07.010.

[38] W.S. Jung, M.J. Lee, S.H. Baek, I.K. Jung, S.J. Yoon, C.Y. Kang, Structural approaches for enhancing output power of piezoelectric polyvinylidene fluoride generator, Nano Energy. 22 (2016) 514-523. doi:10.1016/j.nanoen.2016.02.043.

[39] J. Curie, P. Curie, Development by pressure of polar electricity in hemihedral crystals with inclined faces, Bull Soc Min Fr. 3 (1880) 90.

[40] A. Marino, G.G. Genchi, E. Sinibaldi, G. Ciofani, Piezoelectric effects of materials on biointerfaces, ACS Appl. Mater. Interfaces. (2017). doi:10.1021/acsami.7b04323.

[41] K.S. Ramadan, D. Sameoto, S. Evoy, A review of piezoelectric polymers as functional materials for electromechanical transducers, Smart Mater. Struct. 23 (2014) 033001. doi:10.1088/0964-1726/23/3/033001.

[42] G.M. Sessler, Physical principles of electrets, in: G.M. Sessler (Ed.), Electrets, Springer Berlin Heidelberg, Berlin, Heidelberg, 1987: pp. 13-80. doi:10.1007/3540173358_10.

[43] M. Eguchi, XX. On the permanent electret, Philos. Mag. Ser. 6. 49 (1925) 178-192. doi:10.1080/14786442508634594.

[44] P.K.C. Pillai, E.L. Shriver, Electrets and their applications in contamination studies, NASA Tech. Rep. (1975).

[45] V.N. Kestelman, L.S. Pinchuk, V.A. Goldade, Electret effect and electric technologies, in: Electrets Eng. Fundam. Appl., Springer US, Boston, MA, 2000: pp. 1-45. doi:10.1007/978-14615-4455-5_1.

[46] J.J.M. Halls, C.A. Walsh, N.C. Greenham, E.A. Marseglia, R.H. Friend, S.C. Moratti, A.B. Holmes, Efficient photodiodes from interpenetrating polymer networks, Nature. 376 (1995) 498-500. doi:10.1038/376498a0.

[47] F. Priolo, T. Gregorkiewicz, M. Galli, T.F. Krauss, Silicon nanostructures for photonics and photovoltaics, Nat. Nanotechnol. 9 (2014) 19-32. doi:10.1038/nnano.2013.271.

[48] A. Moliton, J.-M. Nunzi, How to model the behaviour of organic photovoltaic cells, Polym. Int. 55 (2006) 583-600. doi:10.1002/pi.2038.

[49] Z. Tang, W. Tress, O. Inganäs, Light trapping in thin film organic solar cells, Mater. Today. 17 (2014) 389-396. doi:10.1016/j.mattod.2014.05.008.

[50] B. Sun, E. Marx, N.C. Greenham, Photovoltaic devices using blends of branched CdSe nanoparticles and conjugated polymers, Nano Lett. 3 (2003) 961-963. doi:10.1021/n10342895.

[51] S. Dayal, N. Kopidakis, D.C. Olson, D.S. Ginley, G. Rumbles, Photovoltaic devices with a low band gap polymer and CdSe nanostructures exceeding 3\% efficiency, Nano Lett. 10 (2010) 239-242. doi:10.1021/n1903406s.

[52] N.C. Greenham, X. Peng, A.P. Alivisatos, Charge separation and transport in conjugatedpolymer/semiconductor-nanocrystal composites studied by photoluminescence quenching and photoconductivity, Phys. Rev. B. 54 (1996) 17628-17637. doi:10.1103/PhysRevB.54.17628.

[53] G. Grancini, M. Biasiucci, R. Mastria, F. Scotognella, F. Tassone, D. Polli, G. Gigli, G. Lanzani, Dynamic microscopy study of ultrafast charge transfer in a hybrid P3HT/hyperbranched CdSe nanoparticle blend for photovoltaics, J. Phys. Chem. Lett. 3 (2012) 517-523. doi:10.1021/jz3000382.

[54] S. Günes, N. Marjanovic, J.M. Nedeljkovic, N.S. Sariciftci, Photovoltaic characterization of hybrid solar cells using surface modified TiO 2 nanoparticles and poly(3-hexyl)thiophene, Nanotechnology. 19 (2008) 424009. doi:10.1088/0957-4484/19/42/424009.

[55] B.R. Saunders, M.L. Turner, Nanoparticle-polymer photovoltaic cells, Adv. Colloid Interface Sci. 138 (2008) 1-23. doi:10.1016/j.cis.2007.09.001.

[56] W.U. Huynh, J.J. Dittmer, A.P. Alivisatos, Hybrid nanorod-polymer solar cells, Science. 295 (2002) 2425-2427. doi:10.1126/science.1069156. 
[57] A. Ghezelbash, B. Koo, B.A. Korgel, Self-Assembled Stripe Patterns of CdS Nanorods, Nano Lett. 6 (2006) 1832-1836. doi:10.1021/n10610351.

[58] D. Ciprari, K. Jacob, R. Tannenbaum, Characterization of Polymer nanocomposite interphase and its impact on mechanical properties, Macromolecules. 39 (2006) 6565-6573. doi:10.1021/ma0602270.

[59] P. Ravirajan, A.M. Peiró, M.K. Nazeeruddin, M. Graetzel, D.D.C. Bradley, J.R. Durrant, J. Nelson, Hybrid polymer/zinc oxide photovoltaic devices with vertically oriented $\mathrm{ZnO}$ nanorods and an amphiphilic molecular interface layer, J. Phys. Chem. B. 110 (2006) 76357639. doi:10.1021/jp0571372.

[60] J. Bouclé, H.J. Snaith, N.C. Greenham, Simple approach to hybrid polymer/porous metal oxide solar cells from solution-processed ZnO nanocrystals, J. Phys. Chem. C. 114 (2010) 36643674. doi:10.1021/jp909376f.

[61] B. Zinger, L.L. Miller, Timed release of chemicals from polypyrrole films, J. Am. Chem. Soc. 106 (1984) 6861-6863. doi:10.1021/ja00334a076.

[62] E. Shamaeli, N. Alizadeh, Kinetic studies of electrochemically controlled release of salicylate from nanostructure conducting molecularly imprinted polymer, Electrochimica Acta. 114 (2013) 409-415. doi:10.1016/j.electacta.2013.10.119.

[63] L. Sui, X.J. Song, J. Ren, W.J. Cai, L.H. Ju, Y. Wang, L.Y. Wang, M. Chen, In vitro and in vivo evaluation of poly(3,4-ethylenedioxythiophene)/poly(styrene sulfonate)/dopamine-coated electrodes for dopamine delivery, J. Biomed. Mater. Res. A. 102 (2014) 1681-1696. doi:10.1002/jbm.a.34837.

[64] M. Hepel, F. Mahdavi, Application of the electrochemical quartz crystal microbalance for electrochemically controlled binding and release of chlorpromazine from conductive polymer matrix, Microchem. J. 56 (1997) 54-64. doi:10.1006/mchj.1996.1436.

[65] K. Krukiewicz, B. Bednarczyk-Cwynar, R. Turczyn, J.K. Zak, EQCM verification of the concept of drug immobilization and release from conducting polymer matrix, Electrochimica Acta. 212 (2016) 694-700. doi:10.1016/j.electacta.2016.07.055.

[66] B.C. Thompson, S.E. Moulton, J. Ding, R. Richardson, A. Cameron, S. O'Leary, G.G. Wallace, G.M. Clark, Optimising the incorporation and release of a neurotrophic factor using conducting polypyrrole, J. Control. Release Off. J. Control. Release Soc. 116 (2006) 285-294. doi:10.1016/j.jconrel.2006.09.004.

[67] D. Uppalapati, B.J. Boyd, S. Garg, J. Travas-Sejdic, D. Svirskis, Conducting polymers with defined micro- or nanostructures for drug delivery, Biomaterials. 111 (2016) 149-162. doi:10.1016/j.biomaterials.2016.09.021.

[68] R. Wadhwa, C.F. Lagenaur, X.T. Cui, Electrochemically controlled release of dexamethasone from conducting polymer polypyrrole coated electrode, J. Controlled Release. 110 (2006) 531541. doi:10.1016/j.jconrel.2005.10.027.

[69] Y. Li, K.G. Neoh, E.T. Kang, Controlled release of heparin from polypyrrole-poly(vinyl alcohol) assembly by electrical stimulation, J. Biomed. Mater. Res. A. 73 (2005) 171-181. doi:10.1002/jbm.a.30286.

[70] L.L. Miller, X.Q. Zhou, Poly(N-methylpyrrolylium) poly(styrenesulfonate) - a conductive, electrically switchable cation exchanger that cathodically binds and anodically releases dopamine, Macromolecules. 20 (1987) 1594-1597. doi:10.1021/ma00173a027.

[71] K. Kontturi, P. Pentti, G. Sundholm, Polypyrrole as a model membrane for drug delivery, J. Electroanal. Chem. 453 (1998) 231-238. doi:10.1016/S0022-0728(98)00246-0.

[72] R.L. Williams, P.J. Doherty, A preliminary assessment of poly(pyrrole) in nerve guide studies, J. Mater. Sci. Mater. Med. 5 (1994) 429-433. doi:10.1007/BF00058978.

[73] Susanne Löffler, Silke Seyock, Rolf Nybom, Gunilla B. Jacobson, Agneta Richter-Dahlfors, Electrochemically triggered release of acetylcholine from scCO2 impregnated conductive polymer films evokes intracellular Ca2+ signaling in neurotypic SH-SY5Y cells, J. Controlled Release. 243 (2016) 283-290. 
[74] K. Krukiewicz, A. Stokfisz, J.K. Zak, Two approaches to the model drug immobilization into conjugated polymer matrix, Mater. Sci. Eng. C. 54 (2015) 176-181. doi:10.1016/j.msec.2015.05.017.

[75] C. Arbizzani, M. Mastragostino, L. Nevi, L. Rambelli, Polypyrrole: A drug-eluting membrane for coronary stents, Electrochimica Acta. 52 (2007) 3274-3279. doi:10.1016/j.electacta.2006.10.003.

[76] G. Bidan, C. Lopez, F. Mendes-Viegas, E. Vieil, A. Gadelle, Incorporation of sulphonated cyclodextrins into polypyrrole: an approach for the electro-controlled delivering of neutral drugs, Biosens. Bioelectron. 10 (1995) 219-229. doi:10.1016/0956-5663(95)96808-C.

[77] D. Ge, X. Tian, R. Qi, S. Huang, J. Mu, S. Hong, S. Ye, X. Zhang, D. Li, W. Shi, A polypyrrole-based microchip for controlled drug release, Electrochimica Acta. 55 (2009) 271275. doi:10.1016/j.electacta.2009.08.049.

[78] J. Ge, E. Neofytou, T.J. Cahill, R.E. Beygui, R.N. Zare, Drug release from electric-fieldresponsive nanoparticles, ACS Nano. 6 (2012) 227-233. doi:10.1021/nn203430m.

[79] B. Massoumi, A. Entezami, Electrochemically controlled binding and release of dexamethasone from conducting polymer bilayer films, J. Bioact. Compat. Polym. 17 (2002) 51-62. doi:10.1177/0883911502017001813.

[80] C. Chen, X. Chen, H. Zhang, Q. Zhang, L. Wang, C. Li, B. Dai, J. Yang, J. Liu, D. Sun, Electrically-responsive core-shell hybrid microfibers for controlled drug release and cell culture, Acta Biomater. 55 (2017) 434-442. doi:10.1016/j.actbio.2017.04.005.

[81] X. Luo, X.T. Cui, Electrochemically controlled release based on nanoporous conducting polymers, Electrochem. Commun. 11 (2009) 402-404. doi:10.1016/j.elecom.2008.11.052.

[82] X. Luo, X.T. Cui, Sponge-like nanostructured conducting polymers for electrically controlled drug release, Electrochem. Commun. 11 (2009) 1956. doi:10.1016/j.elecom.2009.08.027.

[83] N. Alizadeh, E. Shamaeli, Electrochemically controlled release of anticancer drug methotrexate using nanostructured polypyrrole modified with cetylpyridinium: Release kinetics investigation, Electrochimica Acta. $130 \quad$ (2014) 488-496. doi:10.1016/j.electacta.2014.03.055.

[84] S. Carquigny, B. Lakard, S. Lakard, V. Moutarlier, J.-Y. Hihn, L. Viau, Investigation of pharmaceutically active ionic liquids as electrolyte for the electrosynthesis of polypyrrole and active component in controlled drug delivery, Electrochimica Acta. 211 (2016) 950-961. doi:10.1016/j.electacta.2016.06.080.

[85] E. Shamaeli, N. Alizadeh, Functionalized gold nanoparticle-polypyrrole nanobiocomposite with high effective surface area for electrochemical $/ \mathrm{pH}$ dual stimuli-responsive smart release of insulin, Colloids Surf. B Biointerfaces. $126 \quad$ (2015) 502-509. doi:10.1016/j.colsurfb.2015.01.003.

[86] P.M. George, D.A. LaVan, J.A. Burdick, C.-Y. Chen, E. Liang, R. Langer, Electrically controlled drug delivery from biotin-doped conductive polypyrrole, Adv. Mater. 18 (2006) 577-581. doi:10.1002/adma.200501242.

[87] D. Esrafilzadeh, J.M. Razal, S.E. Moulton, E.M. Stewart, G.G. Wallace, Multifunctional conducting fibres with electrically controlled release of ciprofloxacin, J. Controlled Release. 169 (2013) 313-320. doi:10.1016/j.jconrel.2013.01.022.

[88] D. Svirskis, B.E. Wright, J. Travas-Sejdic, A. Rodgers, S. Garg, Development of a controlled release system for risperidone using polypyrrole: mechanistic studies, Electroanalysis. 22 (2010) 439-444. doi:10.1002/elan.200900401.

[89] S. Jiang, Y. Sun, X. Cui, X. Huang, Y. He, S. Ji, W. Shi, D. Ge, Enhanced drug loading capacity of polypyrrole nanowire network for controlled drug release, Synth. Met. 163 (2013) 19-23. doi:10.1016/j.synthmet.2012.12.010.

[90] A. Pourjavadi, M. Doroudian, Synthesis and characterization of semi-conductive nanocomposite based on hydrolyzed collagen and in vitro electrically controlled drug release study, Polymer. 76 (2015) 287-294. doi:10.1016/j.polymer.2015.06.050. 
1036

1037

1038

1039

1040

1041

1042

1043

1044

1045

1046

1047

1048

1049

1050

1051

1052

1053

1054

1055

1056

1057

1058

1059

1060

1061

1062

1063

1064

1065

1066

1067

1068

1069

1070

1071

1072

1073

1074

1075

1076

1077

1078

1079

1080

1081

1082

1083

1084

1085

1086

1087

[91] M. Sharma, G.I.N. Waterhouse, S.W.C. Loader, S. Garg, D. Svirskis, High surface area polypyrrole scaffolds for tunable drug delivery, Int. J. Pharm. 443 (2013) 163-168. doi:10.1016/j.ijpharm.2013.01.006.

[92] E. Shamaeli, N. Alizadeh, Nanostructured biocompatible thermal/electrical stimuli-responsive biopolymer-doped polypyrrole for controlled release of chlorpromazine: kinetics studies, Int. J. Pharm. 472 (2014) 327-338. doi:10.1016/j.ijpharm.2014.06.036.

[93] S.H. Takahashi, L.M. Lira, S.I.C. de Torresi, Zero-order release profiles from a multistimuli responsive electro-conductive hydrogel, J. Biomater. Nanobiotechnology. 03 (2012) 262. doi:10.4236/jbnb.2012.322032.

[94] R. Wang, Y. Peng, M. Zhou, D. Shou, Smart montmorillonite-polypyrrole scaffolds for electro-responsive drug release, Appl. Clay Sci. 134 (2016) 50-54. doi:10.1016/j.clay.2016.05.004.

[95] J.-M. Pernaut, J.R. Reynolds, Use of conducting electroactive polymers for drug delivery and sensing of bioactive molecules. A Redox chemistry approach, J. Phys. Chem. B. 104 (2000) 4080-4090. doi:10.1021/jp994274o.

[96] D.D. Zhou, X.T. Cui, A. Hines, R.J. Greenberg, Conducting polymers in neural stimulation applications, in: D. Zhou, E. Greenbaum (Eds.), Implant. Neural Prostheses 2, Springer New York, 2009: pp. 217-252. doi:10.1007/978-0-387-98120-8_8.

[97] G. NK, Gomez N, Schmidt CE, Conducting engineering, Prog Polym Sci. 32 (2007) 876-921.

[98] C. Boehler, C. Kleber, N. Martini, Y. Xie, I. Dryg, T. Stieglitz, U.G. Hofmann, M. Asplund, Actively controlled release of Dexamethasone from neural microelectrodes in a chronic in vivo study, Biomaterials. 129 (2017) 176-187. doi:10.1016/j.biomaterials.2017.03.019.

[99] R.T. Richardson, B. Thompson, S. Moulton, C. Newbold, M.G. Lum, A. Cameron, G. Wallace, R. Kapsa, G. Clark, S. O’Leary, The effect of polypyrrole with incorporated neurotrophin-3 on the promotion of neurite outgrowth from auditory neurons, Biomaterials. 28 (2007) 513-523. doi:10.1016/j.biomaterials.2006.09.008.

[100] R.T. Richardson, A.K. Wise, B.C. Thompson, B.O. Flynn, P.J. Atkinson, N.J. Fretwell, J.B. Fallon, G.G. Wallace, R.K. Shepherd, G.M. Clark, S.J. O’Leary, Polypyrrole-coated electrodes for the delivery of charge and neurotrophins to cochlear neurons, Biomaterials. 30 (2009) 2614-2624. doi:10.1016/j.biomaterials.2009.01.015.

[101] Darren Svirskis, Jadranka Travas- Sejdic, Anthony Rodgers, Sanjay Garg, Polypyrrole film as a drug delivery system for the controlled release of risperidone, AIP Conf. Proc. 1151 (2009).

[102] D. Svirskis, B.E. Wright, J. Travas-Sejdic, A. Rodgers, S. Garg, Evaluation of physical properties and performance over time of an actuating polypyrrole based drug delivery system, Sens. Actuators B Chem. 151 (2010) 97-102. doi:10.1016/j.snb.2010.09.042.

[103] B.C. Thompson, R.T. Richardson, S.E. Moulton, A.J. Evans, S. O'Leary, G.M. Clark, G.G. Wallace, Conducting polymers, dual neurotrophins and pulsed electrical stimulation--dramatic effects on neurite outgrowth, J. Control. Release Off. J. Control. Release Soc. 141 (2010) 161167. doi:10.1016/j.jconrel.2009.09.016.

[104] K. Krukiewicz, M. Cichy, P. Ruszkowski, R. Turczyn, T. Jarosz, J.K. Zak, M. Lapkowski, B. Bednarczyk-Cwynar, Betulin-loaded PEDOT films for regional chemotherapy, Mater. Sci. Eng. C Mater. Biol. Appl. 73 (2017) 611-615. doi:10.1016/j.msec.2016.12.115.

[105] M.R. Abidian, D.-H. Kim, D.C. Martin, Conducting-polymer nanotubes for controlled drug release, Adv. Mater. 18 (2006) 405-409. doi:10.1002/adma.200501726.

[106] J. Pokki, O. Ergeneman, K. M. Sivaraman, B. Özkale, M. A. Zeeshan, T. Lühmann, B. J. Nelson, S. Pané, Electroplated porous polypyrrole nanostructures patterned by colloidal lithography for drug -delivery applications, Nanoscale. 4 (2012) 3083-3088. doi:10.1039/C2NR30192J.

[107] A. Seyfoddin, A. Chan, W.-T. Chen, I.D. Rupenthal, G.I.N. Waterhouse, D. Svirskis, Electroresponsive macroporous polypyrrole scaffolds for triggered dexamethasone delivery, Eur. J. Pharm. Biopharm. Off. J. Arbeitsgemeinschaft Pharm. Verfahrenstechnik EV. 94 (2015) 419426. doi:10.1016/j.ejpb.2015.06.018. 
1088

1089

1090

1091

1092

1093

1094

1095

1096

1097

1098

1099

1100

1101

1102

1103

1104

1105

1106

1107

1108

1109

1110

1111

1112

1113

1114

1115

1116

1117

1118

1119

1120

1121

1122

1123

1124

1125

1126

1127

1128

1129

1130

1131

1132

1133

1134

1135

1136

1137

1138

1139

[108] B.C. Thompson, J. Chen, S.E. Moulton, G.G. Wallace, Nanostructured aligned CNT platforms enhance the controlled release of a neurotrophic protein from polypyrrole, Nanoscale. 2 (2010) 499-501. doi:10.1039/B9NR00259F.

[109] S. Sirivisoot, R. Pareta, T.J. Webster, Electrically controlled drug release from nanostructured polypyrrole coated on titanium, Nanotechnology. 22 (2011) 085101. doi:10.1088/09574484/22/8/085101.

[110] Y. Xiao, X. Ye, L. He, J. Che, New carbon nanotube-conducting polymer composite electrodes for drug delivery applications, Polym. Int. 61 (2012) 190-196. doi:10.1002/pi.3168.

[111] X. Luo, C. Matranga, S. Tan, N. Alba, X.T. Cui, Carbon nanotube nanoreservior for controlled release of anti-inflammatory dexamethasone, Biomaterials. 32 (2011) 6316-6323. doi:10.1016/j.biomaterials.2011.05.020.

[112] C.L. Weaver, J.M. LaRosa, X. Luo, X.T. Cui, Electrically controlled drug delivery from graphene oxide nanocomposite films, ACS Nano. 8 (2014) 1834-1843. doi:10.1021/nn406223e.

[113] K. Catt, H. Li, V. Hoang, R. Beard, X.T. Cui, Self-powered therapeutic release from conducting polymer/graphene oxide films on magnesium, Nanomedicine Nanotechnol. Biol. Med. 0 (2017). doi:10.1016/j.nano.2017.02.021.

[114] Y. Kong, H. Ge, J. Xiong, S. Zuo, Y. Wei, C. Yao, L. Deng, Palygorskite polypyrrole nanocomposite: A new platform for electrically tunable drug delivery, Appl. Clay Sci. 99 (2014) 119-124. doi:10.1016/j.clay.2014.06.020.

[115] P. Chansai, A. Sirivat, S. Niamlang, D. Chotpattananont, K. Viravaidya-Pasuwat, Controlled transdermal iontophoresis of sulfosalicylic acid from polypyrrole/poly(acrylic acid) hydrogel, Int. J. Pharm. 381 (2009) 25-33. doi:10.1016/j.ijpharm.2009.07.019.

[116] J.A. Chikar, J.L. Hendricks, S.M. Richardson-Burns, Y. Raphael, B.E. Pfingst, D.C. Martin, The use of a dual PEDOT and RGD-functionalized alginate hydrogel coating to provide sustained drug delivery and improved cochlear implant function, Biomaterials. 33 (2012) 1982-1990. doi:10.1016/j.biomaterials.2011.11.052.

[117] V.B. Bueno, S.H. Takahashi, L.H. Catalani, S.I.C. de Torresi, D.F.S. Petri, Biocompatible xanthan/polypyrrole scaffolds for tissue engineering, Mater. Sci. Eng. C Mater. Biol. Appl. 52 (2015) 121-128. doi:10.1016/j.msec.2015.03.023.

[118] D. Ge, X. Ru, S. Hong, S. Jiang, J. Tu, J. Wang, A. Zhang, S. Ji, V. Linkov, B. Ren, W. Shi, Coating metals on cellulose-polypyrrole composites: A new route to self-powered drug delivery system, Electrochem. Commun. $12 \quad$ (2010) 1367-1370. doi:10.1016/j.elecom.2010.07.022.

[119] X. Ru, W. Shi, X. Huang, X. Cui, B. Ren, D. Ge, Synthesis of polypyrrole nanowire network with high adenosine triphosphate release efficiency, Electrochimica Acta. 56 (2011) 98879892. doi:10.1016/j.electacta.2011.08.063.

[120] Y. Cho, R.B. Borgens, Biotin-doped porous polypyrrole films for electrically controlled nanoparticle release, Langmuir ACS J. Surf. Colloids. 27 (2011) 6316-6322. doi:10.1021/la200160q.

[121] H.T. Nguyen, T.H. Tran, R.K. Thapa, C.D. Phung, B.S. Shin, J.-H. Jeong, H.-G. Choi, C.S. Yong, J.O. Kim, Targeted co-delivery of polypyrrole and rapamycin by trastuzumabconjugated liposomes for combined chemo-photothermal therapy, Int. J. Pharm. 527 (2017) 61-71. doi:10.1016/j.ijpharm.2017.05.034.

[122] M.F. Attia, N. Anton, I.U. Khan, C.A. Serra, N. Messaddeq, A. Jakhmola, R. Vecchione, T. Vandamme, One-step synthesis of iron oxide polypyrrole nanoparticles encapsulating ketoprofen as model of hydrophobic drug, Int. J. Pharm. 508 (2016) 61-70. doi:10.1016/j.ijpharm.2016.04.073.

[123] D. Samanta, J.L. Meiser, R.N. Zare, Polypyrrole nanoparticles for tunable, pH-sensitive and sustained drug release, Nanoscale. 7 (2015) 9497-9504. doi:10.1039/c5nr02196k.

[124] G. Jeon, S.Y. Yang, J. Byun, J.K. Kim, Electrically actuatable smart nanoporous membrane for pulsatile drug release, Nano Lett. 11 (2011) 1284-1288. doi:10.1021/nl104329y. 
[125] J.G. Hardy, D.J. Mouser, N. Arroyo-Currás, S. Geissler, J.K. Chow, L. Nguy, J.M. Kim, C.E. Schmidt, Biodegradable electroactive polymers for electrochemically-triggered drug delivery, J. Mater. Chem. B. 2 (2014) 6809-6822. doi:10.1039/C4TB00355A.

[126] J. G. Hardy, M. N. Amend, S. Geissler, V. M. Lynch, C. E. Schmidt, Peptide-directed assembly of functional supramolecular polymers for biomedical applications: electroactive molecular tongue-twisters (oligoalanine-oligoaniline-oligoalanine) for electrochemically enhanced drug delivery, J. Mater. Chem. B. 3 (2015) 5005-5009. doi:10.1039/C5TB00106D.

[127] S. Niamlang, A. Sirivat, Electrically controlled release of salicylic acid from poly(p-phenylene vinylene)/polyacrylamide hydrogels, Int. J. Pharm. 371 (2009) 126-133. doi:10.1016/j.ijpharm.2008.12.032.

[128] G. Liu, C. Shen, Z. Yang, X. Cai, H. Zhang, A disposable piezoelectric micropump with high performance for closed-loop insulin therapy system, Sens. Actuators Phys. 163 (2010) 291296. doi:10.1016/j.sna.2010.06.030.

[129] D.H. Abdelkader, M.A. Osamn, S.A. Elgizawy, A.M. Faheem, P.A. McCarron, The Role of Insulin in Wound Healing Process : Mechanism of Action and Pharmaceutical Applications, J. Anal. Pharm. Res. 2 (2016) 1-6. doi:10.15406/japlr.2016.02.00007.

[130] D. Dumont-Fillon, H. Tahriou, C. Conan, E. Chappel, Insulin micropump with embedded pressure sensors for failure detection and delivery of accurate monitoring, Micromachines. 5 (2014) 1161-1172. doi:10.3390/mi5041161.

[131] M. Hrynyk, R.J. Neufeld, Insulin and wound healing, Burns. 40 (2014) 1433-1446. doi:10.1016/j.burns.2014.03.020.

[132] G. Gainza, S. Villullas, J.L. Pedraz, R.M. Hernandez, M. Igartua, Advances in drug delivery systems (DDSs) to release growth factors for wound healing and skin regeneration, Nanomedicine Nanotechnol. Biol. Med. 11 (2015) 1551-1573. doi:10.1016/j.nano.2015.03.002.

[133] C. Dempsey, I. Lee, K.R. Cowan, J. Suh, Coating barium titanate nanoparticles with polyethylenimine improves cellular uptake and allows for coupled imaging and gene delivery, Colloids Surf. B Biointerfaces. 112 (2013) 108-112. doi:10.1016/j.colsurfb.2013.07.045.

[134] G. Ciofani, S. Danti, D. D\&apos;Alessandro, S. Moscato, M. Petrini, A. Menciassi, Barium titanate nanoparticles: Highly cytocompatible dispersions in glycol-chitosan and doxorubicin complexes for cancer therapy, Nanoscale Res. Lett. 5 (2010) 1093-1101. doi:10.1007/s11671010-9607-0.

[135] J. Niskanen, I. Zhang, Y. Xue, D. Golberg, D. Maysinger, F.M. Winnik, Boron nitride nanotubes as vehicles for intracellular delivery of fluorescent drugs and probes., Nanomed. 11 (2016) 447-463. doi:10.2217/nnm.15.214.

[136] S. Aggarwal, B. Eladi, P. Amitava, Experimental characterization of piezoelectrically actuated micromachined silicon valveless micropump, Microfluid. Nanofluidics. 21 (2017) 1-11. doi:10.1007/s10404-016-1837-8.

[137] A. Nisar, N. Afzulpurkar, B. Mahaisavariya, A. Tuantranont, MEMS-based micropumps in drug delivery and biomedical applications, $130 \quad$ (2008) 917-942. doi:10.1016/j.snb.2007.10.064.

[138] A. Mahnama, A. Nourbakhsh, G. Ghorbaniasl, A survey on the applications of implantable micropump systems in drug delivery., Curr. Drug Deliv. 11 (2014) 123-31.

[139] A. Cobo, R. Sheybani, E. Meng, MEMS: Enabled Drug Delivery Systems, Adv. Healthc. Mater. 4 (2015) 969-982. doi:10.1002/adhm.201400772.

[140] P.B. Eladi, D. Chatterjee, A. DasGupta, Design and Development of a Piezoelectrically Actuated Micropump for Drug Delivery Application, in: K.J. Vinoy, G.K. Ananthasuresh, R. Pratap, S.B. Krupanidhi (Eds.), Micro Smart Devices Syst., Springer India, New Delhi, 2014: pp. 127-141. doi:10.1007/978-81-322-1913-2_8.

[141] J. Ni, F. Huang, B. Wang, Y. Wei, R. Torah, K. Yang, S. Beeby, J. Tudor, A novel fabrication process to realize a valveless micropump on a flexible substrate, (n.d.). doi:10.1088/0964$1726 / 23 / 2 / 025034$. 
[142] S. Yang, X. He, S. Yuan, J. Zhu, Z. Deng, Sensors and Actuators A: Physical A valveless piezoelectric micropump with a Coanda jet element, Sens. Actuators Phys. 230 (2015) 74-82. doi:10.1016/j.sna.2015.04.016.

[143] X.Y. Wang, Y.T. Ma, G.Y. Yan, Z.H. Feng, A compact and high fl ow-rate piezoelectric micropump with a folded vibrator, (n.d.). doi:10.1088/0964-1726/23/11/115005.

[144] K. Junwu, Y. Zhigang, P. Taijiang, C. Guangming, W. Boda, Design and test of a highperformance piezoelectric micropump for drug delivery, 121 (2005) 156-161. doi:10.1016/j.sna.2004.12.002.

[145] P. Cazorla, O. Fuchs, M. Cochet, S. Maubert, G. Le, Y. Fouillet, E. Defay, Sensors and Actuators A : Physical A low voltage silicon micro-pump based on piezoelectric thin films, Sens. Actuators Phys. 250 (2016) 35-39. doi:10.1016/j.sna.2016.09.012.

[146] E. Meng, T. Hoang, Micro- and nano-fabricated implantable drug-delivery systems., Ther. Deliv. 3 (2012) 1457-67. doi:10.4155/tde.12.132.

[147] R. Riahi, A. Tamayol, S. Ali, M. Shaegh, A.M. Ghaemmaghami, M.R. Dokmeci, A. Khademhosseini, Microfluidics for advanced drug delivery systems, Curr. Opin. Chem. Eng. 7 (2015) 101-112. doi:10.1016/j.coche.2014.12.001.

[148] P. Vaněk, Z. Kolská, T. Luxbacher, J.A.L. García, M. Lehocký, M. Vandrovcová, L. Bačáková, J. Petzelt, Electrical activity of ferroelectric biomaterials and its effects on the adhesion, growth and enzymatic activity of human osteoblast-like cells, J. Phys. Appl. Phys. 49 (2016) 175403. doi:10.1088/0022-3727/49/17/175403.

[149] X. Zhang, C. Zhang, Y. Lin, P. Hu, Y. Shen, K. Wang, S. Meng, Y. Chai, X. Dai, X. Liu, Y. Liu, X. Mo, C. Cao, S. Li, X. Deng, L. Chen, Nanocomposite membranes enhance bone regeneration through restoring physiological electric microenvironment, ACS Nano. 10 (2016) 7279-7286. doi:10.1021/acsnano.6b02247.

[150] D. Farmanzadeh, S. Ghazanfary, BNNTs under the influence of external electric field as potential new drug delivery vehicle of Glu, Lys, Gly and ser amino acids: A first-principles study, Appl. Surf. Sci. 320 (2014) 391-399. doi:10.1016/j.apsusc.2014.09.061.

[151] T. He, J. Wang, P. Huang, B. Zeng, H. Li, Q. Cao, S. Zhang, Z. Luo, D.Y.B. Deng, H. Zhang, W. Zhou, Electrospinning polyvinylidene fluoride fibrous membranes containing anti-bacterial drugs used as wound dressing, Colloids Surf. B Biointerfaces. 130 (2015) 278-286. doi:10.1016/j.colsurfb.2015.04.026.

[152] J. Jiang, Z. Wang, L. Ha, M. Zhang, L. Cui, Z. Xia, Study on healing effect of PTFE electrets on pig wound, (1996) 4-8.

[153] J. Jiang, Y.Y. Liang, L.L. Cui, X.M. Hou, Y. Tang, X.T. Ye, Y.J. Yang, M.H. Song, Influence of porous PTFE/LDPE/PP composite electret in skin ultrastructure, J. Phys. Conf. Ser. 142 (2008) 012050. doi:10.1088/1742-6596/142/1/012050.

[154] J. Jiang, Y.Y. Liang, L.L. Cui, X.M. Hou, Y. Tang, X.T. Ye, Y.J. Yang, M.H. Song, Influence of porous PTFE/LDPE/PP composite electret in skin ultrastructure, J. Phys. Conf. Ser. 142 (2008) 012050. doi:10.1088/1742-6596/142/1/012050.

[155] L. Cui, Y. Liang, F. Dong, L. Ma, Y. Tu, H. Liu, J. Jiang, Structure of rat skin after application of electret characterized by DSC, J Phys Conf Ser. 301 (2011). doi:10.1088/17426596/301/1/012027.

[156] J. Jiang, Y. Liang, D. Fajie, M. Lin, L. Hongyue, L. Cui, Studies of penetration of electrostatic field of electret through skin and its stability, Proc. - Int. Symp. Electrets. (2011) 51-52. doi:10.1109/ISE.2011.6084977.

[157] J. Jiang, Y. Liang, D. Fajie, M. Lin, L. Hongyue, L. Cui, Studies of penetration of electrostatic field of electret through skin and its stability, Proc. - Int. Symp. Electrets. (2011) 51-52. doi:10.1109/ISE.2011.6084977.

[158] Y. Tu, X. Wang, Y. Lu, H. Zhang, Y. Yu, Y. Chen, J. Liu, Z. Sun, L. Cui, J. Gao, Y. Zhong, Promotion of the transdermal delivery of protein drugs by N-trimethyl chitosan nanoparticles combined with polypropylene electret, Int. J. Nanomedicine. 11 (2016) 5549-5561. doi:10.2147/IJN.S109552. 
1244

1245

1246

1247

1248

1249

1250

1251

1252

1253

1254

1255

1256

1257

1258

1259

1260

1261

1262

1263

1264

1265

1266

1267

1268

1269

1270

1271

1272

1273

1274

1275

1276

1277

1278

1279

1280

1281

1282

1283

1284

1285

1286

1287

1288

1289

1290

1291

1292

1293

1294

1295

1296

[159] J. Jiang, Y. Liang, F. Dong, H. Liu, Y. Tu, L. Cui, Study of electret effect of rat skin by thermally stimulated discharge analysis, J. Electrost. $70 \quad$ (2012) 258-263. doi:10.1016/j.elstat.2012.03.007.

[160] L. Cui, H. Liu, Enhanced transdermal delivery of cyclosporine A by PP electret and ethyl oleate, 19 (2012) 1191-1194.

[161] L.L. Cui, X.M. Hou, J. Jiang, G.D. Li, Y.Y. Liang, X. Xin, Comparative enhancing effects of electret with chemical enhancers on transdermal delivery of meloxicam in vitro, J. Phys. Conf. Ser. 142 (2008) 012015. doi:10.1088/1742-6596/142/1/012015.

[162] N.S. Narasimha Sathyanarayana Murthy, V.A. Boguda, K. Payasada, Electret enhances transdermal drug permeation., Biol. Pharm. Bull. 31 (2008) 99-102. doi:10.1248/bpb.31.99.

[163] M. Bhuyan, S. Ambure, D. Reyna, J. Rodriguez-Devora, T. Xu, Targeted drug delivery system using photovoltaic devices, Int. J. Drug Deliv. 4 (2013) 398-406.

[164] A. Yildirim, E. Ozgur, M. Bayindir, Impact of mesoporous silica nanoparticle surface functionality on hemolytic activity, thrombogenicity and non-specific protein adsorption, J. Mater. Chem. B. 1 (2013) 1909-1920. doi:10.1039/C3TB20139B.

[165] Q. Cai, W.Y. Zou, Z.S. Luo, Q.X. Wen, W.Q. Pang, F.Z. Cui, Rectifying and photovoltaic effects observed in mesoporous MCM-41 silica film on silicon, Mater. Lett. 58 (2004) 1-4. doi:10.1016/S0167-577X(03)00393-8.

[166] J.V.N. Batchu, A.U. Ebong, Photovoltaic therapy: Conceptual nanoscopic photovoltaic device for transporting chemotherapeutic drugs, in: 2013 High Capacity Opt. Netw. EmergingEnabling Technol., 2013: pp. 72-77. doi:10.1109/HONET.2013.6729760.

[167] S. Chowdhury, F. Yusof, W.W.A.W. Salim, N. Sulaiman, M.O. Faruck, An overview of drug delivery vehicles for cancer treatment: Nanocarriers and nanoparticles including photovoltaic nanoparticles, J. Photochem. Photobiol. B. 164 (2016) 151-159. doi:10.1016/j.jphotobiol.2016.09.013.

[168] H.S. Choi, W. Liu, P. Misra, E. Tanaka, J.P. Zimmer, B.I. Ipe, M.G. Bawendi, J.V. Frangioni, Renal clearance of nanoparticles, Nat. Biotechnol. 25 (2007) 1165-1170. doi:10.1038/nbt1340.

[169] J.S. Souris, C.-H. Lee, S.-H. Cheng, C.-T. Chen, C.-S. Yang, J.A. Ho, C.-Y. Mou, L.-W. Lo, Surface charge-mediated rapid hepatobiliary excretion of mesoporous silica nanoparticles, Biomaterials. 31 (2010) 5564-5574. doi:10.1016/j.biomaterials.2010.03.048.

[170] F. Alexis, E. Pridgen, L.K. Molnar, O.C. Farokhzad, Factors affecting the clearance and biodistribution of polymeric nanoparticles, Mol. Pharm. 5 (2008) 505-515. doi:10.1021/mp800051m.

[171] R.L. Martin, M. Haranczyk, Optimization-based design of metal-organic framework materials, J. Chem. Theory Comput. 9 (2013) 2816-2825. doi:10.1021/ct400255c.

[172] H.-C. Zhou, J.R. Long, O.M. Yaghi, Introduction to metal-organic frameworks, Chem. Rev. 112 (2012) 673-674. doi:10.1021/cr300014x.

[173] P. Horcajada, C. Serre, M. Vallet-Regí, M. Sebban, F. Taulelle, G. Férey, Metal-organic frameworks as efficient materials for drug delivery, Angew. Chem. Int. Ed. 45 (2006) 59745978. doi:10.1002/anie.200601878.

[174] P. Horcajada, C. Serre, G. Maurin, N.A. Ramsahye, F. Balas, M. Vallet-Regí, M. Sebban, F. Taulelle, G. Férey, Flexible porous metal-organic frameworks for a controlled drug delivery, J. Am. Chem. Soc. 130 (2008) 6774-6780. doi:10.1021/ja710973k.

[175] P. Horcajada, T. Chalati, C. Serre, B. Gillet, C. Sebrie, T. Baati, J.F. Eubank, D. Heurtaux, P. Clayette, C. Kreuz, J.-S. Chang, Y.K. Hwang, V. Marsaud, P.-N. Bories, L. Cynober, S. Gil, G. Férey, P. Couvreur, R. Gref, Porous metal-organic-framework nanoscale carriers as a potential platform for drug delivery and imaging, Nat. Mater. 9 (2010) 172-178. doi:10.1038/nmat2608.

[176] C.-Y. Sun, C. Qin, X.-L. Wang, Z.-M. Su, Metal-organic frameworks as potential drug delivery systems, Expert Opin. Drug Deliv. 10 (2013) 89-101. doi:10.1517/17425247.2013.741583.

[177] J. Rocca, D. Liu, W. Lin, Nanoscale metal-organic frameworks for biomedical imaging and drug delivery, Acc. Chem. Res. 44 (2011) 957-968. doi:10.1021/ar200028a. 
[178] B. Xiao, P.S. Wheatley, X. Zhao, A.J. Fletcher, S. Fox, A.G. Rossi, I.L. Megson, S. Bordiga, L. Regli, K.M. Thomas, R.E. Morris, High-capacity hydrogen and nitric oxide adsorption and storage in a metal-organic framework, J. Am. Chem. Soc. 129 (2007) 1203-1209. doi:10.1021/ja066098k.

[179] C. Rigo, L. Ferroni, I. Tocco, M. Roman, I. Munivrana, C. Gardin, W.R.L. Cairns, V. Vindigni, B. Azzena, C. Barbante, B. Zavan, Active silver nanoparticles for wound healing, Int. J. Mol. Sci. 14 (2013) 4817-4840. doi:10.3390/ijms14034817.

[180] A.P. Kornblatt, V.G. Nicoletti, A. Travaglia, The neglected role of copper ions in wound healing, J. Inorg. Biochem. 161 (2016) 1-8. doi:10.1016/j.jinorgbio.2016.02.012.

[181] J. Luo, A.F. Chen, Nitric oxide: a newly discovered function on wound healing, Acta Pharmacol. Sin. 26 (2005) 259-264. doi:10.1111/j.1745-7254.2005.00058.x.

[182] J. Xiao, S. Chen, J. Yi, H.F. Zhang, G.A. Ameer, A cooperative copper metal-organic framework-hydrogel system improves wound healing in diabetes, Adv. Funct. Mater. 27 (2017) n/a-n/a. doi:10.1002/adfm.201604872.

[183] N.J. Hinks, A.C. McKinlay, B. Xiao, P.S. Wheatley, R.E. Morris, Metal organic frameworks as NO delivery materials for biological applications, Microporous Mesoporous Mater. 129 (2010) 330-334. doi:10.1016/j.micromeso.2009.04.031.

[184] P.S. Wheatley, A.C. McKinlay, R.E. Morris, A comparison of zeolites and metal organic frameworks as storage and delivery vehicles for biologically active nitric oxide, Stud. Surf. Sci. Catal. 174 (2008) 441-446. doi:10.1016/S0167-2991(08)80236-4.

[185] C.H. Hendon, D. Tiana, A. Walsh, Conductive metal-organic frameworks and networks: fact or fantasy?, Phys. Chem. Chem. Phys. 14 (2012) 13120-13132. doi:10.1039/C2CP41099K.

[186] D.Y. Lee, C.Y. Shin, S.J. Yoon, H.Y. Lee, W. Lee, N.K. Shrestha, J.K. Lee, S.-H. Han, Enhanced photovoltaic performance of $\mathrm{Cu}$-based metal-organic frameworks sensitized solar cell by addition of carbon nanotubes, Sci. Rep. 4 (2014) srep03930. doi:10.1038/srep03930.

[187] D.Y. Lee, D.V. Shinde, S.J. Yoon, K.N. Cho, W. Lee, N.K. Shrestha, S.-H. Han, Cu-based metal-organic frameworks for photovoltaic application, J. Phys. Chem. C. 118 (2014) 1632816334. doi:10.1021/jp4079663.

[188] R. Kaur, K.-H. Kim, A. K. Paul, A. Deep, Recent advances in the photovoltaic applications of coordination polymers and metal organic frameworks, J. Mater. Chem. A. 4 (2016) 39914002. doi:10.1039/C5TA09668E.

[189] R. Huo, Q. Ma, J.J. Wu, K. Chin-Nuke, Y. Jing, J. Chen, M.E. Miyar, S.C. Davis, J. Li, Noninvasive electromagnetic fields on keratinocyte growth and migration, J. Surg. Res. 162 (2010) 299-307. doi:10.1016/j.jss.2009.02.016.

[190] B. Farboud, R. Nuccitelli, I.R. Schwab, R.R. Isseroff, DC electric fields induce rapid directional migration in cultured human corneal epithelial cells, Exp. Eye Res. 70 (2000) 667673. doi:10.1006/exer.2000.0830.

[191] B. Song, M. Zhao, J. V. Forrester, C.D. McCaig, Electrical cues regulate the orientation and frequency of cell division and the rate of wound healing in vivo, Proc. Natl. Acad. Sci. 99 (2002) 13577-13582. doi:10.1073/pnas.202235299.

[192] P.E. Houghton, K.E. Campbell, C.H. Fraser, C. Harris, D.H. Keast, P.J. Potter, K.C. Hayes, M.G. Woodbury, Electrical stimulation therapy increases rate of healing of pressure ulcers in community-dwelling people with spinal cord injury, Arch. Phys. Med. Rehabil. 91 (2010) 669678. doi:10.1016/j.apmr.2009.12.026.

[193] P. Ferroni, M. Roselli, F. Guadagni, F. Martini, S. Mariotti, E. Marchitelli, C. Cipriani, Biological effects of a software-controlled voltage pulse generator (PhyBack PBK-2C) on the release of vascular endothelial growth factor (VEGF), Vivo Athens Greece. 19 (2005) 949958.

[194] M. Bayat, Z. Asgari-Moghadam, M. Maroufi, F.-S. Rezaie, M. Bayat, M. Rakhshan, Experimental wound healing using microamperage electrical stimulation in rabbits, J. Rehabil. Res. Dev. 43 (2006) 219-226. 
1348

1349

1350

1351

1352

1353

1354

1355

1356

1357

1358

1359

1360

1361

1362

1363

1364

1365

1366

1367

1368

1369

1370

1371

1372

1373

1374

1375

1376

1377

1378

1379

1380

1381

1382

1383

1384

1385

1386

1387

1388

1389

1390

1391

1392

1393

1394

1395

1396

1397

1398

1399

1400

[195] A. Jerčinović, M. Hinsenkamp, B. Scarceriaux, F. Willaert, C. de Graef, M. Heenen, D. Goldshmidt, Effects of direct constant current (DC) on keratinocytes in vitro, Bioelectrochem. Bioenerg. 39 (1996) 209-214. doi:10.1016/0302-4598(95)01900-6.

[196] E. Emmerson, Efficient healing takes some nerve: electrical stimulation enhances innervation in cutaneous human wounds, J. Invest. Dermatol. 137 (2017) 543-545. doi:10.1016/j.jid.2016.10.018.

[197] A. Sebastian, S.W. Volk, P. Halai, J. Colthurst, R. Paus, A. Bayat, Enhanced neurogenic biomarker expression and reinnervation in human acute skin wounds treated by electrical stimulation, J. Invest. Dermatol. 137 (2017) 737-747. doi:10.1016/j.jid.2016.09.038.

[198] C.-S. Huang, Y.-H. Sun, Y.-T. Wang, Y.-H. Pan, S.-F. Wang, Y.-F. Tsai, Asymmetrical responses of skin blood flow in ischemic hindlimbs to electrical stimulation of the unilateral forelimb, Microvasc. Res. 113 (2017) 71-77. doi:10.1016/j.mvr.2017.05.008.

[199] M.T. Ehrensberger, M.E. Tobias, S.R. Nodzo, L.A. Hansen, N.R. Luke-Marshall, R.F. Cole, L.M. Wild, A.A. Campagnari, Cathodic voltage-controlled electrical stimulation of titanium implants as treatment for methicillin-resistant Staphylococcus aureus periprosthetic infections, Biomaterials. 41 (2015) 97-105. doi:10.1016/j.biomaterials.2014.11.013.

[200] M.R. Asadi, G. Torkaman, M. Hedayati, M.R. Mohajeri-Tehrani, M. Ahmadi, R.F. Gohardani, Angiogenic effects of low-intensity cathodal direct current on ischemic diabetic foot ulcers: A randomized controlled trial, Diabetes Res. Clin. Pract. 127 (2017) 147-155. doi:10.1016/j.diabres.2017.03.012.

[201] A.C. Mendonça, C.H. Barbieri, N. Mazzer, Directly applied low intensity direct electric current enhances peripheral nerve regeneration in rats, J. Neurosci. Methods. 129 (2003) 183190.

[202] D. Becker, D.S. Gary, E.S. Rosenzweig, W.M. Grill, J.W. McDonald, Functional electrical stimulation helps replenish progenitor cells in the injured spinal cord of adult rats, Exp. Neurol. 222 (2010) 211-218. doi:10.1016/j.expneurol.2009.12.029.

[203] C.T. Brighton, W. Wang, R. Seldes, G. Zhang, S.R. Pollack, Signal transduction in electrically stimulated bone cells, J. Bone Joint Surg. Am. 83-A (2001) 1514-1523.

[204] I.S. Kim, J.K. Song, Y.M. Song, T.H. Cho, T.H. Lee, S.S. Lim, S.J. Kim, S.J. Hwang, Novel effect of biphasic electric current on in vitro osteogenesis and cytokine production in human mesenchymal stromal cells, Tissue Eng. Part A. 15 (2009) 2411-2422. doi:10.1089/ten.tea.2008.0554.

[205] G. Thamsborg, A. Florescu, P. Oturai, E. Fallentin, K. Tritsaris, S. Dissing, Treatment of knee osteoarthritis with pulsed electromagnetic fields: a randomized, double-blind, placebocontrolled study, Osteoarthritis Cartilage. 13 (2005) 575-581. doi:10.1016/j.joca.2005.02.012.

[206] J.A. Spadaro, R.O. Becker, Function of implanted cathodes in electrode-induced bone growth, Med. Biol. Eng. Comput. 17 (1979) 769-775. doi:10.1007/BF02441560.

[207] J.M. Toth, H.B. Seim, J.D. Schwardt, W.B. Humphrey, J.A. Wallskog, A.S. Turner, Direct current electrical stimulation increases the fusion rate of spinal fusion cages, Spine. 25 (2000) $2580-2587$.

[208] R. Babygirija, M. Sood, P. Kannampalli, J.N. Sengupta, A. Miranda, Percutaneous electrical nerve field stimulation modulates central pain pathways and attenuates post-inflammatory visceral and somatic hyperalgesia in rats, Neuroscience. 356 (2017) 11-21. doi:10.1016/j.neuroscience.2017.05.012.

[209] S.A. Mahure, A.S. Rokito, Y.W. Kwon, Transcutaneous electrical nerve stimulation for postoperative pain relief after arthroscopic rotator cuff repair: a prospective double-blinded randomized trial, J. Shoulder Elbow Surg. 26 (2017) 1508-1513. doi:10.1016/j.jse.2017.05.030.

[210] H. Xu, J.M. Holzwarth, Y. Yan, P. Xu, H. Zheng, Y. Yin, S. Li, P.X. Ma, Conductive PPY/PDLLA conduit for peripheral nerve regeneration, Biomaterials. 35 (2014) 225-235. doi:10.1016/j.biomaterials.2013.10.002.

[211] R. Mondragon-Lozano, C. Ríos, E. Roldan-Valadez, G.J. Cruz, M.G. Olayo, R. Olayo, H. Salgado-Ceballos, J. Morales, M. Mendez-Armenta, L. Alvarez-Mejia, O. Fabela, A. Morales- 
Guadarrama, S. Sánchez-Torres, A. Diaz-Ruiz, Delayed injection of polypyrrole doped with iodine particle suspension after spinal cord injury in rats improves functional recovery and decreased tissue damage evaluated by 3.0 Tesla in vivo magnetic resonance imaging, Spine J. 17 (2017) 562-573. doi:10.1016/j.spinee.2016.02.012.

[212] M. Dodel, N. Hemmati Nejad, S.H. Bahrami, M. Soleimani, L. Mohammadi Amirabad, H. Hanaee-Ahvaz, A. Atashi, Electrical stimulation of somatic human stem cells mediated by composite containing conductive nanofibers for ligament regeneration, Biol. J. Int. Assoc. Biol. Stand. 46 (2017) 99-107. doi:10.1016/j.biologicals.2017.01.007.

[213] A.L.P.S. Bailey, A.M. Pisanelli, K.C. Persaud, Development of conducting polymer sensor arrays for wound monitoring, Sens. Actuators B Chem. 131 (2008) 5-9. doi:10.1016/j.snb.2007.12.035.

[214] B. Bideau, J. Bras, S. Saini, C. Daneault, E. Loranger, Mechanical and antibacterial properties of a nanocellulose-polypyrrole multilayer composite, Mater. Sci. Eng. C Mater. Biol. Appl. 69 (2016) 977-984. doi:10.1016/j.msec.2016.08.005.

[215] N.A. Chowdhury, A.M. Al-Jumaily, Regenerated cellulose/polypyrrole/silver nanoparticles/ionic liquid composite films for potential wound healing applications, Wound Med. 14 (2016) 16-18. doi:10.1016/j.wndm.2016.07.001.

[216] A. Varesano, A. Aluigi, L. Florio, R. Fabris, Multifunctional cotton fabrics, Synth. Met. 159 (2009) 1082-1089. doi:10.1016/j.synthmet.2009.01.036.

[217] R. Kumar, M. Oves, T. Almeelbi, N.H. Al-Makishah, M.A. Barakat, Hybrid chitosan/polyaniline-polypyrrole biomaterial for enhanced adsorption and antimicrobial activity, J. Colloid Interface Sci. 490 (2017) 488-496. doi:10.1016/j.jcis.2016.11.082.

[218] N. Maráková, P. Humpolíček, V. Kašpárková, Z. Capáková, L. Martinková, P. Bober, M. Trchová, J. Stejskal, Antimicrobial activity and cytotoxicity of cotton fabric coated with conducting polymers, polyaniline or polypyrrole, and with deposited silver nanoparticles, Appl. Surf. Sci. 396 (2017) 169-176. doi:10.1016/j.apsusc.2016.11.024.

[219] Y. Wang, M. Rouabhia, Z. Zhang, Pulsed electrical stimulation benefits wound healing by activating skin fibroblasts through the TGF $\beta 1 /$ ERK/NF- $\mathrm{kB}$ axis, Biochim. Biophys. Acta. 1860 (2016) 1551-1559. doi:10.1016/j.bbagen.2016.03.023.

[220] G. Shi, M. Rouabhia, Z. Wang, L.H. Dao, Z. Zhang, A novel electrically conductive and biodegradable composite made of polypyrrole nanoparticles and polylactide, Biomaterials. 25 (2004) 2477-2488.

[221] S.I. Jeong, I.D. Jun, M.J. Choi, Y.C. Nho, Y.M. Lee, H. Shin, Development of electroactive and elastic nanofibers that contain polyaniline and poly(L-lactide-co-epsilon-caprolactone) for the control of cell adhesion, Macromol. Biosci. 8 (2008) 627-637. doi:10.1002/mabi.200800005.

[222] G. Shi, M. Rouabhia, S. Meng, Z. Zhang, Electrical stimulation enhances viability of human cutaneous fibroblasts on conductive biodegradable substrates, J. Biomed. Mater. Res. A. 84 (2008) 1026-1037. doi:10.1002/jbm.a.31337.

[223] G. Shi, Z. Zhang, M. Rouabhia, The regulation of cell functions electrically using biodegradable polypyrrole-polylactide conductors, Biomaterials. 29 (2008) 3792-3798. doi:10.1016/j.biomaterials.2008.06.010.

[224] Y. Li, X. Li, R. Zhao, C. Wang, F. Qiu, B. Sun, H. Ji, J. Qiu, C. Wang, Enhanced adhesion and proliferation of human umbilical vein endothelial cells on conductive PANI-PCL fiber scaffold by electrical stimulation, Mater. Sci. Eng. C. 72 (2017) 106-112. doi:10.1016/j.msec.2016.11.052.

[225] N. Gomez, C.E. Schmidt, Nerve growth factor-immobilized polypyrrole: bioactive electrically conducting polymer for enhanced neurite extension, J. Biomed. Mater. Res. A. 81 (2007) 135149. doi:10.1002/jbm.a.31047.

[226] J.Y. Lee, C.A. Bashur, A.S. Goldstein, C.E. Schmidt, Polypyrrole-coated electrospun PLGA nanofibers for neural tissue applications, Biomaterials. 30 (2009) 4325-4335. doi:10.1016/j.biomaterials.2009.04.042. 
1453

1454

1455

1456

1457

1458

1459

1460

1461

1462

1463

1464

1465

1466

1467

1468

1469

1470

1471

1472

1473

1474

1475

1476

1477

1478

1479

1480

1481

1482

1483

1484

1485

1486

1487

1488

1489

1490

1491

1492

1493

1494

1495

1496

1497

1498

1499

1500

1501

1502

1503

1504

1505

[227] L. Ghasemi-Mobarakeh, M.P. Prabhakaran, M. Morshed, M.H. Nasr-Esfahani, S. Ramakrishna, Electrical stimulation of nerve cells Using conductive nanofibrous scaffolds for nerve tissue engineering, Tissue Eng. Part A. 15 (2009) 3605-3619. doi:10.1089/ten.tea.2008.0689.

[228] P.M. George, T.M. Bliss, T. Hua, A. Lee, B. Oh, A. Levinson, S. Mehta, G. Sun, G.K. Steinberg, Electrical preconditioning of stem cells with a conductive polymer scaffold enhances stroke recovery, Biomaterials. $142 \quad$ (2017) 31-40. doi:10.1016/j.biomaterials.2017.07.020.

[229] W.-W. Hu, Y.-T. Hsu, Y.-C. Cheng, C. Li, R.-C. Ruaan, C.-C. Chien, C.-A. Chung, C.-W. Tsao, Electrical stimulation to promote osteogenesis using conductive polypyrrole films, Mater. Sci. Eng. C Mater. Biol. Appl. 37 (2014) 28-36. doi:10.1016/j.msec.2013.12.019.

[230] J. Zhang, M. Li, E.-T. Kang, K.G. Neoh, Electrical stimulation of adipose-derived mesenchymal stem cells in conductive scaffolds and the roles of voltage-gated ion channels, Acta Biomater. 32 (2016) 46-56. doi:10.1016/j.actbio.2015.12.024.

[231] Y. Min, Y. Liu, Y. Poojari, J.-C. Wu, B.E. Hildreth III, T.J. Rosol, A.J. Epstein, Self-doped polyaniline-based interdigitated electrodes for electrical stimulation of osteoblast cell lines, Synth. Met. 198 (2014) 308-313. doi:10.1016/j.synthmet.2014.10.035.

[232] E. Wang, M. Zhao, Regulation of tissue repair and regeneration by electric fields, Chin. J. Traumatol. Zhonghua Chuang Shang Za Zhi. 13 (2010) 55-61.

[233] M. Zhao, Electrical fields in wound healing-An overriding signal that directs cell migration, Semin. Cell Dev. Biol. 20 (2009) 674-682. doi:10.1016/j.semcdb.2008.12.009.

[234] G.G. Genchi, E. Sinibaldi, L. Ceseracciu, M. Labardi, A. Marino, S. Marras, G. De Simoni, V. Mattoli, G. Ciofani, Ultrasound-activated piezoelectric P(VDF-TrFE)/boron nitride nanotube composite films promote differentiation of human SaOS-2 osteoblast-like cells, Nanomedicine Nanotechnol. Biol. Med. (2017) 1-12. doi:10.1016/j.nano.2017.05.006.

[235] S. Danti, G. Ciofani, S. Moscato, D. D’Alessandro, E. Ciabatti, C. Nesti, R. Brescia, G. Bertoni, A. Pietrabissa, M. Lisanti, M. Petrini, V. Mattoli, S. Berrettini, Boron nitride nanotubes and primary human osteoblasts: in vitro compatibility and biological interactions under low frequency ultrasound stimulation, Nanotechnology. 24 (2013) 465102. doi:10.1088/0957-4484/24/46/465102.

[236] L. Ricotti, T. Fujie, H. Vazão, G. Ciofani, R. Marotta, R. Brescia, C. Filippeschi, I. Corradini, M. Matteoli, V. Mattoli, L. Ferreira, A. Menciassi, Boron nitride nanotube-mediated stimulation of cell co-culture on micro-engineered hydrogels, PLoS ONE. 8 (2013). doi:10.1371/journal.pone.0071707.

[237] G. Ciofani, S. Danti, D. D’Alessandro, L. Ricotti, S. Moscato, G. Bertoni, A. Falqui, S. Berrettini, M. Petrini, V. Mattoli, A. Menciassi, Enhancement of neurite outgrowth in neuronal-like cells following boron nitride nanotube-mediated stimulation, ACS Nano. 4 (2010) 6267-6277. doi:10.1021/nn101985a.

[238] A. Marino, G.G. Genchi, V. Mattoli, G. Ciofani, Piezoelectric nanotransducers: The future of neural stimulation, Nano Today. 14 (2016) 9-12. doi:10.1016/j.nantod.2016.12.005.

[239] L. Ricotti, R.P. Das Neves, G. Ciofani, C. Canale, S. Nitti, V. Mattoli, B. Mazzolai, L. Ferreira, A. Menciassi, Boron nitride nanotube-mediated stimulation modulates F/G-actin ratio and mechanical properties of human dermal fibroblasts, J. Nanoparticle Res. 16 (2014). doi:10.1007/s11051-014-2247-z.

[240] E.G. Fine, R.F. Valentini, R. Bellamkonda, P. Aebischer, Improved nerve regeneration through piezoelectric vinylidenefluoride-trifluoroethylene copolymer guidance channels, Biomaterials. 12 (1991) 775-780. doi:10.1016/0142-9612(91)90029-A.

[241] P. Aebischer, R.F. Valentini, P. Dario, C. Domenici, V. Guénard, S.R. Winn, P.M. Galletti, Piezoelectric nerve guidance channels enhance peripheral nerve regeneration., ASAIO Trans. 33 (1987) 456-8.

[242] P. Aebischer, R.F. Valentini, P. Dario, C. Domenici, P.M. Galletti, Piezoelectric guidance channels enhance regeneration in the mouse sciatic nerve after axotomy, Brain Res. 436 (1987) 165-168. doi:10.1016/0006-8993(87)91570-8. 
1506

1507

1508

1509

1510

1511

1512

1513

1514

1515

1516

1517

1518

1519

1520

1521

1522

1523

1524

1525

1526

1527

1528

1529

1530

1531

1532

1533

1534

1535

1536

1537

1538

1539

1540

1541

1542

1543

1544

1545

1546

1547

1548

1549

1550

1551

1552

1553

1554

1555

1556

1557

[243] T. Gordon, O.A.R. Sulaiman, A. Ladak, Chapter 24 Electrical Stimulation for Improving Nerve Regeneration: Where do we Stand?, 1st ed., Elsevier Inc., 2009. doi:10.1016/S00747742(09)87024-4.

[244] M.P. Willand, M.-A. Nguyen, G.H. Borschel, T. Gordon, Electrical Stimulation to Promote Peripheral Nerve Regeneration., Neurorehabil. Neural Repair. (2015) $1545968315604399-$. doi:10.1177/1545968315604399.

[245] L. Vannozzi, C. Filippeschi, S. Sartini, V. Piazza, P. Pingue, C. La Motta, A. Menciassi, Nanostructured ultra-thin patches for ultrasound- modulated delivery of anti-restenotic drug, (2016) 69-92.

[246] G. Ciofani, A. Menciassi, eds., Piezoelectric Nanomaterials for Biomedical Applications, Springer Berlin Heidelberg, Berlin, Heidelberg, 2012. doi:10.1007/978-3-642-28044-3.

[247] A. Marino, S. Arai, Y. Hou, E. Sinibaldi, M. Pellegrino, Y. Chang, B. Mazzolai, V. Mattoli, M. Suzuki, G. Ciofani, Piezoelectric Nanoparticle-Assisted Wireless Neuronal Stimulation, ACS Nano. 9 (2015) 7678-7689. doi:10.1021/acsnano.5b03162.

[248] N. Royo-Gascon, M. Wininger, J.I. Scheinbeim, B.L. Firestein, W. Craelius, Piezoelectric substrates promote neurite growth in rat spinal cord neurons, Ann. Biomed. Eng. 41 (2013) 112-122. doi:10.1007/s10439-012-0628-y.

[249] M. Hoop, X.-Z. Chen, A. Ferrari, F. Mushtaq, G. Ghazaryan, T. Tervoort, D. Poulikakos, B. Nelson, S. Pan?, Ultrasound-mediated piezoelectric differentiation of neuron-like PC12 cells on PVDF membranes, Sci. Rep. 7 (2017) 4028. doi:10.1038/s41598-017-03992-3.

[250] Y.S. Lee, G. Collins, T. Livingston Arinzeh, Neurite extension of primary neurons on electrospun piezoelectric scaffolds, Acta Biomater. 7 (2011) 3877-3886. doi:10.1016/j.actbio.2011.07.013.

[251] C. Mota, M. Labardi, L. Trombi, L. Astolfi, M. D’Acunto, D. Puppi, G. Gallone, F. Chiellini, S. Berrettini, L. Bruschini, S. Danti, Design, fabrication and characterization of composite piezoelectric ultrafine fibers for cochlear stimulation, Mater. Des. 122 (2017) 206-219. doi:10.1016/j.matdes.2017.03.013.

[252] L.C. Lins, F. Wianny, S. Livi, C. Dehay, J. Duchet-Rumeau, J.F. G??rard, Effect of polyvinylidene fluoride electrospun fiber orientation on neural stem cell differentiation, J. Biomed. Mater. Res. - Part B Appl. Biomater. (2016) 1-18. doi:10.1002/jbm.b.33778.

[253] Y.S. Lee, S. Wu, T.L. Arinzeh, M.B. Bunge, Enhanced noradrenergic axon regeneration into schwann cell-filled PVDF-TrFE conduits after complete spinal cord transection, Biotechnol. Bioeng. 114 (2017) 444-456. doi:10.1002/bit.26088.

[254] Y.-S. Lee, T.L. Arinzeh, The Influence of Piezoelectric Scaffolds on Neural Differentiation of Human Neural Stem/Progenitor Cells, Tissue Eng. Part A. 18 (2012) 2063-2072. doi:10.1089/ten.TEA.2011.0540.

[255] G.G. Genchi, L. Ceseracciu, A. Marino, M. Labardi, S. Marras, F. Pignatelli, L. Bruschini, V. Mattoli, G. Ciofani, P(VDF-TrFE)/BaTiO3 Nanoparticle Composite Films Mediate Piezoelectric Stimulation and Promote Differentiation of SH-SY5Y Neuroblastoma Cells, Adv. Healthc. Mater. 5 (2016) 1808-1820. doi:10.1002/adhm.201600245.

[256] A.S. Motamedi, H. Mirzadeh, F. Hajiesmaeilbaigi, S. Bagheri-Khoulenjani, M.A. Shokrgozar, Piezoelectric electrospun nanocomposite comprising $\mathrm{Au}$ NPs/PVDF for nerve tissue engineering, J. Biomed. Mater. Res. - Part A. (2017) 1984-1993. doi:10.1002/jbm.a.36050.

[257] S. Danti, G. Ciofani, G. Pertici, S. Moscato, D. D’Alessandro, E. Ciabatti, F. Chiellini, M. D'Acunto, V. Mattoli, S. Berrettini, Boron nitride nanotube-functionalised myoblast/microfibre constructs: a nanotech-assisted tissue-engineered platform for muscle stimulation, J. Tissue Eng. Regen. Med. 9 (2015) 847-851. doi:10.1002/term.1878.

[258] B.M. Gaub, D.J. M??ller, Mechanical Stimulation of Piezo1 Receptors Depends on Extracellular Matrix Proteins and Directionality of Force, Nano Lett. 17 (2017) 2064-2072. doi:10.1021/acs.nanolett.7b00177.

[259] E. Piddini, Epithelial Homeostasis: A Piezo of the Puzzle, Curr. Biol. 27 (2017) R232-R234. doi:10.1016/j.cub.2017.02.002. 
1558

1559

1560

1561

1562

1563

1564

1565

1566

1567

1568

1569

1570

1571

1572

1573

1574

1575

1576

1577

1578

1579

1580

1581

1582

1583

1584

1585

1586

1587

1588

1589

1590

1591

1592

1593

1594

1595

1596

1597

1598

1599

1600

1601

1602

1603

1604

1605

1606

1607

1608

1609

[260] H.F. Guo, Z.S. Li, S.W. Dong, W.J. Chen, L. Deng, Y.F. Wang, D.J. Ying, Piezoelectric PU/PVDF electrospun scaffolds for wound healing applications, Colloids Surf. B Biointerfaces. 96 (2012) 29-36. doi:10.1016/j.colsurfb.2012.03.014.

[261] S.H. Bhang, W.S. Jang, J. Han, J.K. Yoon, W.G. La, E. Lee, Y.S. Kim, J.Y. Shin, T.J. Lee, H.K. Baik, B.S. Kim, Zinc Oxide Nanorod-Based Piezoelectric Dermal Patch for Wound Healing, Adv. Funct. Mater. 27 (2017). doi:10.1002/adfm.201603497.

[262] G. Tan, S. Wang, Y. Zhu, L. Zhou, P. Yu, X. Wang, T. He, J. Chen, C. Mao, C. Ning, L. Industry, S. Life, U. States, Surface-Selective Preferential Production of Reactive Oxygen Species on Piezoelectric Ceramics for Bacterial Killing., 8 (2016) 24306-24309. doi:10.1021/acsami.6b07440.

[263] R. Balint, N.J. Cassidy, S.H. Cartmell, Electrical Stimulation: A Novel Tool for Tissue Engineering, Tissue Eng. Part B-Rev. 19 (2013) 48-57. doi:10.1089/ten.TEB.2012.0183.

[264] X. Zhang, C. Zhang, Y. Lin, P. Hu, Y. Shen, K. Wang, S. Meng, Y. Chai, X. Dai, X. Liu, Y. Liu, X. Mo, C. Cao, S. Li, X. Deng, L. Chen, Nanocomposite membranes enhance bone regeneration through restoring physiological electric microenvironment, ACS Nano. 10 (2016) 7279-7286. doi:10.1021/acsnano.6b02247.

[265] H. Shokrollahi, F. Salimi, A. Doostmohammadi, The fabrication and characterization of barium titanate/akermanite nano-bio-ceramic with a suitable piezoelectric coefficient for bone defect recovery, J. Mech. Behav. Biomed. Mater. 74 (2017) 365-370. doi:10.1016/j.jmbbm.2017.06.024.

[266] T.G.M. Bonadio, V.F. Freitas, T.T. Tominaga, R.Y. Miyahara, J.M. Rosso, L.F. Cótica, M.L. Baesso, W.R. Weinand, I.A. Santos, R. Guo, A.S. Bhalla, Polyvinylidene fluoride/hydroxyapatite/ $\beta$-tricalcium phosphate multifunctional biocomposite: Potentialities for bone tissue engineering, Curr. Appl. Phys. 17 (2017) 767-773. doi:10.1016/j.cap.2017.02.022.

[267] C. Ribeiro, D.M. Correia, I. Rodrigues, L. Guardão, S. Guimarães, R. Soares, S. LancerosMéndez, In-vivo demonstration of the suitability of piezoelectric stimuli for bone reparation, Mater. Lett. (2017). doi:10.1016/j.matlet.2017.07.099.

[268] W. Chen, Z. Yu, J. Pang, P. Yu, G. Tan, C. Ning, Fabrication of biocompatible potassium sodium niobate piezoelectric ceramic as an electroactive implant, Materials. 10 (2017) 18-21. doi:10.3390/ma10040345.

[269] B. Liu, L. Chen, C. Shao, F. Zhang, K. Zhou, J. Cao, D. Zhang, Improved osteoblasts growth on osteomimetic hydroxyapatite/BaTiO3 composites with aligned lamellar porous structure, Mater. Sci. Eng. C. 61 (2016) 8-14. doi:10.1016/j.msec.2015.12.009.

[270] M. Nakamura, A study on tissue regeneration of the functionalized bioceramics, Nippon Seramikkusu Kyokai Gakujutsu RonbunshiJournal Ceram. Soc. Jpn. 122 (2014) 755-761. doi:10.2109/jcersj2.122.755.

[271] F.R. Baxter, C.R. Bowen, I.G. Turner, A.C.E. Dent, Electrically active bioceramics: A review of interfacial responses, Ann. Biomed. Eng. 38 (2010) 2079-2092. doi:10.1007/s10439-0109977-6.

[272] Y. Qu, D. Ao, P. Wang, Y. Wang, X. Kong, Y. Man, Chitosan/nano-hydroxyapatite composite electret membranes enhance cell proliferation and osteoblastic expression in vitro, J. Bioact. Compat. Polym. 29 (2014) 3-14. doi:10.1177/0883911513513094.

[273] M. Nakamura, A. Nagai, T. Hentunen, J. Salonen, Y. Sekijima, T. Okura, K. Hashimoto, Y. Toda, H. Monma, K. Yamashita, Surface electric fields increase osteoblast adhesion through improved wettability on hydroxyapatite electret, ACS Appl. Mater. Interfaces. 1 (2009) 21812189. doi:10.1021/am900341v.

[274] M. Nakamura, T. Soya, R. Hiratai, A. Nagai, K. Hashimoto, I. Morita, K. Yamashita, Endothelial cell migration and morphogenesis on silk fibroin scaffolds containing hydroxyapatite electret, J. Biomed. Mater. Res. - Part A. 100 A (2012) 969-977. doi:10.1002/jbm.a.34046.

[275] R. Okabayashi, M. Nakamura, T. Okabayashi, Y. Tanaka, A. Nagai, K. Yamashita, Efficacy of polarized hydroxyapatite and silk fibroin composite dressing gel on epidermal recovery from 
1622

1623

1624

1625

1626

1627

1628

1629

1630

1631

1632

1633

1634

1635

1636

1637

1638

1639

1640

1641

1642

1643

1644

1645

1646

1647

1648

1649

1650

1651

1652

1653

1654

1655

1656

1657

1658

1659

1660

full-thickness skin wounds, J. Biomed. Mater. Res. - Part B Appl. Biomater. 90 B (2009) 641646. doi:10.1002/jbm.b.31329.

[276] Y. Qu, Y. Wang, X. Kong, J. Li, Y. Zuo, Q. Zou, P. Gong, Y. Man, Heat-treated membranes with bioelectricity promote bone regeneration, J. Biomater. Sci. Polym. Ed. 25 (2014) $211-$ 223. doi:10.1080/09205063.2013.849903.

[277] Yanying Wang, Yili Qu, Ping Gong, Ping Wang, Yi Man, Jidong Li, Preparation and in vitro evaluation of chitosan bioelectret membranes for guided bone regeneration, J. Bioact. Compat. Polym. 25 (2010) 622-633. doi:10.1177/0883911510382765.

[278] Y. Wang, R. Shi, P. Gong, J. Li, J. Li, D. Ao, P. Wang, Y. Yang, Y. Man, Y. Qu, Bioelectric effect of a chitosan bioelectret membrane on bone regeneration in rabbit cranial defects, J. Bioact. Compat. Polym. 27 (2012) 122-132. doi:10.1177/0883911512436773.

[279] T. Kizuki, M. Ohgaki, M. Katsura, S. Nakamura, K. Hashimoto, Y. Toda, S. Udagawa, K. Yamashita, Effect of bone-like layer growth from culture medium on adherence of osteoblastlike cells, Biomaterials. 24 (2003) 941-947.

[280] S. Nakamura, T. Kobayashi, M. Nakamura, K. Yamashita, Enhanced in vivo responses of osteoblasts in electrostatically activated zones by hydroxyapatite electrets, J. Mater. Sci. Mater. Med. 20 (2009) 99-103. doi:10.1007/s10856-008-3546-7.

[281] S. Itoh, S. Nakamura, T. Kobayashi, K. Shinomiya, K. Yamashita, S. Itoh, Effect of electrical polarization of hydroxyapatite ceramics on new bone formation, Calcif. Tissue Int. 78 (2006) 133-142. doi:10.1007/s00223-005-0213-6.

[282] R.F. Valentini, T.G. Vargo, J.A. Gardella, P. Aebischer, Electrically charged polymeric substrates enhance nerve fibre outgrowth in vitro, Biomaterials. 13 (1992) 183-190.

[283] R.F. Valentini, A.M. Sabatini, P. Dario, P. Aebischer, Polymer electret guidance channels enhance peripheral nerve regeneration in mice, Brain Res. 480 (1989) 300-304.

[284] D.J. Bryan, J.B. Tang, S.A. Doherty, D.D. Hile, D.J. Trantolo, D.L. Wise, I.C. Summerhayes, Enhanced peripheral nerve regeneration through a poled bioresorbable poly(lactic-co-glycolic acid) guidance channel, J. Neural Eng. 1 (2004) 91. doi:10.1088/1741-2560/1/2/004.

[285] H. Lorach, G. Goetz, R. Smith, X. Lei, Y. Mandel, T. Kamins, K. Mathieson, P. Huie, J. Harris, A. Sher, D. Palanker, Photovoltaic restoration of sight with high visual acuity, Nat. Med. 21 (2015) 476-482. doi:10.1038/nm.3851.

[286] Y. Mandel, G. Goetz, D. Lavinsky, P. Huie, K. Mathieson, L. Wang, T. Kamins, L. Galambos, R. Manivanh, J. Harris, D. Palanker, Cortical responses elicited by photovoltaic subretinal prostheses exhibit similarities to visually evoked potentials, Nat. Commun. 4 (2013) ncomms2980. doi:10.1038/ncomms2980.

[287] L. Wang, K. Mathieson, T.I. Kamins, J.D. Loudin, L. Galambos, G. Goetz, A. Sher, Y. Mandel, P. Huie, D. Lavinsky, J.S. Harris, D. V. Palanker, Photovoltaic retinal prosthesis: implant fabrication and performance, J. Neural Eng. 9 (2012) 046014. doi:10.1088/17412560/9/4/046014.

[288] K. Mathieson, J. Loudin, G. Goetz, P. Huie, L. Wang, T.I. Kamins, L. Galambos, R. Smith, J.S. Harris, A. Sher, D. Palanker, Photovoltaic retinal prosthesis with high pixel density, Nat. Photonics. 6 (2012) 391-397. doi:10.1038/nphoton.2012.104.

[289] Y.-S. Hsiao, Y.-H. Liao, H.-L. Chen, P. Chen, F.-C. Chen, Organic photovoltaics and bioelectrodes providing electrical stimulation for PC12 cell differentiation and neurite outgrowth, ACS Appl. Mater. Interfaces. 8 (2016) 9275-9284. doi:10.1021/acsami.6b00916.

[290] G. Torkaman, Electrical stimulation of wound healing: A Review of animal experimental evidence, Adv. Wound Care. 3 (2014) 202-218. doi:10.1089/wound.2012.0409.

[291] S. Ud-Din, A. Bayat, Electrical stimulation and cutaneous wound healing: A review of clinical evidence, Healthcare. 2 (2014) 445-467. doi:10.3390/healthcare2040445.

[292] N. Martino, P. Feyen, M. Porro, C. Bossio, E. Zucchetti, D. Ghezzi, F. Benfenati, G. Lanzani, M.R. Antognazza, Photothermal cellular stimulation in functional bio-polymer interfaces, Sci. Rep. 5 (2015) srep08911. doi:10.1038/srep08911. 
1661

1662

1663

1664

1665

1666

1667

1668

1669

1670

1671

1672

1673

1674

1675

1676

1677

1678

1679

1680

1681

1682

1683

1684

1685

1686

1687

1688

1689

1690

1691

1692

1693

1694

1695

1696

1697

1698

1699

1700

1701

1702

1703

1704

1705

1706

1707

1708

1709

1710

1711

1712

1713

[293] J.-L. Wu, F.-C. Chen, M.-K. Chuang, K.-S. Tan, Near-infrared laser-driven polymer photovoltaic devices and their biomedical applications, Energy Environ. Sci. 4 (2011) 33743378. doi:10.1039/C1EE01723C.

[294] S.N. Leite, T.A.M. de Andrade, D. dos S. Masson-Meyers, M.N. Leite, C.S. Enwemeka, M.A.C. Frade, Phototherapy promotes healing of cutaneous wounds in undernourished rats, An. Bras. Dermatol. 89 (2014) 899-904. doi:10.1590/abd1806-4841.20143356.

[295] A.L. Whinfield, I. Aitkenhead, The light revival: Does phototherapy promote wound healing? A review, The Foot. 19 (2009) 117-124. doi:10.1016/j.foot.2009.01.004.

[296] G. Jin, M. P. Prabhakaran, D. Kai, M. Kotaki, S. Ramakrishna, Electrospun photosensitive nanofibers: potential for photocurrent therapy in skin regeneration, Photochem. Photobiol. Sci. 12 (2013) 124-134. doi:10.1039/C2PP25070E.

[297] T.J. Rivers, T.W. Hudson, C.E. Schmidt, Synthesis of a novel, biodegradable electrically conducting polymer for biomedical applications, Adv. Funct. Mater. 12 (2002) 33-37. doi:10.1002/1616-3028(20020101)12:1<33::AID-ADFM33>3.0.CO;2-E.

[298] N.K.E. Guimard, J.L. Sessler, C.E. Schmidt, Towards a biocompatible, biodegradable copolymer incorporating electroactive oligothiophene units, Macromolecules. 42 (2009) 502511. doi: $10.1021 / \mathrm{ma} 8019859$.

[299] C.A. Thomas, K. Zong, P. Schottland, J.R. Reynolds, Poly(3,4-alkylenedioxypyrrole)s as highly stable aqueous-compatible conducting polymers with biomedical implications, Adv. Mater. 12 (2000) 222-225. doi:10.1002/(SICI)1521-4095(200002)12:3<222::AIDADMA222>3.0.CO;2-D.

[300] S. Sankoh, M.Y. Vagin, A.N. Sekretaryova, P. Thavarungkul, P. Kanatharana, W.C. Mak, Colloid electrochemistry of conducting polymer: towards potential-induced in-situ drug release, Electrochimica Acta. 228 (2017) 407-412. doi:10.1016/j.electacta.2017.01.028.

[301] S. Szunerits, F. Teodorescu, R. Boukherroub, Electrochemically triggered release of drugs, Eur. Polym. J. 83 (2016) 467-477. doi:10.1016/j.eurpolymj.2016.03.001.

[302] M. Shahid, A.P. Deshpande, C.L. Rao, Electro-mechanical properties of hydrogel composites with micro- and nano-cellulose fillers, Smart Mater. Struct. 24 (2015) 095013. doi:10.1088/0964-1726/24/9/095013.

[303] V. Nguyen, R. Zhu, K. Jenkins, R. Yang, Self-assembly of diphenylalanine peptide with controlled polarization for power generation, Nat. Commun. 7 (2016) ncomms13566. doi:10.1038/ncomms13566.

[304] K.N. Kim, J. Chun, S.A. Chae, C.W. Ahn, I.W. Kim, S.-W. Kim, Z.L. Wang, J.M. Baik, Silk fibroin-based biodegradable piezoelectric composite nanogenerators using lead-free ferroelectric nanoparticles, Nano Energy. 14 (2015) 87-94. doi:10.1016/j.nanoen.2015.01.004.

[305] K. Ryan, J. Beirne, G. Redmond, J.I. Kilpatrick, J. Guyonnet, N. Buchete, A.L. Kholkin, B.J. Rodriguez, Nanoscale Piezoelectric Properties of Self-Assembled Fmoc - FF Peptide Fibrous Networks, (2015). doi:10.1021/acsami.5b01251.

[306] M.H. SHAMOS, L.S. LAVINE, Piezoelectricity as a Fundamental Property of Biological Tissues, Nature. 213 (1967) 267-269. doi:10.1038/213267a0.

[307] D. Denning, J. Guyonnet, B.J. Rodriguez, Applications of piezoresponse force microscopy in materials research: from inorganic ferroelectrics to biopiezoelectrics and beyond, Int. Mater. Rev. 61 (2016) 46-70. doi:10.1179/1743280415Y.0000000013.

[308] X. Guo, Y.Y. Liang, H.Y. Liu, L.L. Cui, J. Jiang, Study on the electrostatic and piezoelectric properties of positive polypropylene electret cyclosporine A patch, J. Phys. Conf. Ser. 418 (2013) 012148. doi:10.1088/1742-6596/418/1/012148.

[309] X. Wang, L. Dong, H. Zhang, R. Yu, C. Pan, Z.L. Wang, Recent progress in electronic skin, Adv. Sci. 2 (2015) 1-21. doi:10.1002/advs.201500169.

[310] J.A. Labastide, M. Baghgar, I. Dujovne, Y. Yang, A.D. Dinsmore, B. G. Sumpter, D. Venkataraman, M.D. Barnes, Polymer nanoparticle superlattices for organic photovoltaic applications, J. Phys. Chem. Lett. 2 (2011) 3085-3091. doi:10.1021/jz2012275.

[311] P.H. Wang, M. Millard, A.G. Brolo, Optimizing plasmonic silicon photovoltaics with Ag and Au nanoparticle mixtures, J. Phys. Chem. C. 118 (2014) 5889-5895. doi:10.1021/jp409351v. 
1714

1715

1716

1717

1718

1719

1720

1721

1722

1723

1724

[312] K.R. Catchpole, A. Polman, Plasmonic solar cells, Opt. Express. 16 (2008) 21793-21800. doi:10.1364/OE.16.021793.

[313] I. Hwang, D. Choi, S. Lee, J.H. Seo, K.-H. Kim, I. Yoon, K. Seo, Enhancement of light absorption in photovoltaic devices using textured polydimethylsiloxane stickers, ACS Appl. Mater. Interfaces. 9 (2017) 21276-21282. doi:10.1021/acsami.7b04525.

[314] H.-J. Koo, S. Tai Chang, J. M. Slocik, R. R. Naik, O. D. Velev, Aqueous soft matter based photovoltaic devices, J. Mater. Chem. 21 (2011) 72-79. doi:10.1039/C0JM01820A.

[315] A.G. Kanaras, C. Sönnichsen, H. Liu, A.P. Alivisatos, Controlled Synthesis of Hyperbranched Inorganic Nanocrystals with Rich Three-Dimensional Structures, Nano Lett. 5 (2005) 21642167. doi: $10.1021 / \mathrm{n} 10518728$. 


\section{Photovoltaics}

- Photovoltaic therapy

- Tissue engineering

- Photothermal treatment

\section{Piezoelectrics}

- Electrical stimulation

- Nano-therapeutics

- Micropumps

- Gene delivery

- Cancer therapy
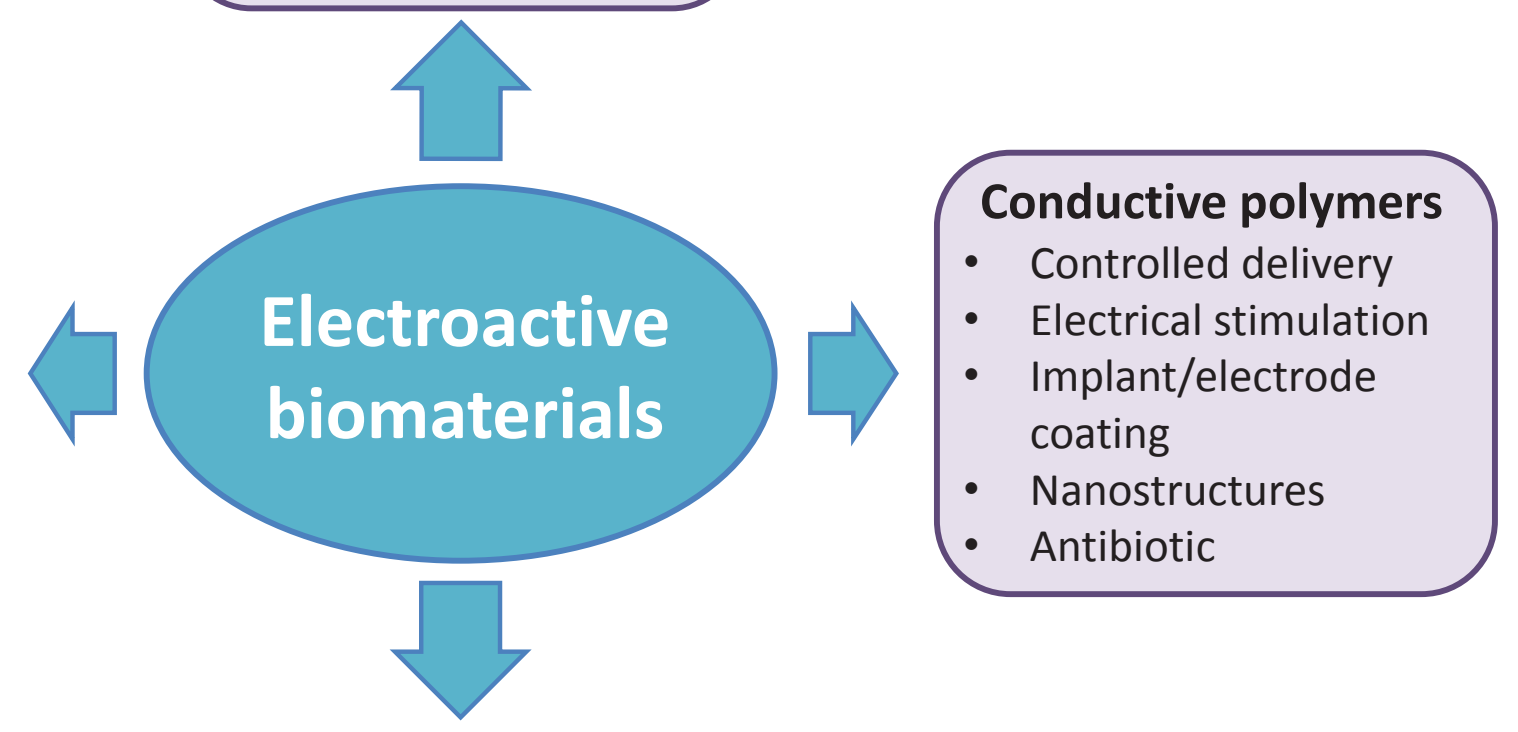

\section{Electrets}

- Transdermal drug delivery

- Electrical restoration of wounds

- Cellular stimulation 
Figure 2

a)

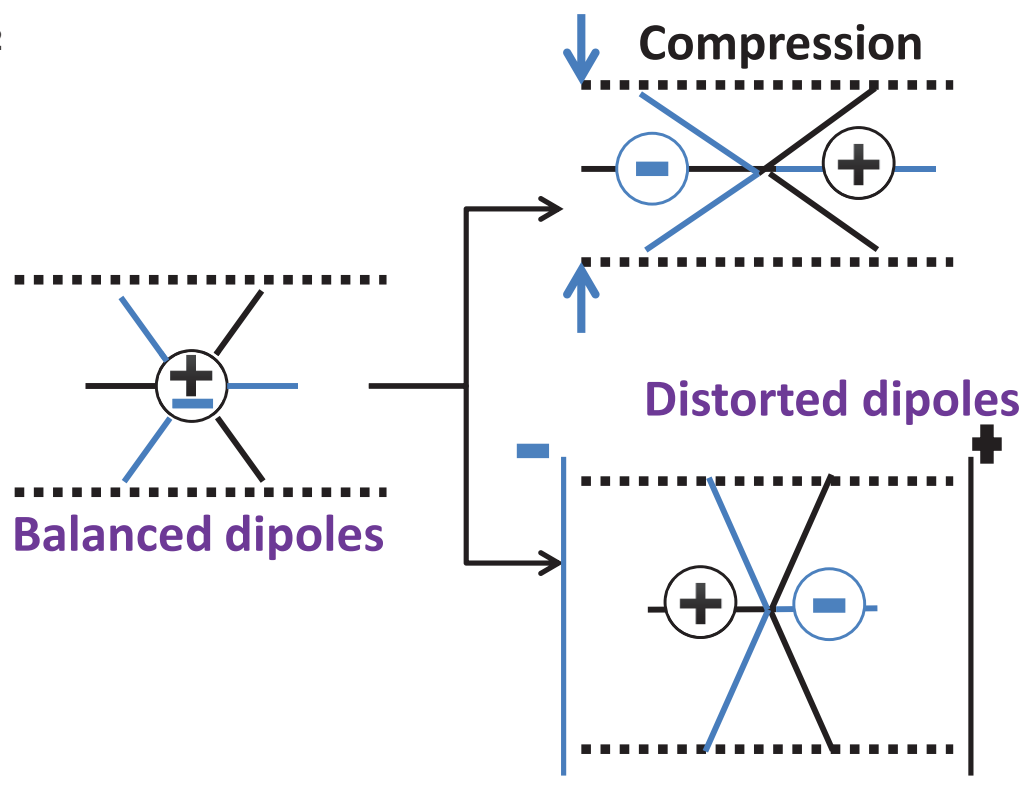

Tension due to applied voltage

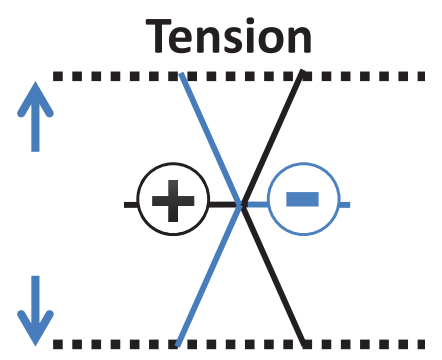

Direct

Piezoelectric effect

Converse

Piezoelectric effect

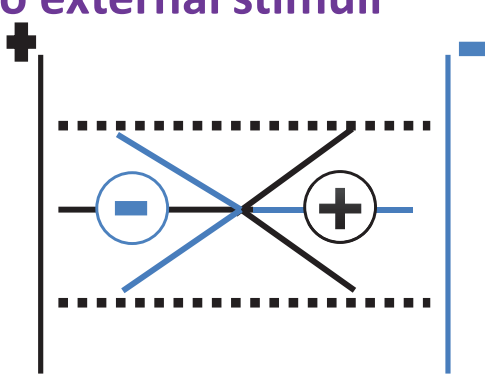

Compression due to reversed polarity b)

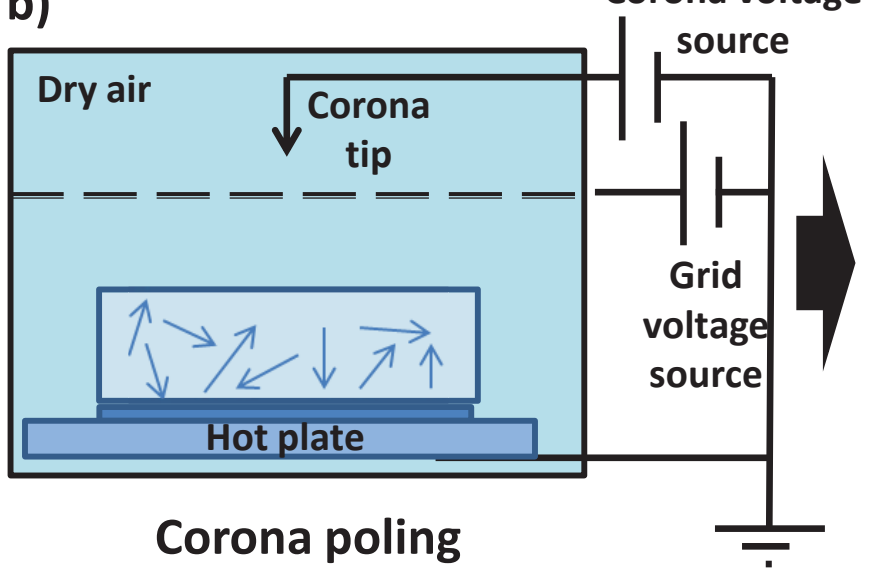

\section{Corona voltage}

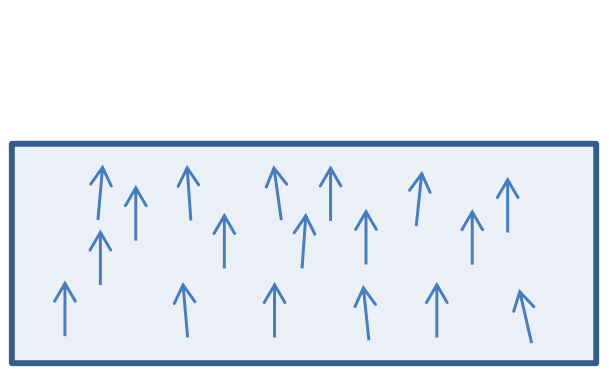

Aligned dipoles in piezoelectric material after poling
To electric supply

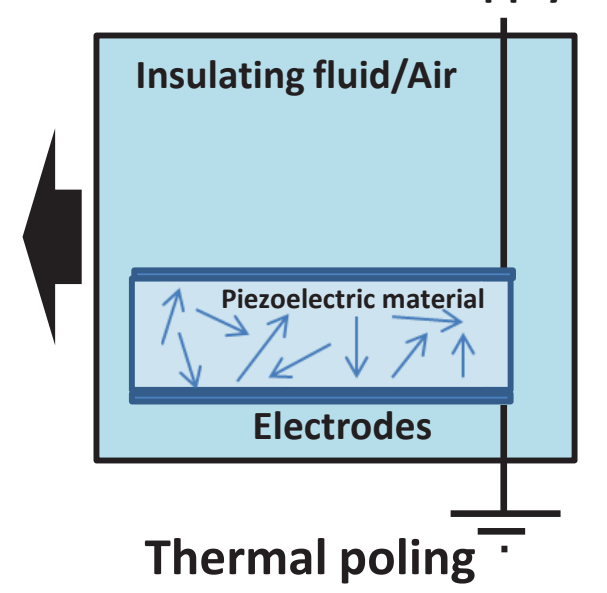


a) Heterocharged Electrets Surface charging opposite to that of electrodes occur due to dipolar, ionic and spatial charge rearrangement.

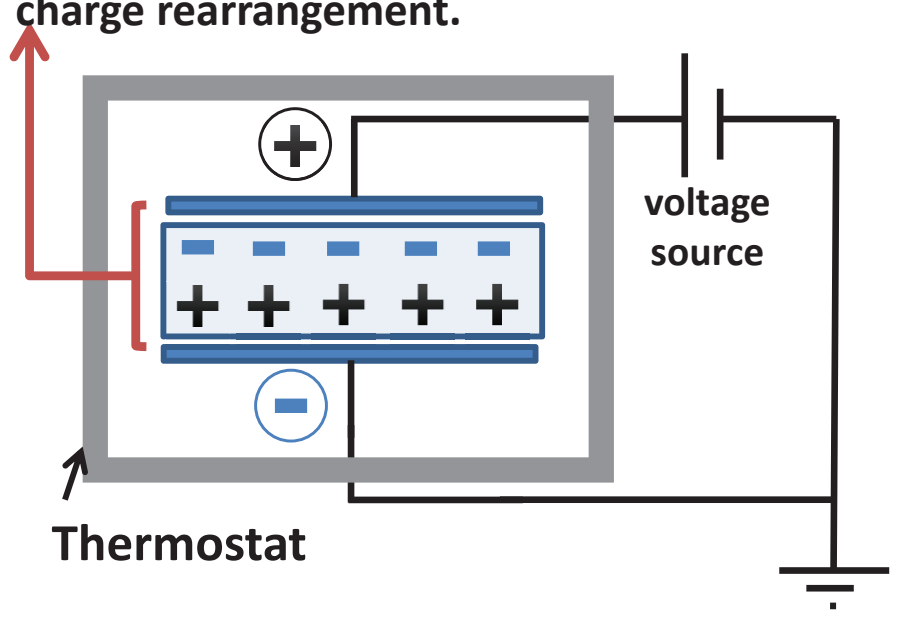

b) Homocharged Electrets Surface charging similar to that of electrodes occur mainly due to charge injection* at high voltages.

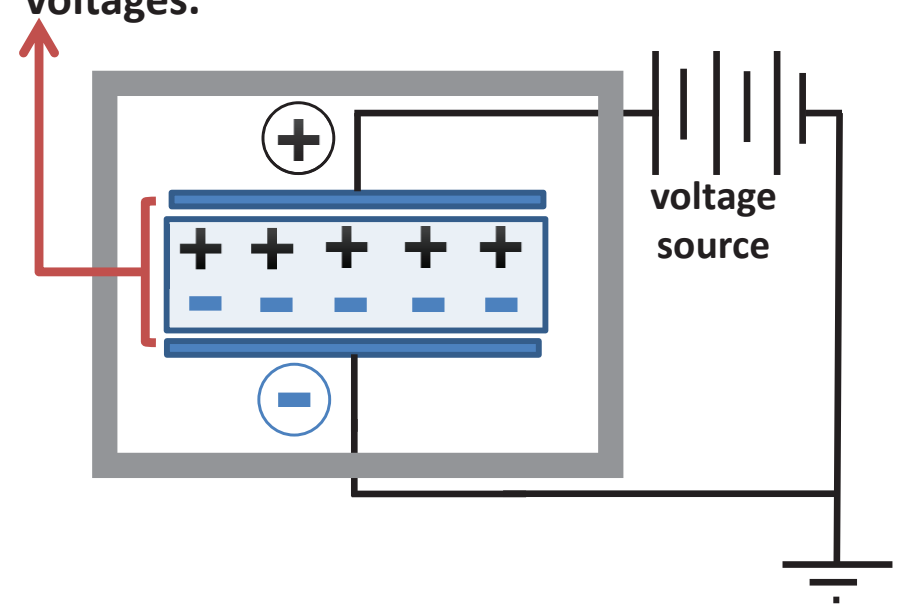

c) Types of Electret charges

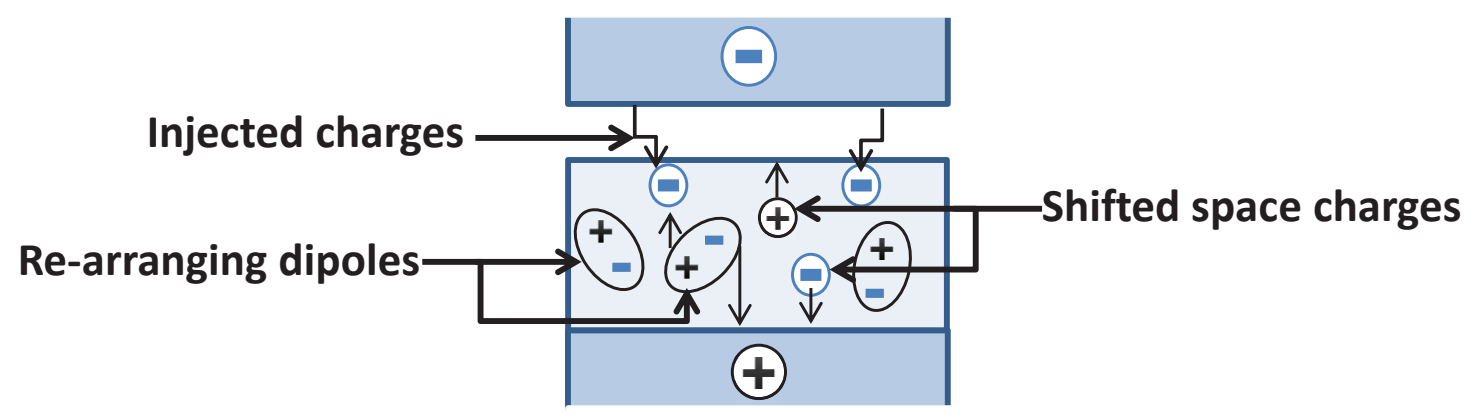




\section{Photovoltaic mechanism}

a)

$$
\text { PV device }
$$

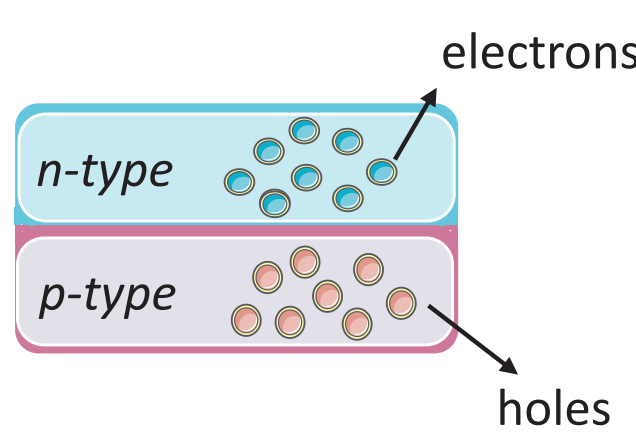

light source

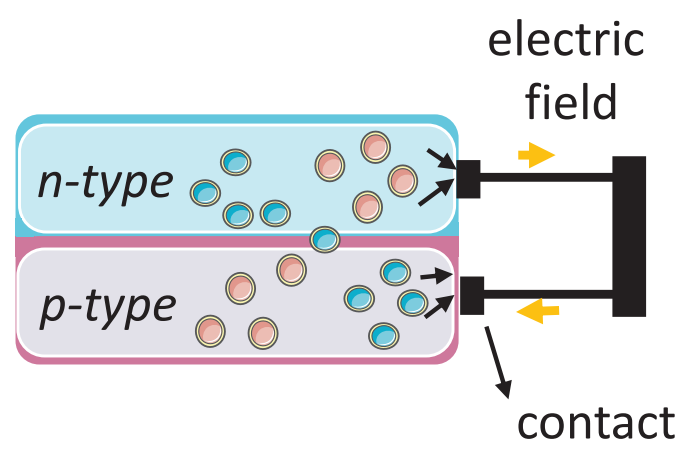

b) Photovoltaic heterojunctions

c) Nanoscopic PV device (NPVD)

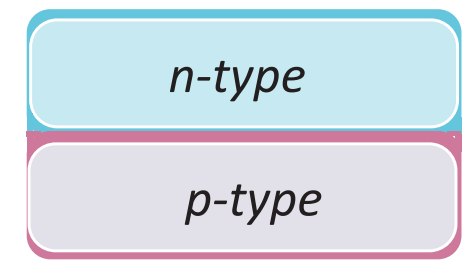

Planar

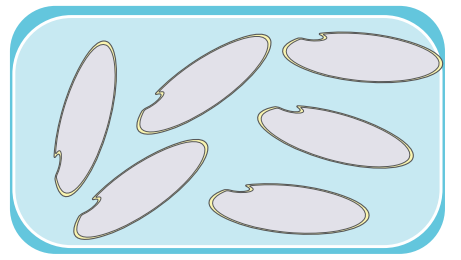

Blended bulk

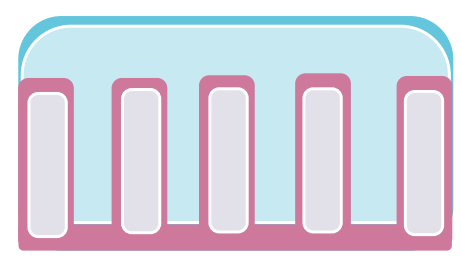

Ordered

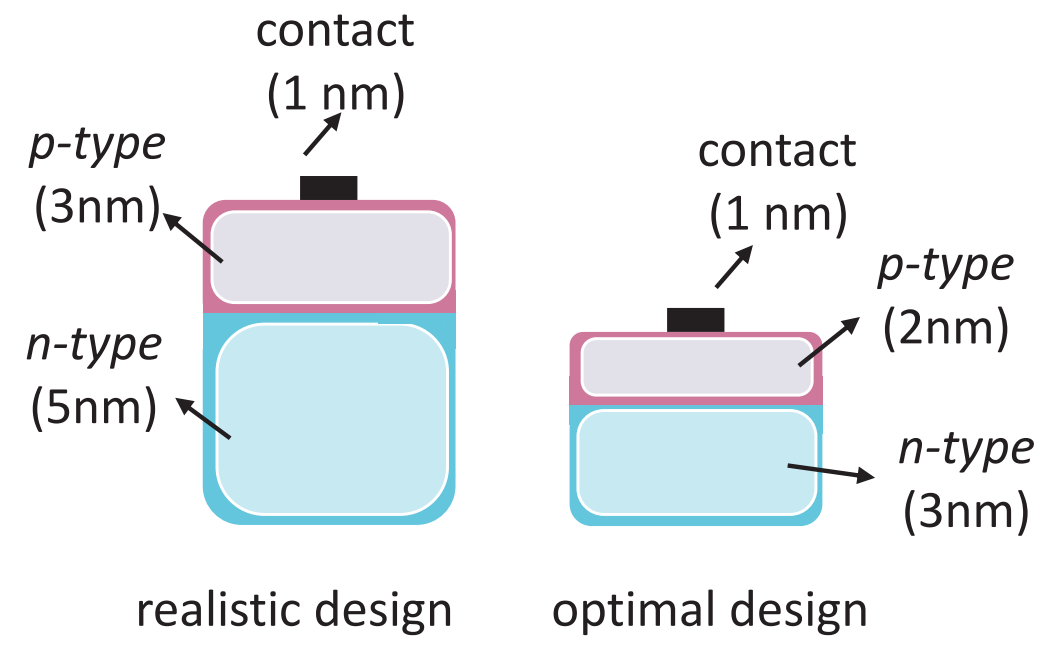




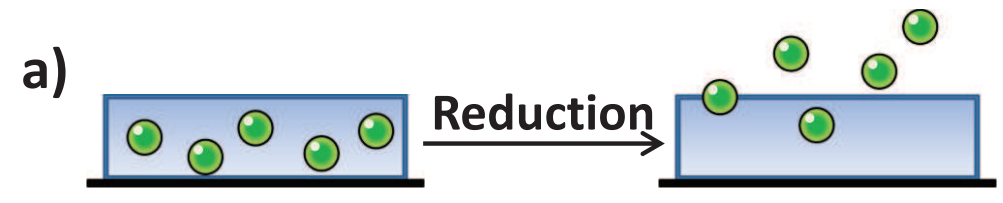

b)

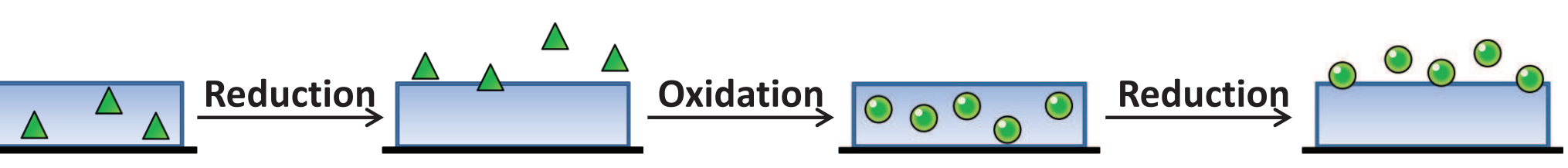

c)

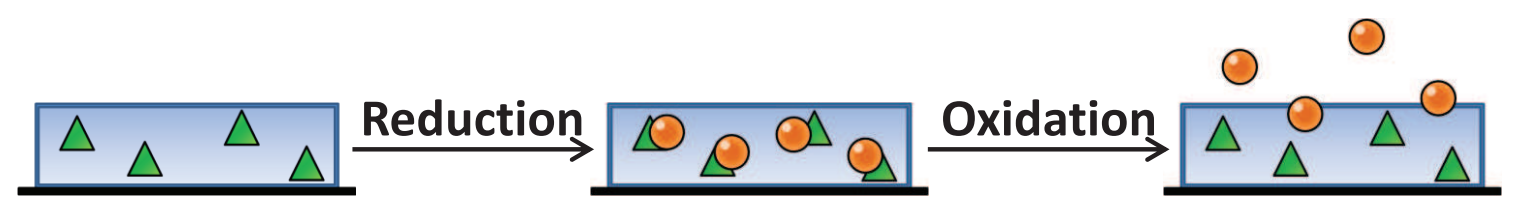

- Anionic drug

$\square$ - Conductive polymer

- Cationic drug

$\triangle$ - Anionic primary dopant 
a)

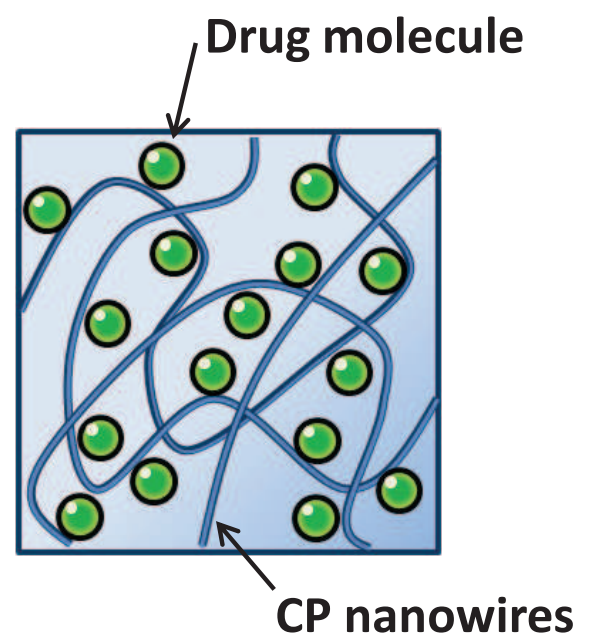

c)

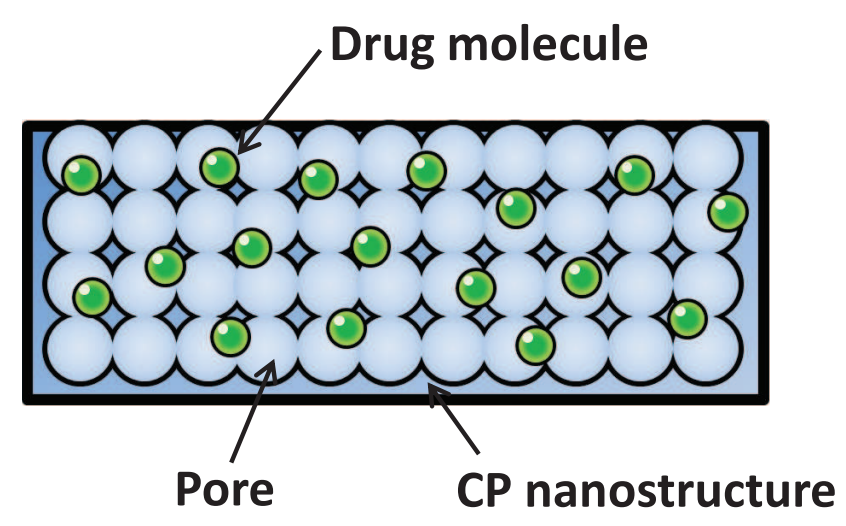

b)

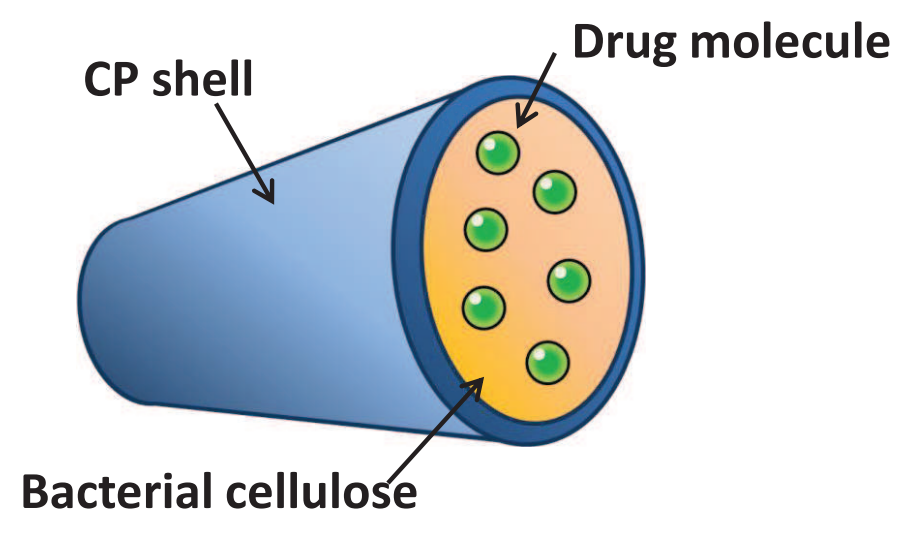

d)

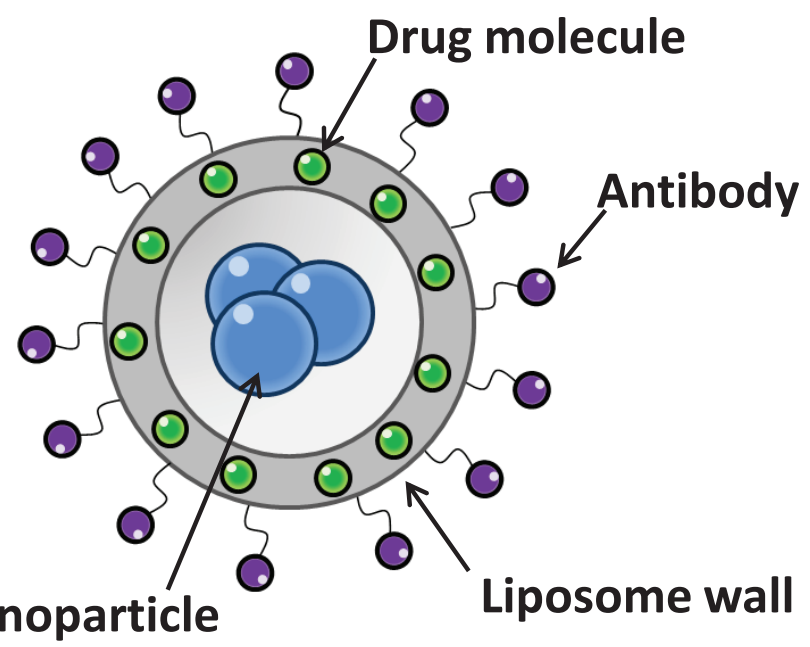


Figure 7
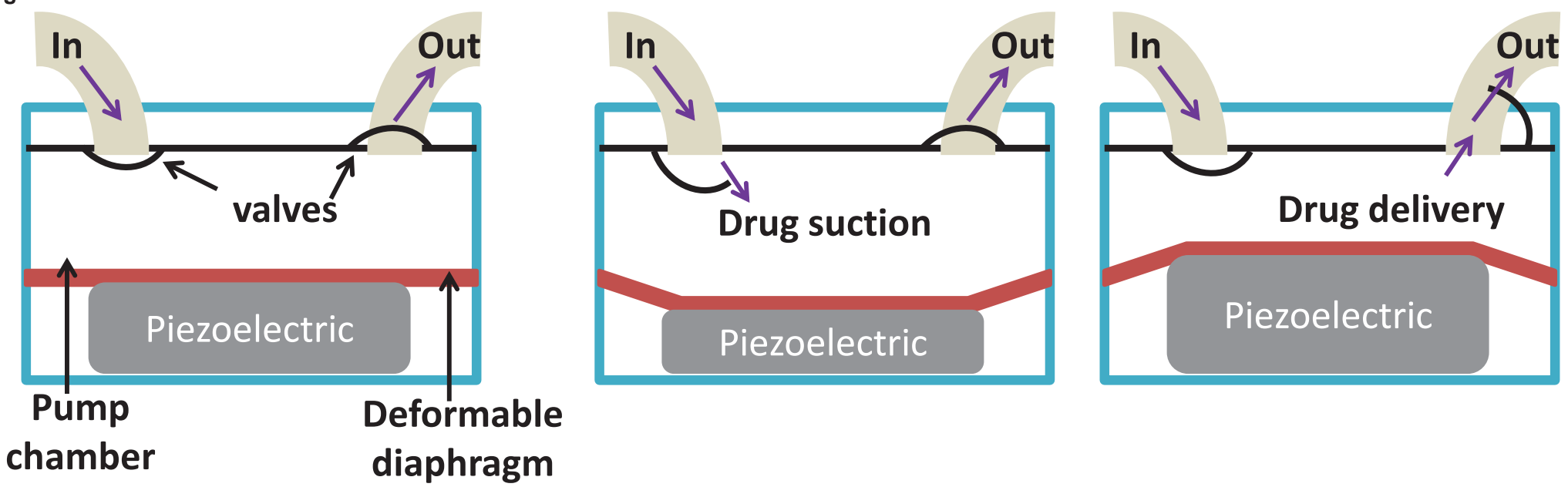

Piezoelectric pump with valves

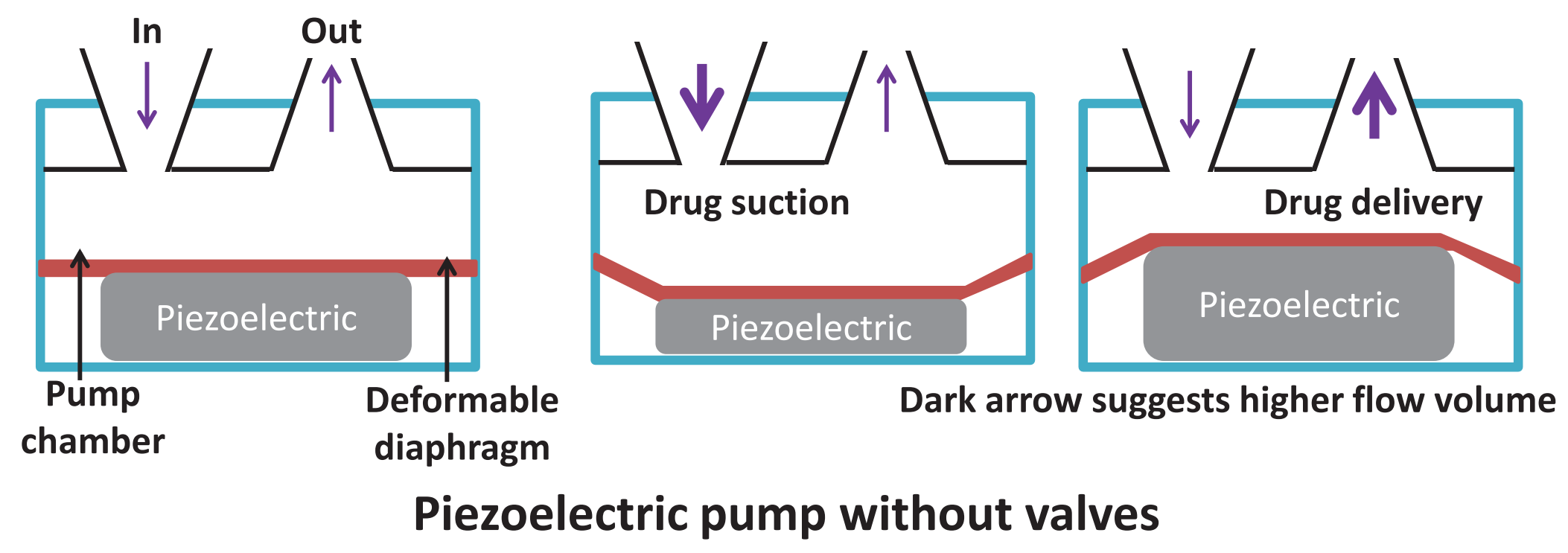




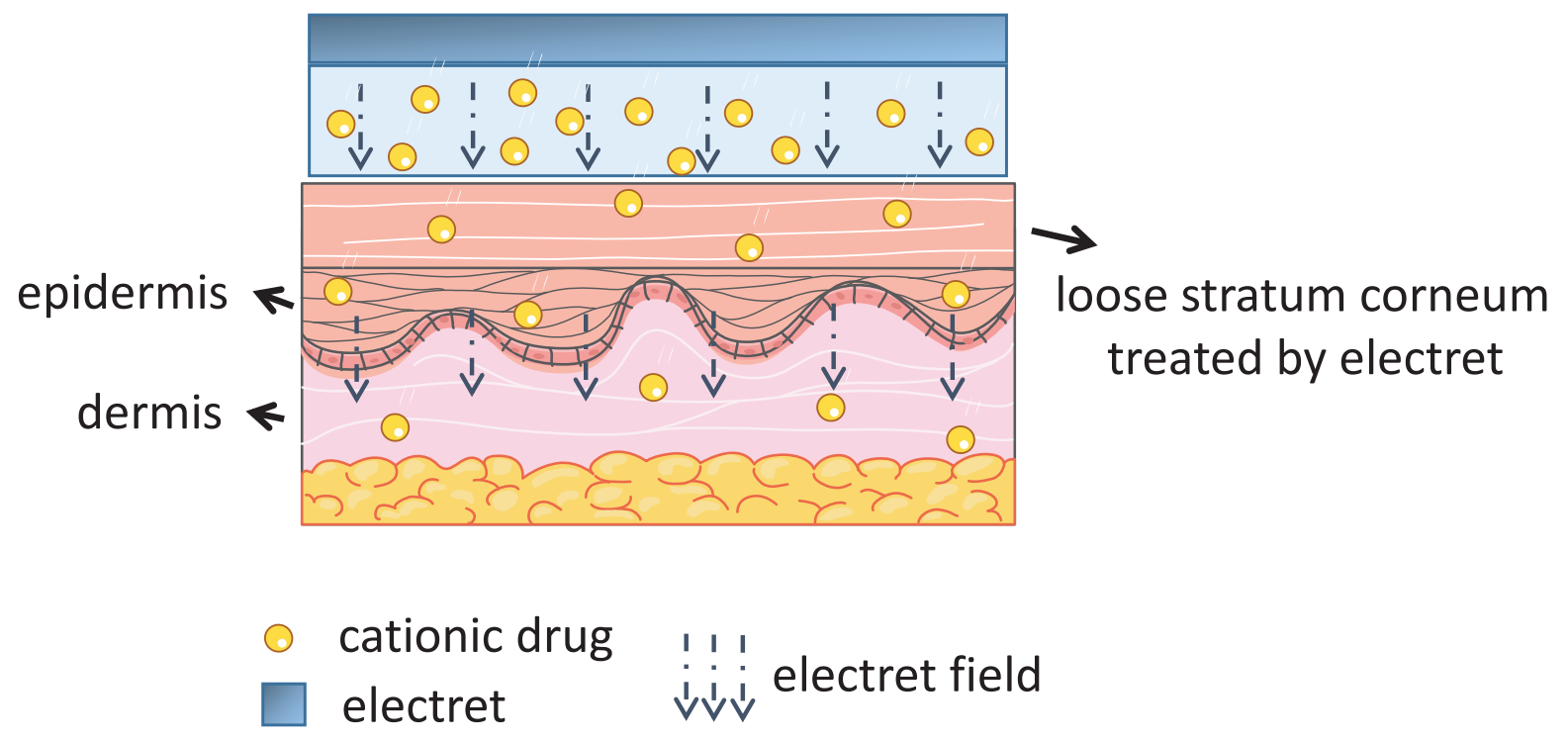


PV devices as drug delivery carriers

a) light source

\begin{tabular}{|rr|}
\hline n-type & neutral \\
\hline -type & neutral \\
& (영
\end{tabular}

cationic drugs
$\Theta \Theta \Theta \Theta$

n-type negative
p-type positive

$\oplus \oplus \oplus \oplus$

$\bigcirc \vee \bigcirc$ repulsion

charged drugs released

upon stimulation

b)

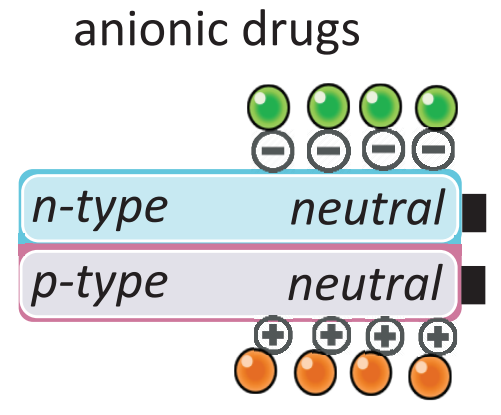

cationic drugs light source

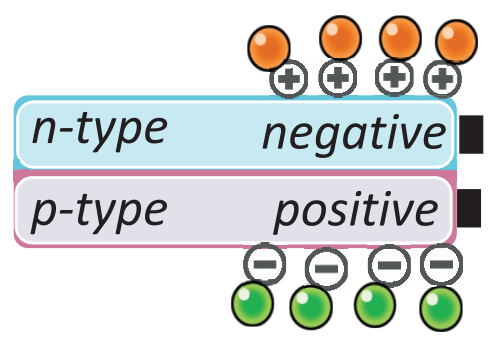

charged drugs are attracted to opposite sites 
Metal organic framework (MOF) structure

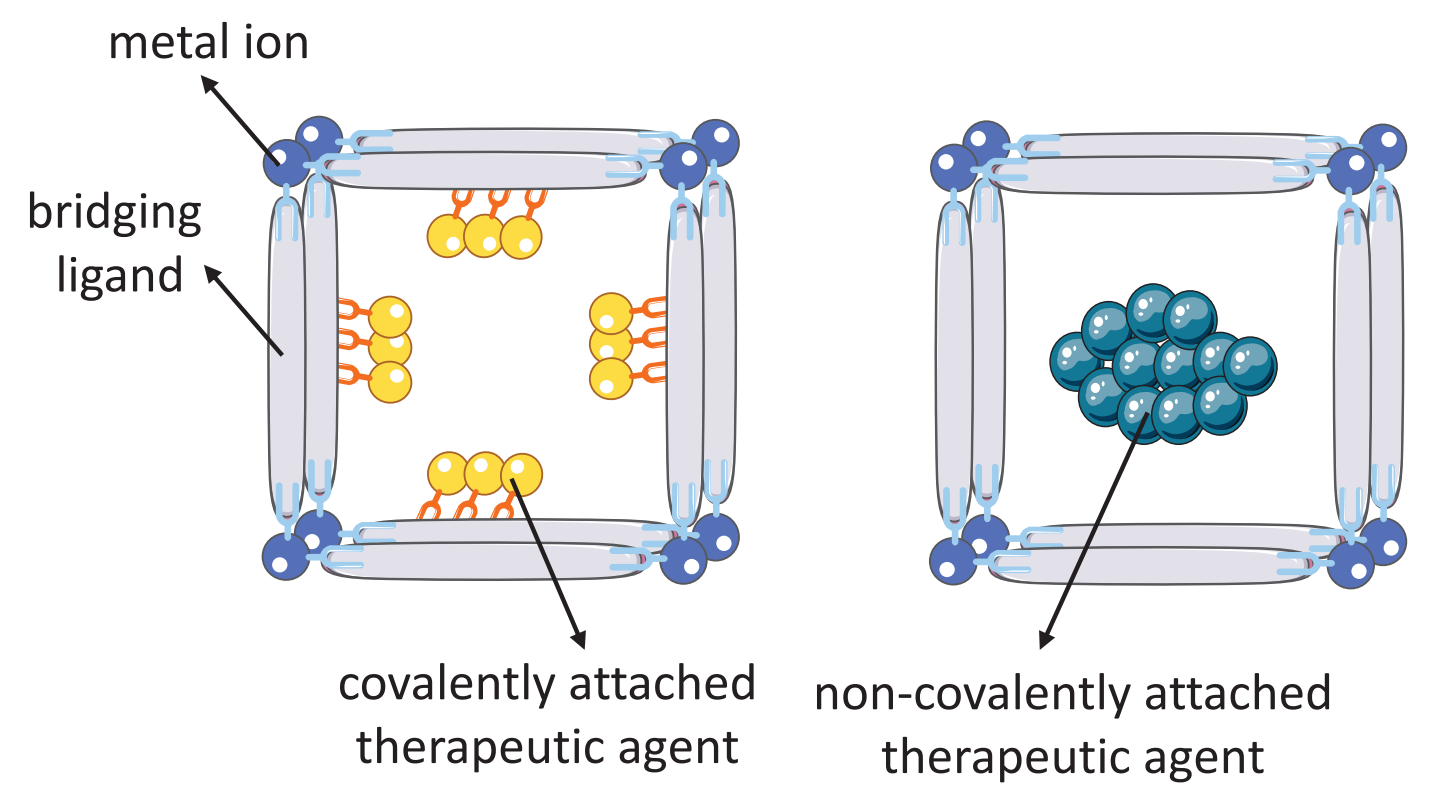




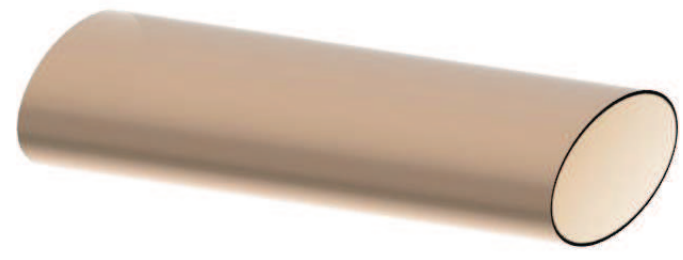

Tubular structure

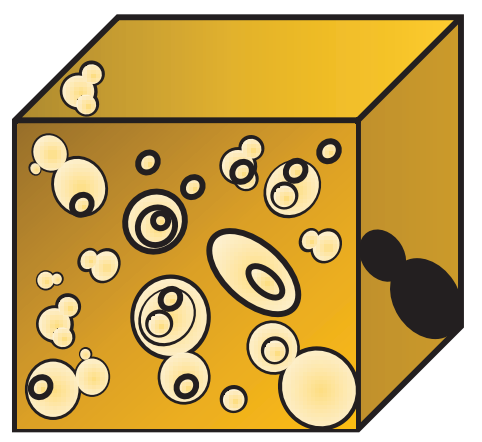




\begin{tabular}{lll}
\hline Polymers & Ceramics & Others \\
\hline Poly(L-Lactide) (PLLA) & Hydroxyapatite (HA) & Diphenylalanine \\
Poly (vinylidene fluoride) (PVDF) & Barium titanate (BT) & Collagen \\
Poly (vinylidene fluoride-trifluro & Lithium sodium potassium & Boron nitride nano tubes \\
ethylene) (PVDF-TrFE) & niobate (LNKN) & (BNNTs) \\
Polyhydroxy butyrate (PHB) & Lithium niobate (LN) & Silk \\
& Lead zirconate titanate (PZT) & \\
\hline
\end{tabular}




\begin{tabular}{lll}
\hline Target tissue & Size particle & Excretion route \\
\hline Any & $3-10 \mathrm{~nm}$ & Renal filtration [165] \\
Liver and brain tissue & $10-30 \mathrm{~nm}$ & Phagocyte system [166] \\
Lung and inflamed tissues & $30-80 \mathrm{~nm}$ & Phagocyte system [167] \\
Liver and spleen & $>80 \mathrm{~nm}$ & Hepatobiliary excretion [166] \\
\hline
\end{tabular}




\section{Figure legends}

Figure 1 The family of electroactive materials and their applications

Figure 2 a) Direct and converse piezoelectric effect mechanisms and b) types of poling procedures to maximize piezoelectricity

Figure 3 Types of electrets: (a) heterocharged and (b) homocharged (*injected charges are those which get deposited on the material surface from the surrounding electrode); and (c) charge carriers involved during the formation of electrets

Figure 4 Photovoltaic mechanism: a) conventional photovoltaic cell where electron-hole pairs migrate to opposite electrodes upon photo stimulation and electric current is produced; $b$ ) photovoltaic cells depicting the schematics of a planar heterojunction, a blended bulk heterojunction and an ordered heterojunction; c) model of a conceptual nanoscopic photovoltaic device depicting realistic and optimal design dimensions

Figure 5 Mechanisms of drug loading and release in CPs: a) one-step loading of anionic drug; b) three-step loading of anionic drug; and c) loading of cationic drug

Figure 6 Examples of advanced CP based drug delivery solutions: a) nanowires [89]; b) microtubes [80]; c) nanoporous structure [106]; and d) nanoparticle [121]

Figure 7 Schematic of working principle of piezoelectric micropumps with or without valves, based on deformable piezoelectric based diaphragms that regulate drug suction and delivery

Figure 8 Transdermal drug delivery system based on electrets

Figure 9 Photovoltaic devices used as drug delivery carriers: a) PV device coated with positively charged drugs, which are released upon stimulation and attracted back again in a retractable-wise manner; b) PV device coated with positively and negatively charged drugs that are attracted to opposite sites upon stimulation of the device instead of being repelled towards the environment

Figure 10 Schematic representation of a metal organic framework (MOF) structure used as a delivery carrier

Figure 11 Examples of different piezoelectric based scaffolds 


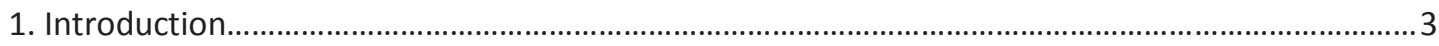

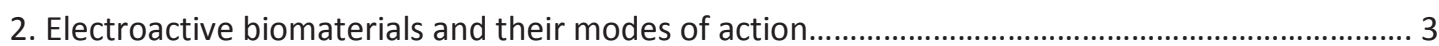

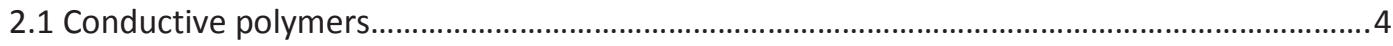

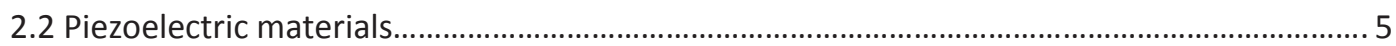

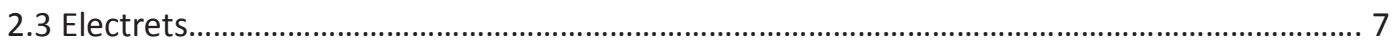

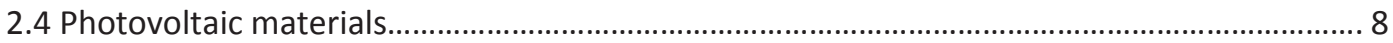

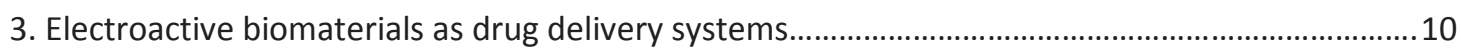

3.1 Electrochemically controlled drug delivery based on CPs..................................................10

3.1.1 Drug loading and release mechanisms for CPs....................................................... 10

3.1.2 Polypyrrole (PPy) and Poly (3,4-ethylenedioxythiophene) (PEDOT)............................ 14

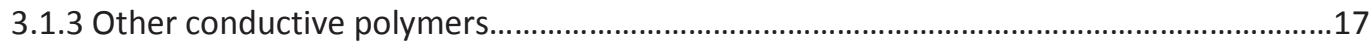

3.2 Piezoelectrically active materials for drug delivery......................................................... 18

3.2.1 Drug release mechanism of piezoelectric based materials...........................................18

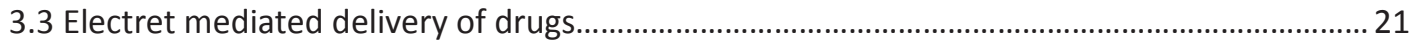

3.4 Targeted drug delivery using photovoltaic materials......................................................... 23

3.4.1 Drug loading on photovoltaic based materials........................................................... 25

3.4.2 Metal organic frameworks as photovoltaic devices in wound care.............................. 26

4. The stimulatory response of electroactive materials in wound healing........................................27

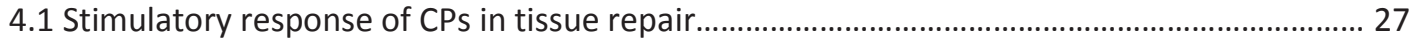

4.2 The piezoelectric mechanism in tissue regeneration.......................................................... 29

4.3 Electrets as exogenous stimulators for wound healing .................................................. 32

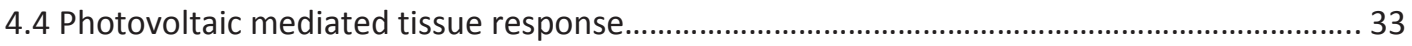

5. Future perspectives on the use of electroactive biomaterials in drug delivery and tissue

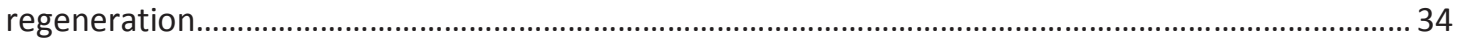

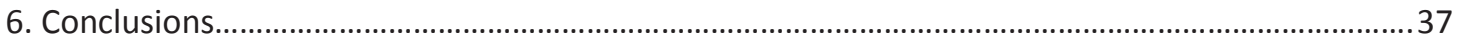

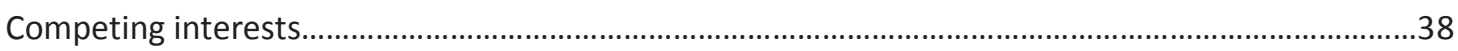

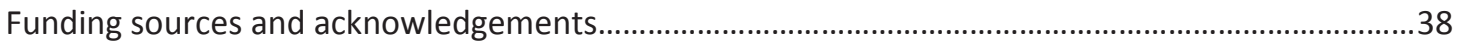

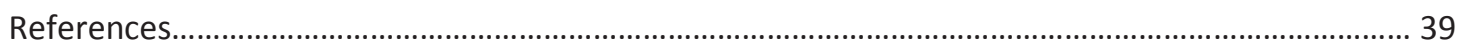

